\title{
Clients Coming Out - Men speak out about purchasing sex in New Zealand's decriminalised environment
}

By

\section{Shannon Betty Mower}

A thesis submitted to the Victoria University of Wellington in fulfilment of the requirements for the degree of Masters of Arts in Criminology

Social and Cultural Studies

Victoria University of Wellington

2019 


\begin{abstract}
This thesis explores the client experience of purchasing sex in New Zealand in the context of decriminalisation. This research was conducted at a time when speculation over the impact of decriminalisation on the conduct of clients was at an all-time high. Despite vast speculation by critics, little to no research exists on client populations in New Zealand. This thesis addresses this knowledge gap and offers an initial insight into the experiences of clients in this context. The research that forms the basis of this thesis involved qualitative semi-structured interviews with 12 men and women who purchase sex in New Zealand, along with three key informants with broader contextual knowledge of clients. The clients interviewed constituted a diverse group, and in many ways, they challenged common stereotypes. For example, while all participants were motivated by sexual desire, half the sample placed more significance on their desire for human interaction. Hegemonic masculinity was also discussed as motivating their engagements with the sex industry. The interviews also revealed the impacts of purchasing sex on participants, which related more to their interactions with sex workers than the physical act of having sex. Lastly, the research explored participants' interactions with sex workers under decriminalisation, finding that they emphasised clear communication, respect of sex worker's boundaries, and a desire to purchase sex ethically. There are three key conclusions of this thesis. Firstly, that client stereotypes are inapplicable to the entire client population as the participants challenged many and provided support for the 'every man perspective'. Second, that support exists for non-sexual client motivations, and following the impacts participants discussed, sex workers and their services can be considered therapeutic and supporting the well-being of participants. Lastly, that legal context does make a difference on the conduct within sex industries and under decriminalisation. The participants' conduct was driven by an awareness for sex worker rights and working conditions, thus producing an informed, harm-reductionist approach to purchasing sex.
\end{abstract}




\section{Acknowledgments}

This thesis would not exist without the support networks which surround me. First and foremost, thank you to my supervisors Lynzi Armstrong and Jan Jordan. Your guidance has shaped this thesis, and I am endlessly grateful. Of equal importance are my parents, Neil and Heather, who have emotionally and financially carried me throughout five years of university education. Thank you, I cannot express in words how much I appreciate you both and your unwavering belief in me. To my friends, thank you for listening to me lament over this thesis, offering motivation when mine was lacking, and for unravelling any self-doubt. To those on level nine of the Murphy building at Victoria University, we have experienced the University journey together - thank you for sharing mine with me. Lastly, to the participants, thank you for sharing your stories with me, all of which were deeply personal. Doing so took courage and vulnerability, yet enabled this thesis, so thank you. 


\section{Table of Contents}

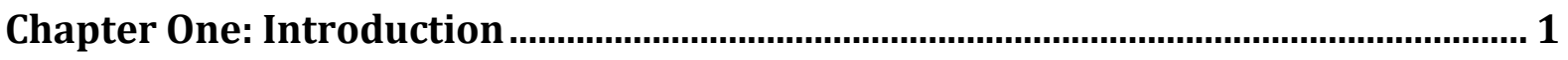

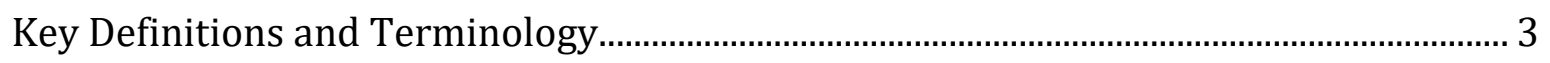

Understanding Commercial Sex in New Zealand .................................................................... 4

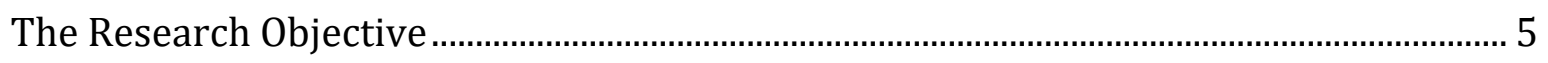

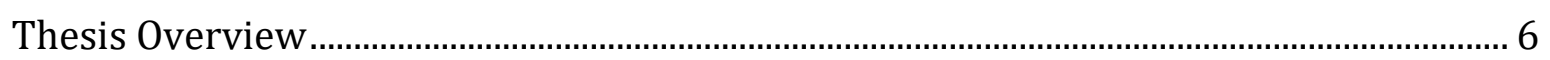

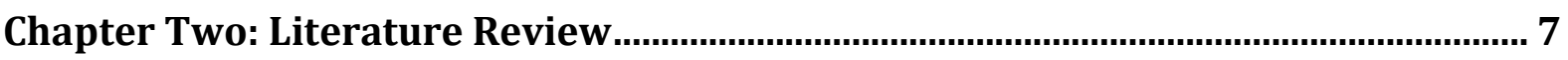

Feminist Theorising on the Sale and Purchase of Sex ............................................................ 7

Contemporary Legislative Approaches to Sex Work ............................................................... 9

Full and Partial Criminalisation....................................................................................... 10

The Swedish Model - Client Specific Criminalisation ...................................................... 12

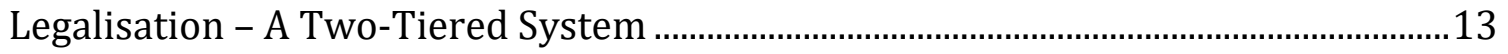

Decriminalisation - A Human Rights Model .......................................................................14

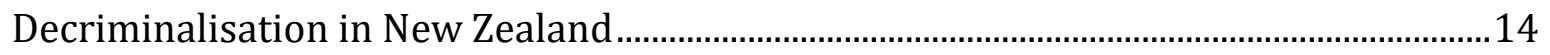

The Arguments Against Decriminalisation - Empirical or Anecdotal? ...........................16

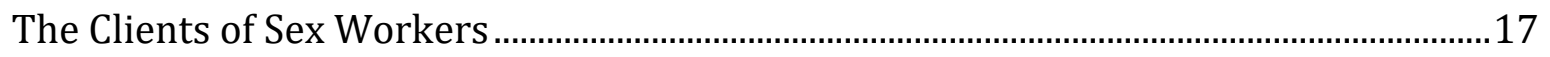

New Zealand Research on Clients Pre-Decriminalisation ................................................ 18

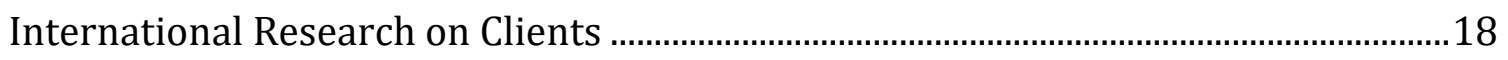

Motivations - Understanding Why Men Purchase Sex......................................................2 20

Sex as the 'Extra' - Client Perceptions of Intimacy ................................................................ 21

Affirming 'Manhood' or Gendered Domination? The Relationship between

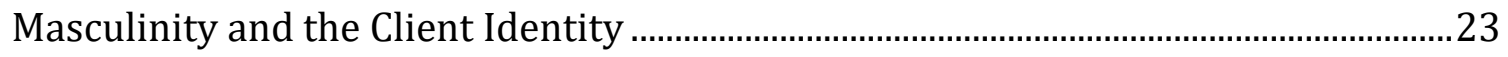

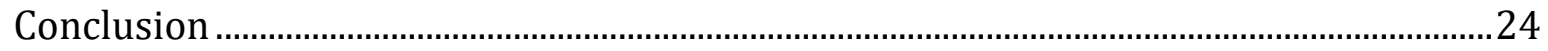

Chapter Three: Methodological Framework ...............................................................26

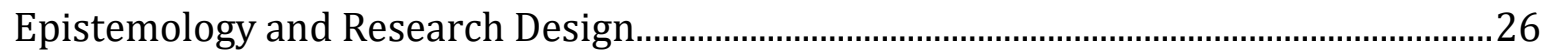

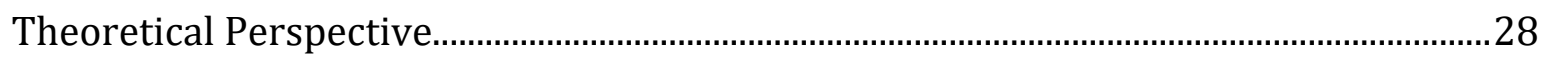

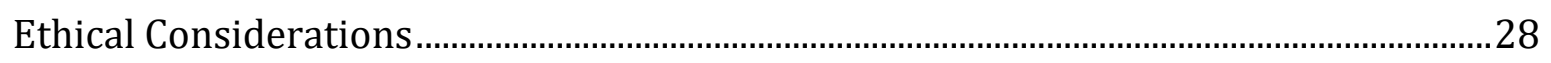

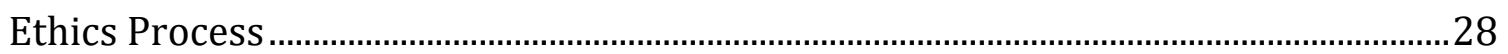

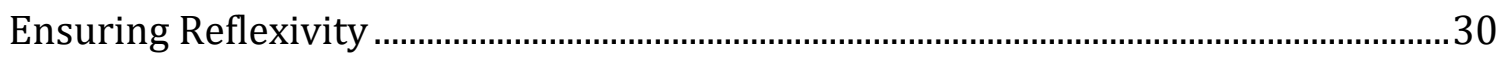

Research Process - Participants, Data Collection, and Analysis .........................................31

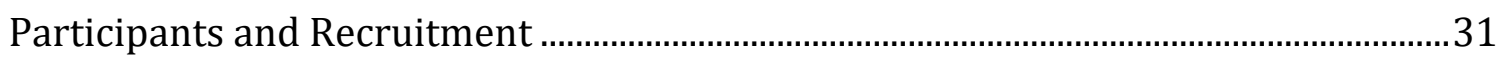

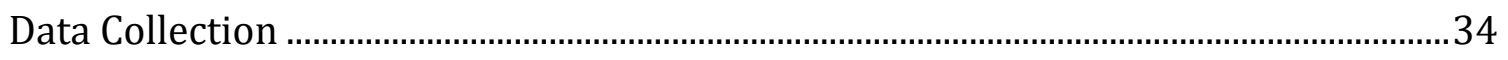

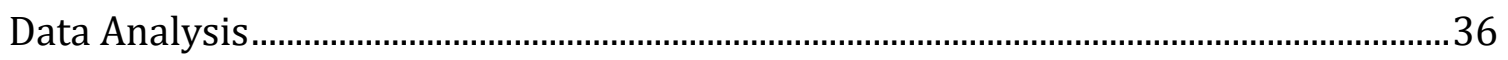

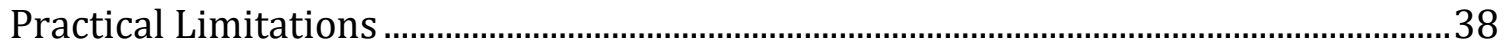


Research Challenges - Conducting Sexually Charged Research as a Woman.

\section{Chapter Four: Introducing the Participants and Addressing Common Client}

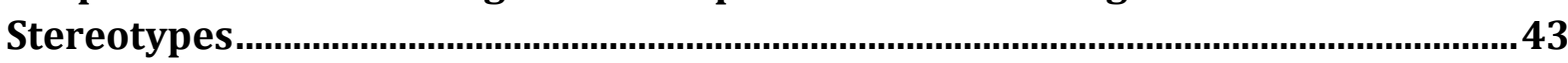

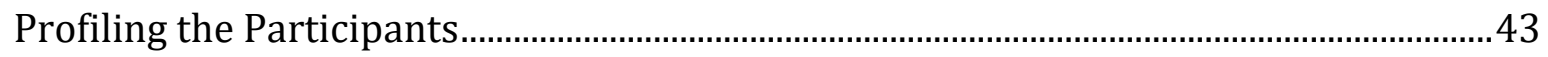

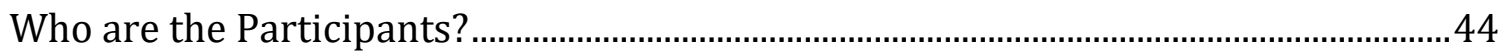

Participant Purchasing Frequencies and Trajectories.................................................... 45

How the Participants Accessed Commercial Sex …..................................................................48

Participants' Preferred Sexual Services................................................................................ 50

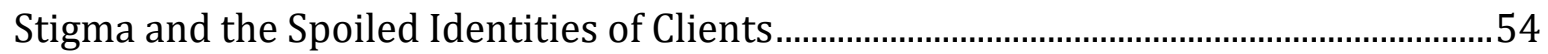

The Impacts of Stigma and Stereotyping on Clients ......................................................... 55

How do the Participants Compare to Common Stigmatisation? ........................................57

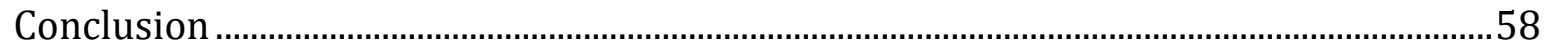

Chapter Five: Client Motivations for Purchasing Sex and the Resulting Impacts...59

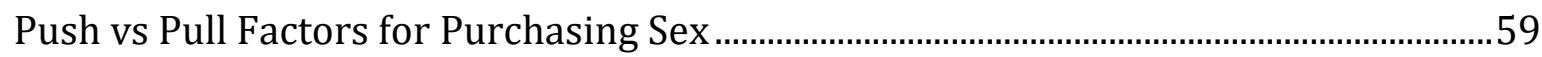

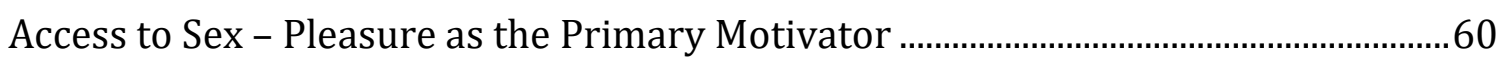

Access to Human Connection - Sex as the Secondary Motivator .....................................63

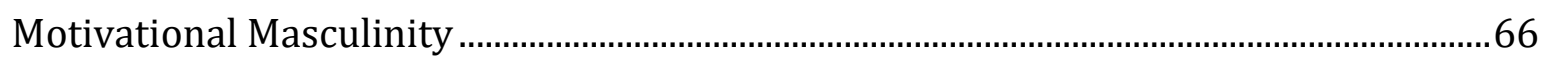

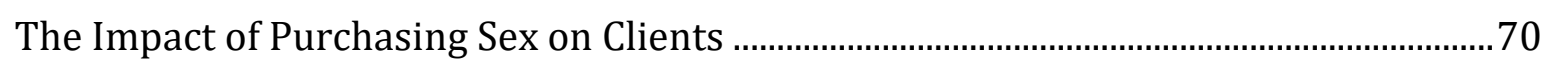

Confidence and Comfort with the Self and Sexuality ....................................................... 71

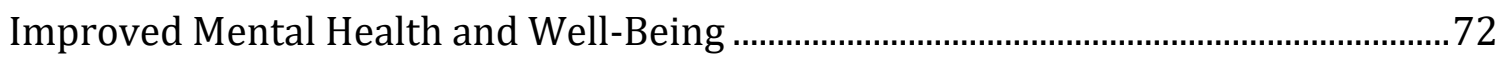

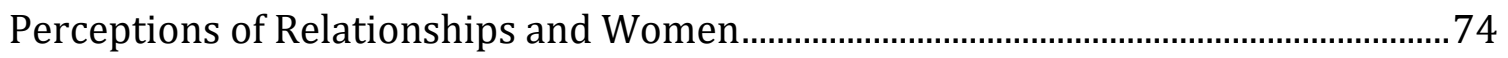

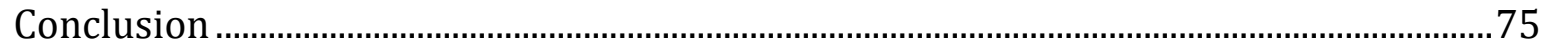

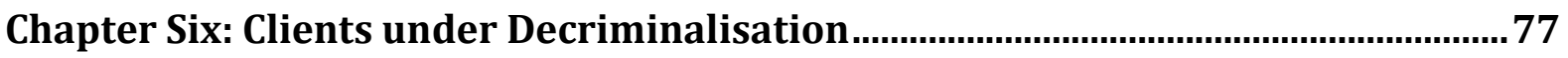

Client Interactions with Sex Workers under Decriminalisation ..........................................77

Client Recognition of Sex Worker Boundaries and Comfort .................................................78

The Safety of Purchasing Under Decriminalisation ................................................................ 80

Communication with Sex Workers and Sex Work Accessibility ......................................82

Clients' Ethical Considerations when Purchasing Sex ........................................................86

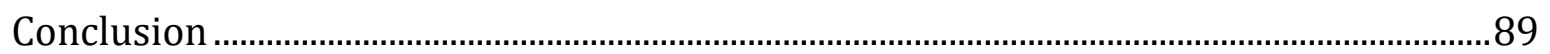

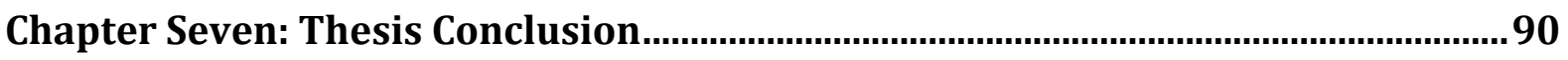

Contextualising Clients - The Good, The Bad, or The Bogus? ...............................................90

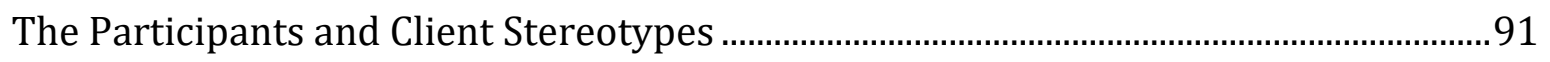

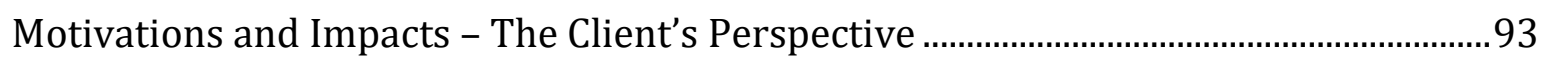

Client Interactions with Sex Workers under Decriminalisation .........................................94

Looking Forward - Recommendations for Future Research ............................................96 
References 98

Appendices

115

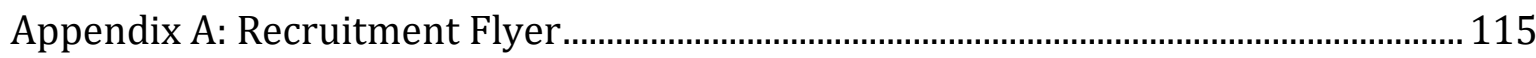

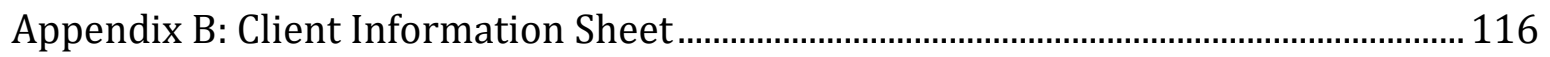

Appendix C: Client Interview Guide .................................................................................. 118

Appendix D: Key Informant Information Sheet ............................................................... 120

Appendix E: Key informant Interview Guide .................................................................... 122

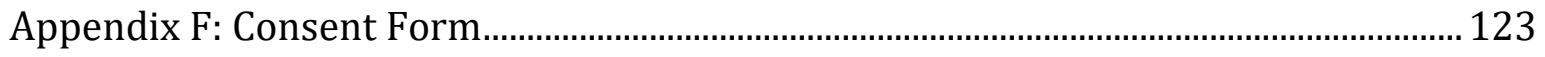




\section{Chapter One: Introduction}

When considering sex work research, Weitzer has asked, "where are the men?" (2000, p. 7). The clients of sex workers have only relatively recently begun to occupy the academic gaze as, historically, research in this field has focused almost exclusively on women who sell sex. As noted by Monto (2000), due to stigma, clients of sex workers are notoriously difficult to access for research and accordingly, Marttila (2008) denotes clients "the invisible subjects of the sex industry" (p. 34). Moreover, Soothill and Sanders (2005) suggest that limited research on clients historically stems from sex workers being socially and politically defined as 'the problem'. Yet, since it has been recognised that clients are underrepresented in research, a substantive body of international literature has documented the clients of sex workers from diverse ideological positions. Such research has covered topics including client motivations for purchasing sex; their sexual interests and service preferences; the number of men who purchase sex; and how they compare against the general population (Birch, 2015; Farley et al., 2017; Michael, Gagnon, Laumann, \& Kolata, 1994; Milrod \& Weitzer, 2012; Sanders, 2008b).

While research addressing client experiences and identities is developing, simultaneously, policy-makers have turned their attention to clients as the potential targets of criminalisation and consequentially, they have begun to feel the heavy moral burden historically reserved for sex workers (Kinnell, 2006). The ever-increasing popularity of morally censoring clients has led legislators in many countries around the world to begin passing laws which criminalise client populations (Brooks-Gordon \& Gelsthorpe, 2003). The 1999 introduction of client criminalisation in Sweden, and the following global proliferation of the Swedish/Nordic model, was driven by the abolitionist feminist perspective which considers sex work an institutionalised form of male violence against women. From this perspective clients are positioned as coercive and abusive men the public requires protection from and those who endorse this seek to eradicate prostitution (Soothill \& Sanders, 2005). However, as noted by Soothill and Sanders (2005), a coalescence of clients with the coercion and abuse of sex workers is dangerous, as the increasingly punitive policies introduced to 'end demand' for sex work have been shown to place sex workers and their clients at risk (Amnesty International, 2016; Kinnell, 2006; Krüsi et al., 2014; Dodillet \& Östergren, 2011). 
However, while tackling demand has characterised sex work regulation in some countries, New Zealand took a different path through decriminalising sex work in 2003 (Abel, 2014). Prior to decriminalisation, New Zealand regulated commercial sex through partial criminalisation lead by the Crimes Act 1961, the Massage Parlours Act 1978, and the Summary Offences Act 1981 (Jordan, 2010). Under this legislation, the act of selling and purchasing sex was legal, but a range of related activities were illegal. Clients remained exempt from this legislation following their social positioning as easily influenced by their sexual desires (Jordan, 2010). Research indicates that, prior to decriminalisation in New Zealand, sex workers were vulnerable to exploitation, coercion and violence (Abel, 2014). Hence, the New Zealand Prostitutes Collective (NZPC) was unrelenting in advocating for sex workers' rights and worked in collaboration with an MP on an initial draft of the Prostitution Reform Act (PRA) 2003 (Abel, 2014; NZPC, 2013).

The core aims of the PRA 2003 emphasise safeguarding the human rights of sex workers, preventing their exploitation, and promoting occupational health and safety (PRA 2003, s 3). New Zealand is the first country to decriminalise sex work and research indicates that the PRA 2003 has overall achieved these goals (Armstrong, 2010, 2016; Abel, Fitzgerald, \& Brunton, 2009; Crofts \& Summerfield, 2006). Yet, little New Zealand data exists on clients (Plumridge, Chetwynd, \& Reed, 1997; Jordan, 1997) and no research has focused on clients since decriminalisation. However, despite this lack of evidence, some commentators, namely abolitionist feminists, have speculated about clients in New Zealand, arguing that "more men go to more and bigger brothels because decriminalisation is out of control and, quite simply, impossible to control" (Raymond, 2004, p. 1163). Similarly, Coy and Molisa (2016) claim that, since the law reform, sex without condoms has been normalised among clients in New Zealand and that men now demand cheaper prices and more 'extras' from sex workers. Geddes (2018) shares this perspective, noting that decriminalisation makes clients "more angry and more violent". Likewise, Farley (2004) describes clients under decriminalisation as "socially tolerated sexual predators" (p. 1118) and Julie Bindel (2017) argues that "rape, beatings and stabbings", and "having sex with distressed, terrified women ... and being violent" defines typical client behaviour since decriminalisation (p. 199). Accordingly, Molisa (2015) argues that decriminalisation locates power and control with clients, noting that "it's the buyers of prostituted people who are the ones being empowered - to use and abuse sex workers as they please". 
Considering this speculation, research which focusses on clients in the New Zealand context is vital. In its final report on the impacts on the PRA, the Prostitution Law Review Committee (PLRC) (2008) stated that "the need remains for research to identify the clients of New Zealand sex workers and to establish a fuller picture of their motivations and reasons for buying sex, in order that New Zealand findings can be compared with those obtained internationally" (p. 166). This thesis contributes to addressing this evidence gap and provides the first insights into client experiences under decriminalisation through drawing on interviews with 12 clients and three key informants with insights into how clients operate in the New Zealand sex industry.

\section{Key Definitions and Terminology}

Sex work is notoriously difficult to define and applying the narrow parameters of 'the sale of sexual acts' oversimplifies an exceptionally complex area within which even the definitions of 'sale' and 'sexual acts' are contested (Schmidt, 2017; Jordan, 2005). The practices understood as 'sex work' encompass a range of activities, including but not limited to prostitution, escorting, exotic dancing or stripping, pornography, and webcamming (Sanders, O'Neil, \& Pitcher, 2009). However, for the purposes of this thesis, sex work is defined according to the conventional "sex-for-pay transaction" (Weitzer, 2009b, p. 217). The services of focus are those referred to as 'direct' sexual services, where "physical contact of a sexual nature is exchanged for money" (Harcourt \& Donovan, 2005, p. 202), and while this may not always involve penetrative intercourse, it is normally involved. While the term 'prostitution' has traditionally defined this, 'prostitution' is considered problematic as it has been used in a derogatory manner (Abel, 2014). Hence, the term 'sex work' is used in this thesis, as it approaches the 'sex-for-pay transaction' from a labour standpoint - it emphasises that selling sex is a legal profession and aids in separating the worker from their work (Jordan, 2005).

The terminology surrounding clients is also greatly contested. While dogmatic language, such as 'prostituted women', is used by abolitionists to emphasise the exploitation of sex workers, the clients of sex workers have similarly been labelled by abolitionists as 'prostitute users' or 'prostitute abusers' (Anderson \& Davidson, 2003; Raymond, 2004). Similar terms that are applied by abolitionist feminists for shock value include 'sex buyers', 'batterers', and 'sexual predators' (Farley et al., 2017; Weitzer, 2009b). The terms 'john', 'punter', and 'kerb-crawler' carry an equally heavy stigma and have also been used 
extensively in the United Kingdom and United States to identify the men who pay women for sex (Brooks-Gordon \& Gelsthorpe, 2003; Weitzer, 2009). Recognising the potentially stigmatising and dehumanising nature of these labels, I will use the term 'client' throughout my research to reflect my perspective that clients are people who pay to spend time with sex workers.

\section{Understanding Commercial Sex in New Zealand}

To provide context for how the participants accessed commercial sex in New Zealand, it is important to discuss where sex work occurs. The three major centres of sex work in New Zealand are Auckland, Christchurch, and Wellington, yet sex work does occur in regional areas (Abel, Fitzgerald, \& Brunton, 2007). The different sectors in which clients may access sex work in New Zealand can broadly be categorised into outdoor streetbased and indoors, yet sex workers also advertise and source clients online. It is difficult to disentangle the contexts where commercial sex is sold - sex workers can operate across platforms simultaneously, as to can clients purchase sex across contexts (Sanders, O'Neil, \& Pitcher, 2009). Abel, Fitzgerald, and Brunton, (2007) have provided the most recent profile of the New Zealand sex industry post-decriminalisation, which indicated that most sex workers work indoors, and that street-based sex work constitutes the smallest sector of the New Zealand sex industry.

Sex workers operating across New Zealand's outdoor and indoor sectors may operate privately (otherwise known as independent sex workers) or be managed through a third party. If operating privately, sex workers may work indoors in a private or shared residence, or work in street-based markets. Street-based markets involve clients soliciting sex in visible, public locations. These sex workers will generally spend a shorter period with their clients, often around 10 minutes, and may deliver the services in a client's car or other public space (Sanders, O’Neil, \& Pitcher, 2009). Conversely, the private indoor sector is the second largest sector of the New Zealand sex industry (Abel, Fitzgerald, \& Brunton, 2007). Sex workers operating independently indoors often manage themselves through online platforms, which provide a means to advertise services, organise bookings, and communicate with clients (Jones, 2015; Jordan, 2005). Technological development has significantly impacted on the sex industry; most sex work is now mediated through digital technologies (Cunningham \& Kendall, 2011; Jones, 2015), and client migration to online platforms has prompted a decline in the popularity 
of more traditional sex markets (Sanders, Connelly, \& King, 2016). The sector differs from international contexts, as since decriminalisation, groups of up to four sex workers may legally work together in small owner-operated brothels, without requiring an operator's certificate providing there is no one in charge (Boyd, 2010; PRA 2003, s 4).

Lastly, the indoor managed sector is the largest sector of the New Zealand sex industry, and involves brothels and escort agencies (Abel, Fitzgerald, \& Brunton, 2007). Brothels are licenced premises specifically designed for the sale of commercial sex where multiple women work on shift at the same time, with a third party organising their bookings, which may also involve outcalls to hotels (Sanders, O'Neil, \& Pitcher, 2009). While still offering these 'in-call' services, escort agencies differ in that sex workers typically work 'on call' and clients must make appointments, as opposed to dropping in anytime during opening hours (Jordan, 2005). Thus, the types of sex work that occur in New Zealand mirror those that occur throughout the world, but the way these businesses can operate - and thus how clients can interact with them - differs significantly due to decriminalisation.

\section{The Research Objective}

The objective of this research is to explore experiences of clients of sex workers in the context of decriminalisation. This research is exploratory and sought to understand how clients perceive and navigate their experiences with sex workers. The overarching research questions were:

1. Who purchases sex in New Zealand, and how/in what ways?

2. What motivates these clients to seek commercial sex, and how does commercial sex appeal to them?

3. How does purchasing sex impact on the lives of clients, and how do they understand these impacts?

4. To what extent has decriminalisation impacted on client conduct and interactions with sex workers?

5. Are clients aware of the Prostitution Reform Act 2003 and how do they perceive their legal responsibilities when purchasing sex under decriminalisation?

This research was motivated by my interest in the impacts of decriminalisation on the sex industry and specifically a desire to understand how clients are impacted, which as 
previously noted, is under-researched. Thus, this thesis contributes to an important gap in providing the first qualitative insights into how clients experience purchasing sex under decriminalisation in New Zealand.

\section{Thesis Overview}

Chapter Two contains a literature review of the feminist debates surrounding sex work, the legal approaches to regulating sex work, and the existing research on the clients of sex workers. Chapter Three discusses the methodological approach for this research, outlines the research methods applied, the limitations of this research, and personal challenges encountered when conducting sexually charged research as a young woman, with older male participants. Chapter Four provides an initial introduction to the participants and documents their engagements with the sex industry in the context of stereotypes. Chapter Five outlines motivations for seeking commercial sex among participants, the role of masculinity, and the impacts the participants experienced from spending time with sex workers. Chapter Six, the final analysis chapter, documents the impact decriminalisation has had on clients in New Zealand, including discussions of how participants interacted with sex workers in this unique context and how they compared this to their experiences seeing sex workers in other countries. Chapter Seven concludes this thesis and offers a discussion of how clients can be conceptualised and the implications of the findings in the context of decriminalisation. 


\section{Chapter Two: Literature Review}

This chapter provides a review of the relevant literature on feminist approaches to sex work, the legal frameworks regulating sex work, and the clients of sex workers. The review begins by offering context to this research through exploring feminist approaches to conceptualising commercial sex. This chapter then situates the differing legal frameworks used to regulate sex work among these feminist narratives and unpacks the impacts of legal models on sex workers and their clients. An analysis of the literature on decriminalisation in New Zealand is then provided, which highlights the gap within the literature based on clients under decriminalisation. Following this, the limited New Zealand research on clients is addressed and connected to a discussion of international research.

\section{Feminist Theorising on the Sale and Purchase of Sex}

Sex work continues to underpin our conversations about sexuality - a space dominated by feminists. Sex work is contentious among feminists and the acceptability of both selling and purchasing sex remains heavily debated (Beran, 2012; Comte, 2013; LeBrun, 1999; Sloan \& Wahab, 2000). These debates largely revolve around a spectrum of choice and control and diverge on the following key issues: the extent to which sex workers are exploited or exercise agency, whether the existence of sex work is harmful to broader society, and the best legal approach to managing the sex industry (Kesler, 2002; Kissil \& Davey, 2010). As Miller and Schwartz (1995) highlight, sex workers are uniquely positioned to experience the brunt of many systems contributing to violence against women, including the patriarchy, ${ }^{1}$ the economy, and gender inequality. Accordingly, feminist arguments on the implications these systems have for the power dynamics between the seller and the buyer are polarised (Sanders, O'Neill, \& Pitcher, 2009).

Abolitionist feminist scholars believe that prostitution exists as a manifestation of the patriarchy. This perspective mandates that prostitution is reminiscent of the original property claim men heralded over women's bodies (Gerassi, 2015). As explained by Carol Pateman (1988) "when women's bodies are on sale as commodities in the capitalist market, the terms of the original contract cannot be forgotten; the law of male sex-right

\footnotetext{
${ }^{1}$ The definition of the patriarchy is contested, yet Walby (1989) summarises its multifaced nature well when arguing that the patriarchy is a "system of social structures and practices in which men dominate, oppress, and exploit women" (p. 214).
} 
is publicly affirmed, and men gain public acknowledgement as women's sexual masters" (p. 208). Likewise, this approach argues that the commodification of female sexuality for men violates the dignity of sex workers, and, to an extent, all women (Bromberg, 1997). Pateman (1988) subscribes to this view, arguing that "womanhood is confirmed in sexual activity, and when a prostitute contracts out use of her body she is thus selling herself" (p. 207). The existence of prostitution is further argued to encourage the persisting patriarchal dominance of men over women - as noted by Dworkin (1993), "prostitution comes from male dominance ... a woman is being prostituted because every hierarchy needs a bottom and prostitution is the bottom of male dominance" (p. 11). As an extension of this argument, some feminist schools insist that prostitution primarily represents women's sexual subservience to men and creates a class of women whose position in society is reduced to servicing male sexuality (Kesler, 2002; Satz, 1995).

Furthermore, as argued by Marxist feminists, prostitution exists due to the economic subservience of women (Gerassi, 2015). This argument proposes women exist in a state of civil inequality and that this economic disadvantage restricts a woman's access to financial free will (Comte, 2013; Sloan \& Wahab, 2000), thus signifying a lack of consent to sex work (Jeffreys, 1997). As explained by MacKinnon (2009), "in prostitution, women have sex with men they would never otherwise have sex with. The money thus acts as a form of force, not as a measure of consent. It acts like physical force does in rape". Such feminist scholars carry the same logic to their conceptualisations of clients (Weitzer, 2010). Radical feminist academics, such as Jeffreys (1997), Dworkin $(1993,1997)$, and MacKinnon (1987, 1989), frequently synonymise clients with women abusers, rapists, sadists, and child molesters, and construct clients as "deviant sexual predators" (Sanders, 2008 b, p. 132). Hence, this feminist approach fundamentally locates the problem of sex work with clients, whom they consider responsible for the trafficking and exploitation of all sex workers (Sanders, 2008b).

However, not all feminists adopt this approach and, instead, argue that most women employ active autonomy and rational choice when entering sex work (Comte, 2013; LeBrun, 1999; Sloan \& Wahab, 2000). As argued by feminist scholar and sex worker Kesler (2002), "to tell women that their choice is always an illusion is to force victimisation on women" (p. 223). Feminists who identify with harm-reductionist reasoning consider sex work to be a legitimate form of employment that deserves the 
recognition of labour rights (Mac, 2016). This perspective maintains that all types of work are shaped by gendered relations and, therefore, sex work is a job much like any other (Weitzer, 2012). While this position does acknowledge that sex workers can experience extortion and forced sexual labour, this is not considered representative of all sex workers (LeBrun, 1999). Alternatively, the elevated risk of physical and sexual violence that sex workers experience is accredited to the criminalisation of their occupation, not clients (Comte, 2013). Moreover, some feminists argue that charging men for sex to which some feel entitled to can be empowering for women (Kissil \& Davey, 2010; Weitzer, 2009a, 2012). Hence, academics including Sullivan (2004) maintain that sex workers actively resist men's traditional power and control over women's sexuality by receiving compensation for an act that is normally freely given.

Due to its politically charged nature, any research focusing on sex workers and their clients cannot be detached from feminism. It is important to locate such research within this context as, previously, feminist discourses on sex work have been instrumental in the framing of sex work legislation (Jolin, 1994). Feminist theory surrounding sex work is not only concerned with the commercialisation of female sexuality but also with those who purchase commercial sex, meaning these debates have strong implications for how clients are perceived and legally responded to across a variety of social and legal contexts (Giusta \& Munro, 2008). The differing legal frameworks governing sex work are particularly salient for this research as it unpacks client experiences as dictated by decriminalisation and thereby, it is important to understand what decriminalisation looks like and how it differs to other contexts globally. Hence, this literature review will now turn to unpacking these frameworks and accessing their impact of sex work.

\section{Contemporary Legislative Approaches to Sex Work}

The sex industry has a long history, yet despite its persisting presence and over 50 years of unrelenting campaigning from sex worker rights advocates, over half of the world still criminalises aspects of sex work (Armstrong, 2017; McCarthy, Benoit, Jansson, \& Kolar, 2012). Moreover, since the late 1980s, a trend towards the criminalisation of clients has emerged in the regulatory approaches of many countries. As Sanders (2008b) explains, "there has been a repositioning of men who buy sex as the problem" (p. 135). That is, clients are increasingly being depicted as responsible for the exploitation of sex workers (Bernstein, 2007; Brooks-Gordon, 2006; Serughetti, 2012). Although sex work essentially 
represents the provision of a 'service', the turbulent nature of sexuality and gendered relations has meant that commercial sex is subject to levels of regulation distinct from other service industries (Schmidt, 2017). Hence, the legislation surrounding sex work generally adopts one of the following approaches - full or partial criminalisation; criminalisation of the client (Swedish or Nordic model); and legalisation or decriminalisation.

\section{Full and Partial Criminalisation}

Under full criminalisation, all parties including the seller, buyer, and other third-parties are criminalised (Hayes-Smith \& Shekarkhar, 2010). Alternatively, and as is more commonly seen, a modified partial criminalisation is enacted where the sale of sex is legal, but surrounding activities are illegal (Abel, Fitzgerald, Healy, \& Taylor, 2010). Legislation that criminalises all or some elements of sex work are heavily informed by moral order and public nuisance discourses (Kantola \& Squires, 2004; Wagenaar \& Altink, 2012). The public nuisance discourse constructs sex workers and clients as threats to public safety through the spreading of venereal diseases and associations with criminal activity. Alternatively, the moralised approach considers sex workers exploited victims at the hands of clients and has emerged due to increasing concerns of human trafficking (Kantola \& Squires, 2004).

Within recent years, countries imposing criminalisation have also dedicated increased attention towards the clients of sex workers and are attempting to 'tackle the demand' for sex work (Kinnell, 2006; Sanders, 2009; Serughetti, 2012). This process was signalled in the United Kingdom by the document 'Paying the Price' (Home Office, 2004). In 'Paying the Price', male clients of female sex workers were positioned as responsible for unsafe sexual practices and substance abuse witnessed within the sex industry. Hence, the document presented a new resolve to target clients through criminal justice means (Home Office, 2004), despite empirical investigation which rendered the document flawed (Brooks-Gordon, 2005). Across many countries, community fear towards clients is also rising. This is well exemplified by a case in the United States, where 'John TV' was created - a weekly show that shared the addresses, names, and pictures of men arrested for solicitation (Weitzer, 2009a). Other strategies of reforming clients are John Schools found in the United States, designed for clients arrested for solicitation, who may then barter for a less severe sentence by enrolling. To prevent client recidivism, John Schools 
provide information on sex work and its negative impacts on the related parties (Serughetti, 2012). The same logic drove the establishment of the Kerb-Crawler Rehabilitation Programmes in the United Kingdom (Serughetti, 2012).

The harms of criminalising sex work have been well documented. As explained by activist and sex worker Juno Mac, "prohibiting the sex industry exacerbates every harm that sex workers are vulnerable to" (2016). Criminalisation confines sex work to informal economies, which prevents workers from unionising and operating collectively for safety (Mac, 2016). Illegality further denies sex workers the protection of law enforcement, which increases their vulnerability to extortion from managers, violent clients, and coercive law enforcement (Decker et al., 2015). For example, in New South Wales prior to decriminalisation, sex workers reported being frequently blackmailed into sex with police officers (Donavan et al., 2008, as cited in Armstrong, 2016). Similar trends have also been noted across the United States and United Kingdom (Phoenix, 2002). Moreover, police under criminalisation do not always take violence against sex workers seriously (Kinnell, 2013) and increase sexual health risks through confiscation of condoms as evidence (Wurth et al., 2013).

Criminalisation further exacerbates the stigma attached to sex work (Sallmann, 2010). Goffman (1963) describes stigma as a spoiled identity resulting from an attribute that is deeply discrediting, which reduces the bearer "from a whole and usual person to a tainted, discounted one" (p. 3). Through engaging with the commodification of an act considered private, clients and sex workers are positioned as violating one of the key taboos in Western-European culture (Rubin, 1992, as cited in Koken, 2011). Following this violation, stereotypes have arisen which paint clients as inadequate men and narrowly isolate them to categories including unattractive, awkward, sexually and socially dysfunctional, incapable of attracting women, irresponsible fathers, and adulterous husbands (Sanders, 2008b, p. 116). Even more concerning, is the stigma that positions clients as disproportionately attracted to violent or perverse sexual acts, thus labelling them as out of control, deviant, and dangerous (Birch, 2015). Considering the detrimental impacts of criminalising sex workers on the entire industry, many politicians, feminists, and academics have advocated for a legal alternative - criminalising clients. 


\section{The Swedish Model - Client Specific Criminalisation}

The Swedish model, otherwise known as the Nordic model, criminalises clients and the act of purchasing sex (Levy \& Jakobsson, 2014). Sweden was the first country to criminalise purchasing sex and under this legislation, clients can receive a fine or up to six months' imprisonment if they are convicted (Jordan, 2005). The logic motivating the Swedish model argues that the most effective way to eliminate sex work is to criminalise its root cause - male consumer demand (Gangoli \& Westmarland, 2011). During initial debates surrounding the model, the abolitionist movement was prominent, while sex workers and their clients received little consultation. Accordingly, key narratives driving the legislation were based on abolitionist discourses, which argue that clients are the perpetrators of gendered violence and that sex work is essentially "the commercialisation of women's bodies", shows "contempt for women", and is "counterproductive to equality" (Svanstrom, 2004, p. 230).

The Swedish model has been heralded in some corners as a success, with claims that it has reduced buyer demand (De Santis, 2005; Ekberg, 2004). Following these claims, countries including Canada and Ireland have adopted this model (Brooks-Gordon \& Gelsthorpe, 2003; Chu \& Glass, 2013; Serughetti, 2013). Sanders (2008b) proposes there are separate processes contributing to the increased popularity of client criminalisation. These include the abolitionist agenda for eradicating sex work and the growth of activism fueled by stereotypes of clients as "sexual predators and perverts warranting increased police attention and official policy response" (Sanders, 2008b, p. 136). It has been argued that there is a strong connection between pathologizing narratives and criminalising clients, which implies the possibility of psychological treatment for clients (Kulick, 2005; Bernstein, 2007; Sanders, 2008a). This is evident in groups emerging in Swedish cities, where social workers assist clients through providing counselling (Sanders, 2008b).

However, despite the spread of the Swedish Model, research only indicates a slight decrease in visible forms of sex work in Sweden (Dodillet \& Östergren, 2011; Levy, 2014), which can be attributed to the displacement effect, where street-based workers relocate indoors, online, or to neighbouring countries (Chu \& Glass, 2013). Moreover, it has been suggested that research presented supporting client criminalisation is methodologically unreliable. As explained by the Swedish National Board of Health and Welfare, it is "difficult to discern any clear trend of development: has the extent of prostitution 
increased or decreased? We cannot give any unambiguous answer to that question" (Socialstyrelsen, 2008, p. 63, as cited in Levy \& Jakobsson, 2014). It has also been argued that criminalising clients adversely affects both clients and sex workers (Amnesty International, 2016). For example, sex workers in Sweden must prioritise the client's safety over their own. Accordingly, Krüsi et al. (2014) found that such sex workers hurried or deserted screening practices and got into client's cars quicker. Clients also demanded bookings in areas away from police presence, often in isolated locations (Krüsi et al., 2014). Due to decreased buyer demand on the street, negotiating power becomes imbalanced in favour of clients, and sex workers are often forced into selling riskier sexual services at lowered prices to continue making a profit (Chu \& Glass, 2013; Dodillet \& Östergren, 2011; Levy \& Jakobsson, 2014).

\section{Legalisation - A Two-Tiered System}

Despite contemporary dominance of legislation that aims to eradicate sex work, historically, the main approach has been to manage its position in society (Jordan, 2005). This regulatory model is known as legalisation and has been adopted in the state of Nevada in the United States and areas within Australia, Germany, and the Netherlands (Sullivan, 2010). The aims of legalisation are two-fold - while it seeks to address the risks sex workers encounter, it also draws on moral rhetoric and attempts to isolate the sex industry to areas that will not impede the public (Abel et al., 2010; Sullivan, 2010). Under legalisation, certain forms of sex work are legally permitted, but only under heavy regulation from the state (Gangoli \& Westmarland, 2011; Weitzer, 2012). For example, sex workers may legally sell sex, but only if they acquire a licence and operate indoors. Likewise, brothel owners must acquire a permit and adhere to several conditions, including operating away from "respectable community areas" (Brents \& Hausbeck, 2005, p. 275; Gangoli \& Westmarland, 2011; Weitzer, 2012).

Legalisation is an improvement on criminalisation and has established a space for legal sex work, which has been shown to positively impact on working conditions and award some labour rights (Kilvington, Day, \& Ward, 2001). However, under legalisation, visible sex work remains illegal, most notably street-based (Abel et al., 2010). Moreover, politicians have deliberately made brothel registration and worker licences difficult to obtain - sex workers must comply with conditions that impact on their agency, such as three-monthly blood-tests and registering with an authority (Abel et al., 2010; Sullivan, 
1999). These conditions have created a two-tiered system of legal and illegal sex work, hence the term "back door criminalisation" (Mac, 2016). Within this two-tier system, the most vulnerable sex workers, such as women of colour or migrant and refugee women, are exposed to the conditions of a criminalised industry (Kilvington, Day, \& Ward, 2001). Moreover, it has been noted that the legalisation of sex work is often poorly implemented following legal inconsistencies (Gangoli \& Westmarland, 2011). As argued by Abel (2014), "it is in the implementation of legalised legislation that the underlying intentions are lost" (p. 590). Considering the harms of these three regulatory approaches, sex workers have advocated for decriminalisation.

\section{Decriminalisation - A Human Rights Model}

Decriminalisation involves the removal of laws that punitively govern sex work, meaning the sex industry is regulated according to pre-existing labour laws and in a manner like its more conventional business counterparts (Abel et al., 2010; Jordan, 2005). This model seeks to minimise the harms associated with sex work and the social exclusion of sex workers, while producing a regulated environment more conducive to public health and safety interests (Gangoli \& Westmarland, 2011; West, 2000). In doing so, decriminalisation acknowledges that the fiscal and societal costs of criminalising sex work are not proportionate to the benefits, and that, regardless of the imposed criminal sanctions, sex work will inevitably persist (Jordan, 2005). The benefits of this conceptualisation are well documented and arise from to prioritising the human rights, health and safety, and working conditions of sex workers over applying criminal sanctions to the sex industry (Human Rights Commission, 2001, as cited in NZPC, 2015). To date, only New Zealand and the state of New South Wales in Australia have adopted decriminalisation globally (Abel et al., 2010).

\section{Decriminalisation in New Zealand}

As previously noted, in 2003, New Zealand became the first country to decriminalise sex work (Abel, 2014). The legislation governing decriminalisation is dissimilar to other international models, as it was designed to be representative of the needs of those engaging with the sex industry (Abel et al., 2010; Jordan, 2005). As argued by Schmidt (2017), "decriminalisation protects the immediate interests of the women who work within it" (p. 35). In a pioneering move, the politicians campaigning for decriminalisation collaborated with the NZPC to ensure the legal reform reflected the needs and rights of 
sex workers (Abel, 2014; NZPC, 2013). The NZPC was founded in 1987 as a sex-worker led lobbying organisation aiming to improve the working conditions of sex workers. This unique collaboration allowed sex workers to negotiate with the New Zealand government and awarded them direct influence over the terms and conditions of decriminalisation (NZPC, 2013).

Research conducted prior to decriminalisation in New Zealand identified an industry within which sex workers experienced high levels of violence (83\%) and sexual coercion (58\%) amounting to pressure for unsafe sex (Plumridge \& Abel, 2001). Plumridge (2001) observed that managing risk was a central component of surviving the industry and, as explained by an interviewed sex worker, "there's quite a lot of violence with other girls and bashings and rapes" (209). Moreover, Plumridge and Abel (2001) recognised a dramatic 'segmentation' of the industry, where street-based workers experienced increased levels of risk, more severe forms of violence, and significantly poorer working conditions than indoor workers. Jordan (1991) also revealed the significant risks sex workers experienced when insisting on safe sex - as explained by working girl Caroline, "another client attacked me ... he broke two ribs as well as splitting my eye open. We were fighting over a condom and it got really violent" (p. 235).

Since decriminalisation, working conditions within the New Zealand sex industry have improved drastically. Sex workers now have the right to legal protection and easier access to justice against exploitative practices, which has been shown to enhance their perceptions of safety and ability to manage risk (Abel, 2010, 2014; Armstrong, 2010, 2014). Research conducted by Abel (2010) indicated that of 772 surveyed sex workers, 95.9\% recognised they had legal rights under the PRA 2003. Moreover, multiple court cases have witnessed sex workers win against exploitative managers, clients, and police officers (Duff, 2014; Humphreys, 2012). Decriminalisation has also been shown to improve sexual health within the industry, as sex workers hold greater power when negotiating condom use with clients (Abel, 2010, 2014). Moreover, since decriminalisation, Armstrong (2016) has found an improvement in police-worker interactions as sex workers are more comfortable reporting violence and expressed confidence that their reports would be taken seriously. As explained by Shania, a New Zealand sex worker, "it builds a relationship I think with the police in the fact that I feel 
confident enough now to go to them if need be ... whereas before you wouldn't" (Armstrong, 2016, p. 579).

\section{The Arguments Against Decriminalisation - Empirical or Anecdotal?}

Despite these clear successes, decriminalisation is still met with staunch opposition. However, most of the arguments mobilised against decriminalisation have largely been debunked (Jordan, 2005). For example, concern spread that the New Zealand sex industry would expand, and sexual health would be compromised. Yet, research conducted by Abel, Fitzgerald, and Brunton (2009) indicates that decriminalisation has caused neither increases nor decreases in the number of people trading commercial sex and encourages safe sexual practise, thus preventing the spread of HIV-AIDS (Abel, 2010; Armstrong, 2016; WHO, 2012). Yet, abolitionists continue to argue against decriminalisation through the clients of sex workers. These arguments position clients as empowered by decriminalisation, allowing them to act violently and coercively towards sex workers (Bindel, 2014, 2017; Coy \& Molisa, 2016; Farley, 2004; Raymond, 2003). Abolitionists further accredit the increase in recorded sexual violence cases witnessed in New Zealand to the sexual entitlement they believe decriminalisation has instilled among clients (Nordic Model Now, 2016).

However, the lack of research on clients under decriminalisation means these arguments merely constitute anecdotal claims. While clauses in the PRA 2003 were specifically created to safeguard sex worker rights and empower them against exploitation (Abel, 2010), we have little understanding of how clients navigate their interactions with sex workers under decriminalisation. Considering that decriminalisation has been shown to positively impact on sex workers, it would logically follow that we must now explore the impact on clients. Yet, this lack of research is not unusual - Perkins (1991) notes that research addressing men's involvement with the sex industry, be that as a client, worker, or management, constitutes less than $1 \%$ of research within this field. Jordan (2005) theorises that this may follow researchers considering the reasons men purchase sex as "self-evident" in that, when posing questions around why men would pay for sex, the assumption tends to be: "why wouldn't they?" (p. 51). However, in more recent decades academics have come to reject this simplistic approach to clients and while there is a significant lack of research with clients in New Zealand's post-decriminalised context, a 
small selection of research was conducted with clients prior to the New Zealand law reform, and a wealth of international literature has been produced on clients.

Though, before engaging the literature, it is important to acknowledge that not clients are male and not all sex workers are female - see Aggleton (1999), Laing, Pilcher, and Smith (2015), Logan (2010), Pilcher (2012), Sausa, Keatley, and Operario (2007), Walby (2012), and Whowell (2010). Despite this, most research has been conducted from a heteronormative perspective and focuses on exchanges between male clients and female workers. This approach is not misguided, as heterosexual sex upholds the industry, yet mainstream research has often failed to explore diverse gendered engagements with commercial sex (Laing, Pilcher, \& Smith, 2015). Yet, as the participants of this research were predominantly heterosexual men, this thesis relies heavily on prior research that emphasises male consumers of female services. However, considering the sample does include a female client and men with fluid sexual orientations, these gender disparities should be considered.

\section{The Clients of Sex Workers}

The success of the sex industry undoubtedly rests on men's willingness to purchase sex. Fundamentally, any service industry is sustained by demand - without clients, sex work would simply cease to exist (Collins \& Judge, 2008). However, the secrecy surrounding clients means that the number of men purchasing sex is difficult to measure, with research offering contradictory results (McKeganey \& Barnard, 1996). Research based on the National Health and Social Life Survey 1992 suggests that approximately 16\% of men in the United States have purchased sex (Michael, Gagnon, Laumann, \& Kolata, 1994). Similarly, Perkins (1991) estimates that one in every 40 men in Sydney purchase sex weekly. More recently, Carael, Slaymaker, Lyerla, and Sarkar (2006) estimate that the proportion of people who had purchased sex globally ranged between 9 to $10 \%$. While the amount of clients are exceptionally difficult to gauge, it is well understood clients significantly outweigh sex workers in numbers (Jordan, 2005). For example, Stein's (1974) research indicates a client-to-worker ratio of 30:1, while Kinnell's (2006) research estimates 50 to 100 clients for every individual sex worker (Kinnell, 2006). Similarly, prior New Zealand research found that on average, individual sex workers saw 14 clients a week (Chetwynd, 1992). Hence, to effectively comprehend the New Zealand sex industry, it is imperative that research seeks to understand clients. 


\section{New Zealand Research on Clients Pre-Decriminalisation}

One of the few New Zealand client studies was conducted as a collaboration between the NZPC and the Health Research Council of New Zealand and involved 30 male clients (Chetwynd \& Plumridge, 1993). When addressing their motivations for purchasing sex, 10 clients reported that the straightforward nature of the sexual exchange appealed to them, while 11 clients were mainly motivated by pleasure, including the need for company, the elevation of boredom, and desire for sexual variety. A smaller selection of participants also cited shyness, sexual inexperience, lack of alternative options, and wanting sexual acts unavailable to them (Chetwynd \& Plumridge, 1993). Interestingly, passivity towards safe sex was observed among these men as most y relied on the sex worker's knowledge of safe sex and exhibited low levels of sexual health awareness (Chetwynd \& Plumridge, 1993). Following research conducted by Plumridge, Chetwynd, and Reed (1997) saw a continuation of this trend.

A smaller qualitative study was conducted by Jan Jordan in 1997 and involved interviews with 13 clients. All 13 participants shared one key reason for purchasing sex - sex however, the importance placed on sexual gratification varied according to their relationship status. For example, four married men felt their wives were no longer able to sexually satisfy them, while single clients purchased sex for its uncomplicated nature. Jordan's (1997) research further indicated that participants sought companionship from sex workers. For example, a participant explained, "it's very depressing to be lonely all the time ... it's not sexual relief that I go for, it's to relieve some loneliness" (Jordan, 1997, p. 62). To summarise, Jordan (1997) found that alongside relieving their sexual needs, the "illusion of closeness" (p. 65) sex workers provided fulfilled the emotional, intimacy, and companionship needs of their clients. Whilst limited research has been conducted with clients in New Zealand, a larger body of international research exists and thus, this literature review will examine this research.

\section{International Research on Clients}

Research exploring sex work has largely focused on sex workers, which Weitzer (2000) argues has led to the oversimplification of clients (Weitzer, 2000). Hence, Monto and McRee (2005) suggest that research on clients can be separated into two conceptual categories - the "peculiar man perspective" and the "every man perspective" (p. 506). The 'peculiar man perspective' argues that clients have certain deficiencies or qualities that 
separate them from non-client populations. As Birch (2015) explains, this perspective draws on theories relating to 'deviancy' and focuses on why (from a negative standpoint) men want to purchase sex, the characteristics that predispose them to this, and the resulting negative consequences. This approach has resulted in many studies that seek to pathologize clients - see Bindel (2017), Farley, Bindel, and Golding (2009), Farley, Macleod, Anderson, and Golding (2011, 2017). Such research contains the underlying assumption that purchasing sex is inherently immoral and thus, seeks to locate an abnormality among clients (Sanders \& Campbell, 2008). Hence, research driven by this perspective has been criticised for marginalising clients and ignoring social and cultural factors influencing men to seek sex workers (Monto \& McRee, 2005).

Conversely, the 'every man perspective' implies that the clients of sex workers are no different from non-client populations (Monto \& McRee, 2005). This research applies a more exploratory approach and focuses on including client samples in research, which allows clients to narrate their own experiences. Birch (2015) explains that such research draws on theories of 'normative value'. This is well exemplified by Kinnell (2006), who argues "the vast majority of men who pay for sex are ordinary men, a cross-section of society, usually employed, law-abiding citizens" (p. 232). Prior research indicates that despite the demonization of clients, most men seeking commercial sex are unremarkable in their social characteristics (Pitts et al., 2004; Sanders, 2008). Campbell, Coleman, and Torkington (1996) further highlight the normalcy of clients, as the interviewed sex workers predominantly referred to them as 'normal' men, explaining that "most of them are just ordinary fellas" (p. 223). Moreover, Monto and Hoteling (2001) challenge the deviancy attached to clients, and argue clients are no more likely than samples of the general population to support beliefs conducive to violence against women.

Additionally, to understand their position within society, previous research has sought to explore the characteristics of clients in comparison to nationally representative samples - see Monto (1999). Yet, Monto and McRee (2005) found that male clients of female sex workers did not differ in significant ways from nationally representative sample of the United States, commenting that "customers as a category differ from other men in degree rather than quality" (p. 505). In culmination, such research has found a significant overlap between clients and representative population samples, indicating that clients are just as diverse and nuanced as non-client populations (Monto, 2004). For this reason, further 
attention will not be dedicated to research of this nature. Instead, the following work will largely be sourced from research conducted in accordance with the 'every man perspective', as this best aligns with the current research.

\section{Motivations - Understanding Why Men Purchase Sex}

Motivations are among the most highly researched facets of clients, meaning we now have an in-depth understanding of why men purchase sex. Louie, Crofts, Pyett, and Snow (1998) conducted surveys with clients and found that quality sex was the most frequently cited motivation (32\%), followed by non-committed and convenient sex (20\%), intimate contact and companionship (15\%), and variety in partners and sexual acts (13\%). Likewise, Pitts et al. (2004) found that satisfying sexual needs was a key motivator (43.8\%), followed by the perception that purchasing sex was less trouble than establishing a relationship (36.4\%), and that it would be entertaining (35.5\%). A factor analysis conducted on these motivations identified three key variables - "ease, engagement, and arousal" (Pitts et al., 2004, p. 357). While survey research provides easier access to client populations, qualitative research has provided a more in-depth explanation of client motivations.

As explained by Sanders (2008b), research exploring client purchasing habits reveals a "spectrum of universal reasons that motivate men to enter into commercial sexual relationships" (p. 40). To better comprehend this spectrum, Sanders (2008b) proposes that client motivations can be separated into 'push' factors - elements within men's lives that are lacking - and 'pull' factors - elements commercial sex that are attractive. Through interviews with clients, Sanders (2008b) identified emotional needs; unsatisfactory sexual relationships; and unease with conventional dating as the key push factors shared by clients. Regarding 'pull' factors, Sanders (2008b) cites the "sexualisation of the nighttime economy" (p. 45) and its establishment as a leisure activity; the illicit or taboo nature of purchasing sex; the ability to purchase sex from a variety of women; and the ability to fulfil sexual fantasies. Sanders (2008b) explained that motivations were strongly related to the stage of the clients' life-course, in that there was no fixed pattern and motivations fluctuated and changed over time according to the client's age and changing social relationships.

Research conducted by McKeganey and Barnard (1996) mirrors these findings and identified the ability to request specific sex acts; the opportunity to have sex with a 
variety of women; the ability to seek out women with specific characteristics; thrill seeking through something that was socially taboo; and the unemotional, uncomplicated, and unlimited qualities of commercial sex as appealing to clients. Clearly, satisfying fantasies and purchasing specific sex is a significant factor attracting clients to sex workers, which Holzman and Pine's (1982) argue relates to men idealising sex workers as women with exceptional sexual powers. Moreover, Egan, Frank, and Johnson (2006), argue that sex work is constructed on fantasy and predicating potential client desires for many men, the ability to suspend reality through accessing something outside of the mundane is a strong factor pulling them to purchase sex (Sanders, 2008b).

Research conducted by Birch (2015) also reveals a plethora of normative and nondeviant client motivations. Birch (2015) conducted interviews with a sample of 36 clients and uncovered motivations include ding desire for intimacy, loneliness or shyness, thrillseeking, and a difficulty attaining sex (Birch, 2015). Most participants initially visited sex workers following the end of a relationship or as their current relationship lacked sex. Considering this, many participants experienced ongoing social issues which restricted their capacity to form meaningful relationships. For these men, purchasing sex helped them develop confidence and address their inability to experience closeness with others. Additionally, worsening self-confidence, shyness, and poor body image were offered by a selection of men as motivations for purchasing sex (Birch, 2015). Birch (2015) concluded that men's engagements with sex workers centred on their emotional, physical, and social needs, as the intimacy sex workers provided lessened emotional turmoil and loneliness. Hence, through fulfilling the motivations discussed so far, Birch (2015) concludes that

purchasing sex can support and enhance the well-being of some men. That said, it is important to note that existing research indicates that men's motivations for visiting sex workers are multi-faceted and hence, motivations should not be considered in isolation, as to do this would deny the nuances of the client experiences.

\section{Sex as the 'Extra' - Client Perceptions of Intimacy}

As theorising around the client-worker exchange develops, commercial sex is beginning to be understood through discourses of intimacy (Bernstein, 2007; Smith \& Laing, 2012). As noted by Earle and Sharp (2008), the concept of intimacy often refers to "knowing, loving and closeness between people" (p. 6), an emotional rather than solely physical connection. However, Hochschild (2003) explains that modernity has witnessed a 
diversion of emotional meaning from private relationships to commodified engagements. Through a reliance on commercial services, we are now able to imbue our lives with the emotional meaning and intimacy previously generated through non-commercial means (Hochschild, 2003). Following this, it is widely established that sex work involves the performance of intimacy (Egan, 2003; Earle \& Sharp, 2008). O'Neill (2001) describes this as 'emotional labour' and outlines that sex workers "manipulating, suppressing and falsifying their own feeling" (p. 89) is inherent to their interactions with clients.

While it has been documented that some clients are drawn to the temporary relationships available through sex work (Atchison, Fraser, \& Lowman, 1998), Xantidis and McCabe (2000) argue that many clients are influenced by a need for intimacy and companionship. Likewise, Sanders (2008b) proposes that the distinctions between commercial and noncommercial relationships are blurred, as for regular clients, sex work represents "an emotional conquest that produces the ... authenticity of an emotional relationship" (p. 407). Jamieson's (1998) conceptualisation of 'disclosing intimacy', where intimacy is constructed through mutual listening, expression of feeling, and sharing of thought, is further reflected in client motivations. For example, Lever and Dolnick (2000) found their participants were primarily attracted to the 'listening service' sex workers provide, where they function as pseudo therapists and attentively listen to the intimate revelations of clients. As explained by a sex worker participating in Sanders (2006) research, "ten percent of the job is sex. 90 percent of the job is chatting, therapy" (p. 2463). Likewise, Plumridge et al. (1997) found that at varying degrees, all participants understood purchasing sex as emotional and many cited the "emotional release" (p. 175) of intimate contact as their primary motivation for purchasing sex.

Akin to other leisure activities, intimacy is now available for a price and changing conceptualisations of sex work have been mirrored by changes in sexual commerce (Milrod \& Weitzer, 2012). This has prompted a diversification in the services sex workers offer, some of which have come to incorporate elements of non-commercial relationships - namely, the Girlfriend Experience (GFE). GFE incorporates acts that are traditionally considered intimate, such as extended conversation, kissing, cuddling, caressing, and mutual oral sex. Analysis of online forums indicates that those sex workers who received the most favourable reviews from clients provided GFE (Holt \& Blevins, 2007). The increasingly popularity of GFE represents a fundamental shift within the sex industry to 
profit from both sex and intimacy, with research indicating this shift is successful (Bernstein, 2007). GFE is often performed by sex workers submissively since it draws on stereotypical construction of the 'girlfriend' role. Hence, men's use of this service could be understood as an expression of masculinity, which has been documented as contributing to men purchasing sex (Joseph \& Black, 2012).

\section{Affirming 'Manhood' or Gendered Domination? The Relationship between Masculinity and the Client Identity}

As clients are predominantly male, they cannot be separated from the social and cultural forces that impact all men. The term masculinity has become the "shortest way to refer to how men act, think, believe and appear" (Hearn \& Pringle, 2006, p. 7). Masculinity theory offers an insight into 'maleness', and theorists such as Courtenay $(1995,2000)$ argue that masculinity creates a hierarchy within which certain types of identities are privileged, causing men who do not meet this standard to be perceived and treated as subordinate. This standard emphasises qualities considered 'male', such as denying weakness, controlling emotions, dismissing the need for help, unrelenting sexual interest, and being physically dominant or aggressive (Courtenay, 2000). As Seidler (1994) explains, social expectations of masculinity 'tell' men how to behave rather than allowing an individual's experiences to take priority, leading to conflict between men and the expectations of masculinity. Leafgren (1990) argues that this conflict may have a negative impact on men's mental health, implying that the socially constructed ideals of masculinity may be harmful to men's well-being.

Previous theorising on clients has relied on masculinity to explain purchasing sex as "men just being men" (Birch, 2015, p. 20; Jordan, 2005). Yet, Månsson (2004) posits that while clients are often driven by natural sexual behaviour, it is equally important to recognise the social origins of purchasing sex. Research indicates that a man's claim to masculinity is not fixed but characterised by malleability - it is a "perpetual achievement" and men are constantly at risk of being perceived as insufficiently masculine (Beneke, 1997, as cited in Joseph \& Black, 2012, p. 488). Sexual achievement is culturally tied to the evaluation of masculinity and, accordingly, affirming and building masculinity can influence men's engagement with commercial sex (Joseph \& Black, 2012). For example, research conducted by Davidson (1998) has found that groups of men often visit sex workers as a male bonding exercise or singularly as a means of affirming their manhood. 
Furthermore, Frank (2003) describes men's engagement with commercial sex as a "masculinising practice" which offers 'safe' sexual interactions with women, in that men do not risk the emasculating experience of rejection when purchasing sex.

Hearn and Pringle (2006) observe that research on masculinity is generally conducted "within the context of patriarchal relations" (p. 7) and often focuses on how masculinity adversely impacts women. While this research is important, it has undoubtedly impacted on sex work research which homogenises and problematises clients (Birch, 2015; Seidler, 1994). For example, Pateman (1988) claims that men's procurement of commercial sex reflects hyper-masculine heterosexuality and is characterised by male violence towards women. Such views suggest that all clients, and, as an extension all men, present the same risk (Birch, 2015). However, Prieur and Taksdal's (1993) research indicates that some men who purchase sex lack power within their social and everyday lives, leading them to sex workers. Moreover, the ideal of masculinity rejects the feminine quality of being emotional and, instead, heralds being "successful, rational and powerful" (Connell, 1995, p. 77). Attending to one's emotional needs is traditionally not a practice associated with masculinity, and Birch (2015) argues this could explain why academics have defaulted to understanding clients through their sexual needs and overlooked their psycho-social well-being.

\section{Conclusion}

The purchase of sex is incredibly complex, yet, as an inherently humanistic pursuit, nothing less could be expected. This literature review has highlighted the key issues surrounding the clients of sex workers and presented arguments situated throughout the spectrum of contemporary understandings of clients. This review has documented feminist theorising which surrounds clients and addressed the harms imposed by the key legal frameworks regulating their conduct. Further, this review has highlighted the key topics addressed by previous research, namely client motivations, notions of intimacy, and the influence of masculinity. This review also highlighted the existing New Zealand research on clients, which proved to be sparse. Through unpacking the decriminalisation of sex work and discussing the international speculation surrounding this law reform, this chapter has identified the literature gap regarding clients under decriminalisation, which this thesis contributes to addressing. Hence, this thesis will now address the methods and methodology which were used in this research. 


\section{Chapter Three: Methodological Framework}

This research sought to gather in-depth perspectives from clients in New Zealand, thus unravelling the secrecy surrounding them. To achieve this, a qualitative methodology was applied through conducting face-to-face interviews, as this best allowed the research to navigate the complexity of these client experiences. This chapter outlines the epistemological and theoretical foundations of this research, before outlining the research process, and offering a comprehensive description of how the research was conducted. The limitations of the research will also be discussed, including factors which impact on the generalisability of the data-set to New Zealand's broader client population. Finally, this chapter will touch on the personal challenges encountered during this research, alongside a discussion of the unique complications of conducting sexually charged research as a young woman with male participants. Undertaking this research began as an interest project, yet quickly developed to a personal journey, as my own experiences, beliefs, and worldviews intertwined with the research and guided it to completion. For these reasons, sections of this chapter are written in the first person.

\section{Epistemology and Research Design}

In all research, epistemological perspectives must be addressed to provide a foundation for the methodology. Broadly speaking, epistemology is the theory of knowledge formation - it considers the way knowledge and understanding are created to explain how we know what we know (Maynard, 1994). There are multiple variations of epistemology, with constructivism and positivism located at opposing ends of the spectrum. Positivist epistemology (also known as objectivism) holds that truth, and therefore meaningful reality, resides within entities themselves and is separate from any consciousness. Hence, the positivist view considers knowledge to be objectified in the individuals studied and argues effective research methodology can discover this objective truth (Creswell, 2014; Crotty, 1998; Phillips, 1995). Constructivist epistemology rejects this view of reality and asserts that knowledge is created through individual subjectivity and our engagement with reality, acknowledging that different individuals construct meaning in opposing ways, even in relation to the same phenomenon (Creswell, 2014; Crotty, 1998; Schwandt, 1998). 
As knowledge formation inherently influences research design, epistemology is embedded within the theoretical underpinnings, methodology, and methods of research. The current research was informed by constructivist epistemology, and acknowledges that the social, gendered, and political structures surrounding a given phenomenon do not occur naturally, cannot be observed as such, and should not be taken for granted (Creswell, 2014; Crotty, 1998; Schwandt, 1998). Following this reasoning, feminist epistemology also guided this research. Yet, feminist epistemology primarily encourages research to be conducted for women, by women, and with women as the key drivers behind the research (Letherby, 2003). This research differs as the participants are predominantly male and is concerned with an overwhelmingly male pursuit. This is contested territory and, in choosing to focus on clients, the appropriateness of applying a feminist theoretical approach needed to be considered. Feminist epistemology was deemed appropriate for this research as it deals with populations and the interviews focussed on the participants' interactions with women. Through addressing clients and decriminalisation, this research tackles issues which impact the safety and fundamental rights of women, meaning feminist epistemology can effectively be applied.

Considering the epistemological basis and aims of the research, qualitative methods were selected to explore the participants' experiences. As explained by Creswell (2014), "qualitative research is an approach for exploring and understanding the meaning individuals or groups ascribe to a social or human problem" (p. 4). A qualitative approach also links well with feminist research, which emphasises personhood and lived experiences (Sprague, 2005). Noaks and Wincup (2004) further note that qualitative methods are often preferred in criminological research, as they allow researchers access to personal accounts of actions that are often hidden. Qualitative data is also considered richer than quantitative data, allowing for a nuanced understanding of criminological phenomena, leading to an "increased appreciation of the social world" (Noaks \& Wincup, 2004, p. 13). Furthermore, Hesse-Biber and Leavy (2011) explain that qualitative methodologies promote rapport and open relationships between researcher and partisans. This is particularly salient for the current research as encouraging the participants to discuss intimate details of their sex with a stranger requires a certain level of comfort. 


\section{Theoretical Perspective}

I was initially drawn to the principles of feminist research, as they reflect my worldview and embrace the way that I aim to navigate my own experiences. As Skegg (1994) argues, "feminist research begins from the premise that the nature of reality in Western society is unequal and hierarchical" (p. 77). This inherent understanding means that such research is simultaneously grounded in political and academic concerns - the most distinguishable feature of feminist works being their commitment to advancing social change (Kemp \& Squires, 1997). Yet, unlike the traditional positivist method, a feminist approach acknowledges that researcher ideology cannot be separated from research processes and celebrates this through encouraging a reflexive approach (Letherby, 2003). Regarding sex work, the research has been conducted from a sex worker rights feminist perspective. This position supports the decriminalisation of all sex work related activities on the basis that working within the sex industry is a legitimate career choice and, hence, vehemently disagrees that a woman's choice to sell sex should be punitively criminalised. Hence, this approach is harm-reductionist and promotes the safety and rights of sex workers, rather than seeking to eradicate the industry. Accordingly, sex worker rights feminism also mandates that criminalising sex work is irrational, impractical, and fundamentally unethical. Regarding clients, the 'every man perspective' (Monto \& McRee, 2005) was adopted during this research, meaning the research does not consider purchasing sex to be deviant, nor clients to be inherently different from nonclients. These perspectives greatly motivated this research and informed the theoretical approach adopted throughout.

\section{Ethical Considerations}

\section{Ethics Process}

As with any research involving human subjects, this research required careful consideration. An application for ethical approval was submitted to the Victoria University of Wellington Human Ethics Committee (\#26055) and successfully granted on 9 May 2018. The ethics process proved relatively straightforward, and I was able to easily manage some concerns shared by the committee, which included fixing minor issues on participant information sheets and clarification around some methodological practices, including the interview locations. I was fortunate my research passed through relatively easily, yet my application comprehensively covered the potential complications of 
conducting research with clients. These complications and how they were managed, are discussed later in this chapter.

Due to the sensitive nature of this research, ensuring an ethical approach was a particularly salient concern. The extent to which research is 'sensitive' depends largely upon the social and cultural norms within which it is situated (McCosker, Barnard \& Gerber, 2001). Renzetti and Lee (1993) claim that sensitive research is that which covers "intimate, discreditable, or incriminating" (p. 9) behaviours that primarily occur in a private setting. Further, Lee (1993) argues that activities which when "revealed might cause stigmatisation" (p. 4) can be defined as sensitive. It is well documented that engaging with the sex industry, either as a worker or client, is heavily stigmatised (Sanders, O’Neill, \& Pitcher, 2009). A key ethical dilemma I encountered was ensuring both the physical and mental safety of myself and of the participants. The strategies applied to protect myself will be discussed later in this chapter, yet I acknowledge that adhering to strict ethical standards is salient when researching vulnerable populations (Liamputtong, 2007). While it is commonly thought clients are solely motivated by sexual pleasure, research indicates that frequenting sex workers is often used to meet emotional needs, such as loneliness, and as a coping strategy or pseudo counselling service during difficult periods (Kinnell, 2006; Sanders, 2008). The risk of emotional harm to participants while revisiting these experiences was managed by providing information on relevant emotional support networks to participants if required, though this was never necessary.

A \$20 supermarket voucher was offered to participants as Koha and acknowledgement of their time. Koha, a Te Reo Māori² concept, denotes a gift or offering which is fundamentally about reciprocity (McCormack, 2008). While the Victoria University of Wellington ethics guidelines do not overtly mandate that researchers provide compensation to participants, it felt necessary as the interviews were time-consuming However, Victor and JC did not accept the voucher - Victor did not want to infringe on the finances of a student and JC believed it would be wrong for a financially secure adult male to take a gift from a younger woman. Instead, Victor advised me to buy something nice for myself, offering flowers or chocolates as an option. As Koha represents reciprocity, it

\footnotetext{
${ }^{2}$ Te Reo is the language spoken by the Māori people, the indigenous population of New Zealand. Te Reo gained recognition as one of New Zealand's official languages in 1987 (Reedy, 2000).
} 
would be wrong to force it onto someone. Pushing the issue further would have led to an uncomfortable exchange with these participants, so ultimately, I decided to act in a way which made JC and Victor most comfortable.

A key issue pertaining to the ethics guiding this research was the management of participant disclosure of harm and how to navigate breaking confidentiality. Breaking the confidentiality agreement was deemed necessary if during the interviews, any participant disclosed intent for immediate harm to themselves or others, such as sex workers. On the consent form (appendix F) participants were advised, "if you disclose that you or another person is at imminent risk of harm the confidentiality agreement may have to be broken. This will be discussed first, unless the researcher's personal safety is at risk". While harm such as the admission of perpetrating sexual violence against sex workers previously could have been included in this threshold, it was not deemed appropriate, as victims may have chosen to not disclose to police and it is not a researcher's place to intervene in this decision. Instead, breaking confidentially was restricted to instances where the research would have been able to tangibly prevent harm. However, no such instance occurred, and confidentiality was kept. The deliberation of these issues was also aided through applying a reflexive approach to the research.

\section{Ensuring Reflexivity}

Throughout this research, a reflexive approach was used. Reflexivity is a crucial quality control in qualitative research - it is a methodological tool used to legitimise research practice by encouraging the researcher to recognise the "politics of the gaze" (Pillow, 2003, p. 175). Reflexivity is recognised as indisputably important because it considers the social identity and social presentation of the researcher, alongside that of the participants (Gertai-Pepin, 2009). Being reflexive requires the researcher to be "critically conscious" (Pillow, 2003, p. 178) and aware of their behaviours and practices across the entire research process. Employing a reflexive approach encourages researchers to understand their role in the creation of knowledge; to recognise pre-existing knowledge; and to proactively manage the influence their perspectives, biases, and personal experiences maintain over their research (Berger, 2015; Guillemin \& Gillam, 2004). These reflective practices improve understanding of the research process, which, as explained by Cutcliffe (2003), further enhances the "credibility of the research findings" (p. 137). 
McCabe and Holmes (2009) explain that to conduct research ethically, the researcher must deliberately and constantly work against fostering unequal power relations. As part of my reflexive approach, I remained distinctly aware of the concerns of ethics, emotionality, and my personal connection to the research. I am an 'outsider' to the sex work community, as I am neither a sex worker nor client, and have primarily engaged with the industry from a researcher's standpoint (Dwyer \& Buckle, 2009). There is a colloquial, yet powerful saying among sex work communities' which heralds "nothing about us, without us". For this reason, it was imperative to seek the support of the NZPC in conducting this research. Through seeking informal permission from the NZPC I reduced the extent to which I was an outsider within their community and bridged the gap between myself, and the sex work community during the research and postpublication.

\section{Research Process - Participants, Data Collection, and Analysis}

\section{Participants and Recruitment}

Contrary to the challenges other researchers have faced when accessing client samples (Girtler, 1997; Monto, 2000), I was able to recruit a large sample of participants. A total of 15 individuals were interviewed - 12 clients and 3 key informants. The three key informants were sourced from a variety of professional backgrounds. Dame Catherine Healy is the National Coordinator of the NZPC - she has worked extensively throughout the New Zealand sex industry, advocated for the decriminalisation of sex work, and was instrumental in drafting the PRA 2003. Mary Brennan is the operator and owner of a popular Wellington brothel and, through this role, interacts with clients daily. Dr Jenny Hayward is a sexual health doctor working in community health centres and for the Wellington NZPC branch. Though her community work, Dr Hayward often engages with clients. Considering their roles within the New Zealand sex industry, these key informants were involved with this research to further contextualise clients and decriminalisation. It is important to note that approval was sought and granted by these key informants to include their occupations and identities in this thesis.

To broaden the reach of this research, advertisements were conducted on a variety of platforms using the recruitment poster (Appendix A). Initially, recruitment was conducted through the Facebook page 'Vic Deals' - an online trading and discussion forum used by locals of the wider Wellington region. The second medium used for 
recruitment was the online client forum 'Adult Forum'. Adult Forum is used by New Zealand clients to review sex workers, share experiences, and discuss their purchasing anonymously. Promoting my research on Adult Forum allowed for direct contact with clients and offered snowballing opportunities with a Wellington-based sex worker who shared the research on social media to her client audience. Lastly, hard-copy recruitment posters were placed in men's bathroom stalls on Victoria University Kelburn campus. The recruitment method elicited the most participants was advertising online through Vic Deals, followed closely by advertising on Adult Forum, while snowballing and physical copy posters helped to recruit one participant each. Prospective key informants were identified through snowballing via the primary supervisor's personal connections and the NZPC.

During the initial stages of contact with participants, information sheets (Appendix B and D) were provided through social media or email. This provided the interested parties with more details on the research project and an opportunity to further consider participation. At this point, many individuals decided against participation, while all key informants who were contacted agreed to participate. For the clients who remained interested, an interview was arranged. The following table summarises the demographic variables of the client sample and includes categories relevant to this research, while a full overview of the demographic characteristics of participants is included in the analysis section. While the following table provides accurate demographic information, it is important to note that pseudonyms are used to prevent the clients being identified. 
Table 2. Participant Demographics

\begin{tabular}{|c|c|c|c|c|c|c|c|c|}
\hline Participant & Gender & Ethnicity & Age & $\begin{array}{l}\text { Education } \\
\text { Level }\end{array}$ & $\begin{array}{l}\text { Relationship } \\
\text { Status }\end{array}$ & $\begin{array}{l}\text { Currently } \\
\text { Purchasi } \\
\text { ng Sex }\end{array}$ & $\begin{array}{l}\text { Purchasing } \\
\text { Frequency }\end{array}$ & $\begin{array}{l}\text { Purchased Sex } \\
\text { Outside of } \\
\text { Decriminalisation }\end{array}$ \\
\hline Adam & Male & NZ European & 23 & Postgraduate & Single & Yes & Bi-monthly & No \\
\hline Steve & Male & NZ European & 34 & Postgraduate & Single & Yes & $\begin{array}{l}\mathrm{Bi}- \\
\text { weekly/monthly }\end{array}$ & No \\
\hline Kevin & Male & NZ European & 39 & Postgraduate & In relationship & No & $\begin{array}{l}\mathrm{Bi}- \\
\text { weekly/monthly }\end{array}$ & No \\
\hline Katie & Female & NZ European & 25 & $\begin{array}{l}\text { Completed } \\
\text { High School }\end{array}$ & Single & Yes & Bi-monthly & No \\
\hline Eddie & Male & NZ European & 37 & Undergraduate & In relationship & No & Bi-weekly & No \\
\hline Riaan & Male & South African & 32 & $\begin{array}{l}\text { Completed } \\
\text { High School }\end{array}$ & Single & Yes & Bi-monthly & Yes \\
\hline Alex & Male & Scottish & 57 & Polytechnic & Married & Yes & Monthly & Yes \\
\hline Mark & Male & NZ European & 43 & Unknown & Single/divorced & Yes & $\begin{array}{l}\text { Bi- } \\
\text { weekly/monthly }\end{array}$ & Yes \\
\hline Arthur & Male & American & 41 & Undergraduate & Single & Yes & Weekly/bi-weekly & Yes \\
\hline Colin & Male & American & 33 & Undergraduate & Single & No & $\begin{array}{l}\text { Singular } \\
\text { experience }\end{array}$ & No \\
\hline Victor & Male & NZ European & 65 & Polytechnic & Single & Yes & Bi-monthly & Yes \\
\hline
\end{tabular}




\section{Data Collection}

Data were collected through face-to-face, semi-structured interviews. Semi-structured interviews were preferred as, according to Hesse-Biber and Leavy (2011), they often produce data that is "contextual, linguistic, narrative, and pragmatic" (p. 95). Considering the incredibly personal nature of this topic, it was necessary to conduct interviews with clients face-to-face, as opposed to using Skype or phone-calls. While previous researchers have found success interviewing clients through online media (Hammond, 2018), this was reserved as an option if recruiting participants proved difficult. The data collection process occurred in two distinct stages - interviews with clients were conducted first between the months of May and July 2018, followed by key informant interviews between July and August 2018. This ensured that any impression gathered from key informants was not carried into the engagements with clients.

The chosen time and location of client interviews was a collaborative effort and negotiated to meet the needs of both the researcher and participants. My personal safety had to be ensured, alongside providing privacy so participants felt comfortable discussing the intimate topic. To meet these requirements, all client interviews were held in private meeting rooms either at Victoria University Kelburn campus, the Wellington City Library or at a central café. Interviews were conducted during working hours or late evenings, as these times best suited the participants. The client interviews ranged from 56 to 93 minutes, with an average duration of 64 minutes, while key informant interviews ranged from 30 to 71 minutes, with an average duration of 60 minutes. Interviews with key informants were scheduled at times convenient for them and were held at their workplace. Extra care had to be taken when scheduling interviews in locations where business is traded on discretion, such as at Mary Brennan's brothel, where visiting was conditional on the location remaining secret. Questions were asked using a semistructured interview guide (Appendix C and E), yet questions remained flexible.

Before the interviews began, participants were required to re-read the information sheet and were offered an opportunity to ask questions about the research and myself as a researcher. Few participants asked questions, apart from querying my interest in the topic. The importance of confidentiality was reiterated, and consent to audio record was reaffirmed. After these formalities, participants signed the consent form and the interviews began. Interview guides were followed, yet not strictly adhered to as to allow 
the participants to guide the interview. Often conversations with clients deviated significantly from the guide and key topics emerged naturally from the points participants raised themselves. After a few interviews, it was clear the richest discussions generally emerged as participants led themselves down tangents and relived experiences with me in tow. Plummer (1994) notes that story-telling has an interactive nature with 'joint actions' - "one actor is the storyteller; the other is the coaxer who brings people to the edge of telling a story they might never have told before" (p. 20). This realisation led to an adaptation of my interviewing approach - while participants were sharing details about their sexual lives and deviating from the guide I had planned, I simply listened to them and their stories, allowing their own narratives to decide the direction of the interview.

Following personal experiences, I have noticed that men generally seem more comfortable discussing details of their sex lives with other men, as opposed to women. I suspected this would also apply to men's experiences of purchasing sex. My suspicion was confirmed by many of the participants, who stated that they would not normally talk to anyone, least of all women, about these issues. Kruger (1994, as cited in Hutchinson, Marsiglio, \& Cohan, 2002) suggests that, in general, people are more inclined to share personal information with others who share a likeness with themselves. Deatrick and Faux (1991) claim this is amplified by gender dynamics, arguing "the sex of the interviewer becomes crucial as the subject matter becomes more sensitive" (p. 215). Accordingly, I unintentionally positioned myself as more relatable to participants, which set them at ease and reduced unwanted sexual advances. During the interviews, I attempted to reduce my femininity to present as 'one of the boys', which entailed relating to participants' experiences, laughing alongside them at jokes or stories they shared, allowing the participants to set the tone of the interview, and taking their lead on the seriousness applied to issues discussed. This persona was also reminiscent of the coping strategies I have applied when working in the hospitality industry and providing bar service, where I often encountered intoxicated men. In doing so, I was able to protect myself and reduce the opportunity for unwanted advances. A similar approach was adopted by Lee (1997), who, when undertaking interviews with men, made a conscious decision to refrain from presenting as traditionally feminine in relation to her use of makeup and dress, as a means of pre-emptively reducing the likelihood of sexual advances from participants. 
Despite the sensitive touch these interviews required, my purposeful laid-back approach to interacting with the participants was effective and allowed them to share these extremely personal experiences. This is well exemplified by a review a participant left on Adult Forum encouraging others to participate in my research:

I've had my interview with Shannon. Lasted one hour and very interesting. She's non-judgmental, very keen to learn about a range of issues with the sex industry, and her research is from the client's perspective. Really great time talking to her about what I'm looking for when visiting an escort, how I find escorts to book, what I like and don't like, how and why I got into purchasing sex, what type of sex I like with an escort. Good discussion about pre-2003 too compared to now. Shannon's really easy to talk to, but you can answer whatever questions you feel comfortable with. Started off talking to a stranger, but didn't take long to feel completely at ease with her. Give it a go people.

Other participants expressed this sentiment and noted they felt comfortable with me during the interviews. Smart (1984, as cited in Grenz, 2005) claims that "women frequently operate as facilitators to male speech ... they tend not to interrupt but rather to encourage and help the flow of men's talk" (p. 155). Furthermore, Winchester (1996) suggests the traditional gender roles which fashion women to be empathic listeners are reinforced when women interview men. While gender can raise issues during interviews, gender may also function to provide a familiar comfort to men during qualitative research. I suspect that during the interview process I was able to strike the correct balance between familiar femininity and a relaxed demeanour which set me aside from other women in the eyes of these men.

To finish the interviews, all participants were asked if they had any further comments they would like to make or if there was anything they wanted me to know about their experiences, before I handed over the Koha voucher and ended the audio recording. All participants were made aware that if they had any follow-up questions regarding the interview they could contact me on the email address provided.

\section{Data Analysis}

This research saw the relationship between theory and data follow an inductive pathway, which locates theories within the data as opposed to a deductive process that tests hypotheses against data (Hesse-Biber \& Leavy, 2011). For this reason, grounded theory was deemed the appropriate methodological approach. Grounded theory is a method of data analysis in which the major themes and findings are grounded in the data set, as 
opposed to being imposed on it (Glaser \& Strauss, 2012). Most fundamentally, grounded theory unites theory development with the research process by providing procedures for handling qualitative data which help develop and apply theory (Chamaz, 1996). More specifically, this research utilised constructivist grounded theory - an adaptation developed by Charmaz (2014, 2017). Charmaz (2006) has been influential in the reconstruction of grounded theory to create a contemporary methodological approach that "sees both data and analysis as created from shared experiences, relationships with participants, and other sources of data" (p. 130). This process allows individual experience to drive the analysis and further encourages the application of participant insight to explain the themes present within the data (Charmaz, 1996; Charmaz \& Bryant, 2010). Hence, constructivist grounded theory is more interpretive and encourages flexibility within methodology, as opposed to the mechanical approach encouraged by previous versions of grounded theory (Charmaz, 2014; Charmaz \& Bryant, 2010). As the client landscape within New Zealand has remained unexplored since decriminalisation in 2003 , this research began with very limited expectations of emerging themes. Therefore, it was imperative I adopted a methodological approach that was flexible and allowed my analysis to evolve alongside a unique and dynamic data set. It is for these reasons that a constructivist grounded theory approach was chosen for this research.

Accordingly, all interviews were transcribed verbatim from audio recordings. The transcription of 15 interviews was a lengthy, yet critical process, as it prompted familiarity with emerging trends in the dataset. To analyse the data, thematic analysis driven by grounded theory was applied. As Braun and Clarke (2006) explain, thematic analysis is a "method for identifying, analysing and reporting patterns within qualitative data" (p. 79). Thematic analysis is a versatile approach to unpacking qualitative data, as it offers researchers an analytical tool - a method - which sports no theoretical commitments (Braun \& Clarke, 2017; Vaismoradi, Turunen, \& Bondas, 2013). The procedures for developing codes and themes this offers can be applied to identify patterns within individual data and across the data set, allowing broader themes to be generated based on the participants' lived experiences (Braun \& Clarke, 2012, 2017). The software NVivo was used for the practical application of thematic analysis when coding the interview data. The findings were compared with existing international literature on clients, and these initial themes aided in the construction and direction of the literature review. 


\section{Practical Limitations}

The eligibility criteria of this research meant that some potentially insightful participants were excluded from the sample. For the research to be manageable within the scope of a Masters' thesis, participants needed to live within the wider Wellington region and be interviewed face-to-face. This excluded a few participants who contacted me and were eager to participate yet lived in Auckland. Further, multiple individuals requested an interview via Skype or Facetime. This related to their fear of public recognition, as well as feeling uncomfortable discussing intimate sexual details with a stranger. Clearly, the medium through which the interviews were conducted was influential on the final decision potential participants made when considering the research. For some, the faceto-face interaction was a deterrent and the ability to participate in an interview anonymously via a video call would have mitigated their concerns. This should be considered by future researchers in this area.

When recruiting participants, I did not restrict the sample according to demographic variables. Although generalisability was not a goal of this thesis, it should be acknowledged that the client sample of this research is predominantly comprised of cisgendered ${ }^{3}$ heterosexual men. While the sample did include one bisexual cis-female, this sample does not perfectly mirror gendered engagement with the sex industry. While research indicates that most clients are heterosexual men, a range of gender and sexual identities engage with the sex industry, both from the position of clients and sex workers (Laing, Pilcher, \& Smith, 2015). Ideally, a more gender-diverse sample would have been recruited. The limited scope of Masters' research further impacted on the categories of participants interviewed. Originally, I planned to interview sex workers to compare their experiences against client experiences under decriminalisation. However, it quickly became clear this was too ambitious and was not possible. Furthermore, I initially planned to include client populations from Auckland and Christchurch, as sex work has a prominent presence in these cities (Abel, Fitzgerald, \& Brunton, 2007). Again, this was not a feasible option and the sample had to be restricted to clients operating within the wider Wellington region. Future research looking to engage with clients under

\footnotetext{
${ }^{3}$ Cis-gendered refers to those who are comfortable living within the gender binary of male and female and identify with the gender assigned to their physical anatomy.
} 
decriminalisation in New Zealand should look to these practical limitations and seek to broaden the categories of clients interviewed.

\section{Research Challenges - Conducting Sexually Charged Research as a Woman}

Poulton (2014) argues that research "can be messy, requiring the researcher to dig themselves out of a hole, negotiate power relations and engage in emotional labour" (p. 78). Power exchanges between researchers and the researched are nuanced and fluctuate according to the content of the inquiry and the stage of the research project. For example, during the interview stage, the researcher appears to be entirely dependent on the participants' readiness to share their knowledge and experiences, which implies that control is located with the participants (Karnieli-Miller \& Pessach, 2009). However, doing gendered research is complicated and, as for a female researcher, conducting sexually charged research with men, presents a unique set of challenges. Hence, when reflecting on this research, we must look beyond the relationship between researchers and the researched to consider the impacts of gender (Schwalbe \& Wolkomir, 2001). The following section will explore some personal challenges I faced during the research process, which are intrinsically connected to the unique subject matter and my position as a female researcher interviewing men about sex.

During the advertising and recruitment process, a great deal of time was invested in engaging with the people who contacted me, yet many interactions did not progress into an interview. This was to be expected, however, I was taken aback by the emotional effort required, for little-to-no return. Through advertising on a public forum, I was vulnerable to receiving vulgar and uncomfortable messages - one man requested a blow-job for $\$ 100$ and become aggressive when denied, while another claimed he loved me and requested an ongoing 'friendship'. Furthermore, some men contacted me and disclosed very personal stories. For example, one man contacted me to express shame over purchasing sex from a male sex worker and essentially 'came out' to me over Facebook Messenger. Another man shared his story in a religious cult, the resulting repression of his sexuality, and the intimate partner violence he experienced during his marriage. Outside of our interview, this participant also sent a detailed play-by-play of his most recent brothel experience. A significant amount of emotional labour was required when engaging with these stories, which, interestingly, mirrors sex workers' engagements with clients, most particularly 'time-wasters' (Joseph \& Black, 2012; Lever \& Dolnick, 2000). 
This emotional investment was not limited to the advertising process and continued throughout the interviews, as many participants experienced conflict and emotional turmoil over their client identities. Consequently, most participants felt unable to discuss their purchasing with those they shared social, familial, or intimate relationships with. As JC explained, "it can be a very isolating existence". Considering the hidden nature of their client identities, many of the interviews contained a 'coming-out' element. The social taboo surrounding purchasing sex seems to have a two-fold effect - while secrecy causes clients to refrain from discussing sex work openly, it also creates a strong need to discuss it with others. I recognised a strong desire within these men to talk about being a client, as multiple participants thanked me for conducting this research and for the opportunity to finally share their experiences with someone.

This 'coming-out' phenomenon was also experienced by Grenz (2005) during her research with clients, who noted "coming out with something considered unethical made participants vulnerable" and that "even though they came out with something they were allowed to do ... they felt ashamed" (p. 2093). The shame and vulnerability involved in the interviews led me to feel a special responsibility and emotional weight as a researcher - a sentiment shared by Grenz (2005). While all participants were awarded confidentiality in keeping with ethics requirements, I felt a heightened responsibility as a researcher to manage these coming-out stories with respect and to represent them accurately within the findings. This responsibility provided me with a stronger emotional connection to my research, yet influenced me to empathise with the participants, leading me to carry some emotional weight following the interview process. While I acknowledge this is an integral part of conducting sensitive research, I would be neglecting the truth if I did not acknowledge that this affected me personally.

Poulton (2014) states that when considering the research process, "there is a real need to candidly reflect upon the 'impact' on the actual researcher and the experiences and emotions confronted with while doing research" (p. 78). It has been extensively noted that undertaking sensitive research can pose many challenges for researchers (Campbell, 2002; Dickson-Swift, James, Kippen, \& Liamputtong, 2007), yet I applied certain strategies to manage this. For example, I took time away from technology during interview periods, applied self-care through physical exercise, and separated interviews by a week, to prevent myself from becoming emotionally overwhelmed during data 
collection. To 'debrief' from interviews, I wrote notes on how I felt before, during and afterwards, and discussed my feelings with my supervisor and friends. These strategies were important as the interviews were complicated by some clients projecting their sexuality onto me. Schutze (1987, as cited in Grenz, 2005) explains that when discussing personal experiences, related emotions can surface and become vivid again. Considering the topic of this research, the interview settings were dominated by sexual discussions and several uncomfortable situations occurred where clients sexualised me and incorporated me into their narratives surrounding purchasing sex. For example, one participant made indirect, yet clear, references to me replacing the sex worker he regularly saw; another made complimentary comments on my figure; and another repeatedly referenced how 'good' he was with his hands and at oral sex, and how big his penis was.

Other female researchers interviewing men on sexual topics, including Davidson and Layder (1994), Grenz (2005), and Lee (1997), have noted similar experiences of being sexualised by participants. Schwalbe and Wolkomir (2001) interpret the sexualisation of female researchers by male participants as attempt at exercising control, through actions such as "flirting, sexual innuendo, touching, and remarks on appearance" (p. 94). While participants never touched me, I did experience much sexual innuendo and the like. Schwalbe and Wolkomir (2001) advise interviewers not to use flirting as a strategy to establish rapport with participants as this encourages "a participant to try and create an impression of himself as sexually desirable" (p. 94). While I avoided flirting, some participants flirted with me, which suggests they were trying to present themselves as sexually desirable. While these actions were framed innocently, Schwalbe and Wolkomir, (2001), argue they represent gendered power relations.

However, I am hesitant to accept that these manifestations of sexuality represented a gendered power play. As explained by Hertz (1995) "the interview - from the moment of initial contact - becomes a socially constructed matrix of shifting multiple identities for both the researchers and respondents" (p. 432). These shifting identities are representative of the power exchanges within the interviews. While I acknowledge experiencing feelings of vulnerability, I also retained control over the interview setting when directing discussion and received no resistance from participants when doing so. Moreover, these men were exceptionally vulnerable during the interview process as for 
many, this was their first time discussing their experiences purchasing sex in-depth with another person. This required significant personal reflection around the psychology of being a client, which indicated that their emotional needs were firmly connected with their experiences seeing sex workers. This cannot be ignored when discussing the power relations between myself as a researcher and the participants, especially when considering the gender dynamics.

Feminist research has traditionally aimed to actively remove power imbalances within research (Karnieli-Miller \& Pessach, 2009). The power dynamics that were enacted during the interviews were constantly shifting - Pini (2005) explains that "power is not held exclusively by men over women, just as it is not possessed exclusively by the researcher rather than the researched. The interaction is much more fluid and dynamic, and the power more dispersed and contested" (p. 203). Similarly, power and control within my research was not an either/or phenomenon; it was a unified experience where both parties simultaneously held influence. The interactions between myself and the clients were moulded by several forces, namely, the sensitive topic being discussed; relationships between researchers and participants; contemporary gender roles; the desire of clients to share their stories; and attempts at eroticism. Considering this complex web, it is important to conceptualise power within the interviews as an evolving exchange between both researcher and the researched. Equally complex, are the participants themselves. Hence, now that an in-depth guide to conducting this research has been provided, the following analysis will begin with introducing the participants. 


\section{Chapter Four: Introducing the Participants and Addressing Common Client Stereotypes}

There is still an awful lot of misconceptions about sex work, you know, methriddled and on the streets. I'll walk down the road and you wouldn't give me a second glance, I'm just a normal bloke, there are no true stereotypes for clients - JC

There exists a significant discrepancy between the stereotypical image of clients and the realities of those who engage with the sex industry. While it is important to acknowledge that the 'whore stigma' attached to sex workers is significantly more harmful and institutionally pervasive, the clients of sex workers also battle a range of degrading, damaging, and distorting stereotypes stemming from this broader stigma (Sanders, 2008b). The purpose of this chapter is to provide an insight into a selection of New Zealand-based clients, thus offering a snapshot of the people who purchase sex in New Zealand. The first section will introduce the participants of this research and discuss the variances found within the sample. To follow, the preferences the clients hold for the commercial sex markets assessed and services purchased will be addressed. The image this builds indicates that overall, the participants were contributing, and relatively regular members of society. Hence, the findings of this chapter actively challenge common stereotypes associated with the clients of sex workers. The introduction of the participants is further intended to serve as a platform from which to view the subsequent chapters.

\section{Profiling the Participants}

The interviews offered an insight into the purchasing habits of the participants and provided a snapshot of people who purchase sex in New Zealand. The following section will build a profile of the participants, which demonstrates that their experiences purchasing sex varied considerably. For example, their purchasing frequencies ranged from weekly, monthly, and yearly, to a single experience, while they applied purchasing sex for different means. The interviews further offered a window into the participants' preferences for the markets and the sexual services they accessed. Evident within these attitudes was a strong discourse regarding the danger of street-based sex work, a sentiment shared by most clients. Accordingly, the clients avoided street-based sex workers and, instead, favoured brothels, escort agencies, and independent sex workers. The services the clients preferred also varied, yet a strong preference for the 'girlfriend 
experience', conversation with sex workers, and kissing dictated their experiences with sex workers.

\section{Who are the Participants?}

The clients who participated in this research varied across a range of demographic variables. Their average age was 41 , with an age range of $23-65$. The ethnicities of the participants also offered some variance, with seven being NZ European, two Scottish, two American, and one South African. The participants also offered a range of education levels - while the education of one individual is unknown, of the remaining, four held postgraduate qualifications, three held undergraduate qualifications, two completed polytechnic programmes, and two completed high school. Most participants were employed full-time at the time of the interviews and worked across a range of sectors, including the defence force, as accountants, finance mangers, contract managers, in marketing, information technologies, and as a sex worker. Two participants were studying and upheld part-time employment, while one participant was unemployed and developing a start-up company.

Eleven of the participants were male, while one was female. Yet, their sexual orientations offered some additional variance. While nine of the interviewees solely purchased sex from women, three deviated from this - Katie purchased sex from both men and women, Adam primarily purchased from transgender women, while Mark mainly purchased from women, yet experiments on occasion with transgender women. There was also significant variance found within the participants' current relationship statuses, as two clients were in a relationship, one was married, two were single yet divorced, and seven were single. Regarding broader engagements with the sex industry, Katie worked as a full-service sex worker, while Mark informally provided sexual services on a few selfcontained instances.

A surface level analysis of these demographic variables indicates the participants do not represent one distinct sector of society. Rather, they are a cross-section of New Zealand society and cannot be collectively identified by their status as clients. Their education levels and occupations suggest they are well-educated contributing members of society, while their sexual orientations suggest that a range of sexualities and genders engage with the New Zealand sex industry. Additionally, the six participants who are currently 
married, previously married, or in a relationship suggests that clients can form meaningful relationships with others outside of the sex industry. The remainder of this chapter will now offer a more in-depth analysis of the participants through exploring the purchasing frequencies and preferences that guide their engagement with the New Zealand sex industry.

\section{Participant Purchasing Frequencies and Trajectories}

Just as there is no single way of understanding who clients are, there is also no singular way to purchase sex. Holzeman and Pines (1992) claim that being a client is neither straightforward nor pattern forming. Instead, purchasing sex can be understood as a series of inter-related decisions and acts that culminate in a plethora of interactions with sex workers. Sanders (2008b) notes that men's pattern of involvement in purchasing sex is complex - it may be fleeting or permanent, compulsive or planned, and can occur at any stage of the life course. Sanders (2008b) further highlights that "these nuances ... determines the nature of the sex industry" (p. 49). During the interviews, the participants shared the amount of sex they were currently or had previously been purchasing. These visits with sex workers varied considerably and it was found that two clients saw sex workers weekly, three fortnightly or monthly, two monthly, four bi-monthly, and one on one occasion. At the highest frequency of the participants sat JC, a self-appointed "prolific" client:

Sometimes I'll go a whole week without seeing someone and other time still be two or three times a week ... I've probably seen well over 100 girls for example. At Paradise Club itself, I'm coming up for my 200th visit ... but I need to work in with my working week. I have a window of opportunity which is up to 6.18 each night, apart from Friday when it can be 10.30.

To manage this amount of purchasing, JC noted he must book his appointments weeks in advance to manoeuvre them around his work demands. Interestingly, those participants who purchased at a high frequency also tended to have a long history of engagement with the sex industry. This was well exemplified by Victor and Alex, who after losing their virginities to sex workers, continued to purchase sex for the following 35 to 40 years. While these participants periodically take breaks from purchasing, they inevitably return. As Victor explained:

It was around about when I was 18. I was a virgin before that, it was my first time ... Now and then I stopped for a period of my own volition. I struck up a relationship with a lady in the office, then when we broke up I started again ... Sometimes I might go two or three months and not do anything, whether I've 
got a cold, or I'm busy at work, or I've got bills coming up. Then I might see someone once or twice in a week, or two people in a week.

Alex also noted he has seen "quite a lot of workers" yet considered this inevitable as "they generally don't tend to stay in the industry that long, so you do end up seeing quite a few, because of the turnover". Participants like JC, Alex, and Victor channelled significant effort into their interactions with sex workers, such as keeping an active journal and reviews of local brothels, booking visits to sex workers weeks ahead of time, forming working relationships with sex workers, and travelling both nationally and internationally to purchase sex. For example, Arthur would travel abroad to purchase sex:

I would come here to New Zealand ... I only ever really did it twice to Europe. The first time it was Amsterdam in early 2000s ... But then I went to Germany because they have a legalised system ... I would also go to the UK.

Considering the expense Arthur went to for sex work, he noted that purchasing sex was one of the core interest hobbies in his life, akin to yoga - "It's like exercise or yoga ... It's just part of my routine now, it's just what I do ... It's like a hobby. I listen to music and whatever, do some yoga, and buy sex". This existence, where sex work is positioned front and centre, is paradoxical to the experiences of Colin, who felt incompatible with the transactional nature of sex work and has not purchased sex since his initial visit to a brothel. Colin noted that:

It feels weird because you're paying. Even if they are very good at doing the girlfriend experience or whatever, it just feels not good. If I'm having sex with someone I want us both to be there for the same reasons, not one for sex and one for money.

Similarly, Eddie and Kevin no longer purchased sex at the time of the interview. Research has found that one of the most common reasons for clients to lose interest in sex work is the development of monogamous relationships (Sanders, 2008b). Reflecting this, Kevin noted that purchasing sex outside of his relationship would be "crossing the line, unless it was acceptable within the confines of our relationship, and if the boundaries were discussed". Eddie shared this sentiment and emphasised: "I couldn't do both at the same time. One was really replacing the other, that all it was last year. Now I'm with my girlfriend, that's what I want". Eddie's reasoning suggests that for some men, purchasing sex serves a distinct purpose, which, when fulfilled, removes the incentive for future engagements with sex workers. Likewise, after his divorce, Steve felt his unmet sexual needs caused 
him difficulty relating to women and so, to learn how to better socially and sexually engage with women he turned to sex workers. Steve explained:

I really want to get to a point in the future where I'm good with women. I have this goal, where I don't need to pay for sex. I'd like to be able to go on dates and pull women home on the regular and it not be a big deal. I'm not there yet, so this is kind of like an interim to keep me sane in the meantime.

Katie presented further variety in participant purchasing frequencies and had purchased sex "a grand total of nine times, nine times over three years, so its maybe quarterly thing. There's been two guys and seven women. That's my spread". Katie is keenly aware of the amount of sex she has purchased and who with, noting that she "looked through my records" before the interview. Interestingly, there was a strong trend of conscious consumption among the participants, as some meticulously managed the rate at which they visited sex workers. As the participants were keenly aware of the financial cost of seeing sex workers, some limited their intake accordingly. For example, Mark aligned his visits to sex workers with his payday:

Once a month, every payday and when I get a quarterly bonus, so every bonus too. So once a month I treat myself this way ... It's not exactly a cheap hobby, which is why I limit it to payday.

Likewise, considering Victor felt that describing his purchasing as frequent "would be an understatement", he tried to remain vigilant of the time he spent with sex workers:

When I was younger, I don't think I was addicted, but I was going once a week or fortnight depending on the money situation ... The more you do it the more you have an appetite for it. I feel that I've got an addictive trait in me, anything I do, I tend to do over-the-top ... I think I've realised that it was too much at times and managed to stop. I've never looked back and thought "shit, I'm running myself into the ground here".

While Arthur also mentioned addiction, he felt he did not purchase sex in an "I can't help myself kind of way". Instead, Arthur explained "It's kind of like, you have your favourite place to eat. Are you addicted to it? If that place closes it's not like you would suffer withdrawal". Irrespective of the high volume of sex they purchased, both Victor and Arthur rejected addiction applying to their circumstances, as they were vigilant of the financial risks following overindulgence. The active management that all participants engaged in suggests that they were not purchasing sex impulsively but were in control. Such findings challenge those who pathologize clients as sex addicted and in need of treatment and contradict the claims of abolitionist Raymond (2003), who argues that clients under decriminalisation are increasing and out of control. 


\section{How the Participants Accessed Commercial Sex}

Through describing the amount of sex they purchased, the participants also explained how and where they accessed commercial sex. It should be acknowledged the participants did not access the street-based sex industry and, therefore, this thesis does not speak to the street-based sex industry under decriminalisation. In saying that, the interviews did indicate that most participants made a conscious decision to avoid streetbased sex workers. In fact, five participants explicitly noted they would never purchase sex from the street, as demonstrated by JC:

I've never seen a street-based worker. I'm very conscious of my health ... I feel that I have far more risk of contracting some form of STI from ... seeing a streetbased sex worker, than I do by seeing a reputable sex worker through an agency or a known independent.

During the interviews, five participants legitimised this preference by arguing that streetbased sex work is riskier than purchasing through alternative markets. For example, Alex noted he feared for this personal safety:

You don't know what's going to happen. I know you've got to be more careful as a worker and really on your toes, but you also have to be careful as a client. They could set you up for a mugging ... just getting stood over and ripped off, someone making you draw money out of a cash machine. Or being beaten up.

Such perspectives indicate these five participants have internalised the stereotypes surrounding street-based sex workers, which construct them as dirtier, riskier, and less responsible than women operating indoors (Armstrong, 2018). International research has consistently indicated that clients perceive this risk as stemming from sex workers' involvement with criminal activity, illicit drug use, and unsafe sexual practices (Plumridge et al., 1996). Accordingly, the participants' experiences were mainly sourced from different contexts, including with independent sex workers and through out-calls and in-calls with escort agencies and brothels. It was common for the participants to simultaneously access these contexts - while one participant only purchased from independent sex workers and four others mainly from brothels, the remaining seven preferred alternating between contexts. When making this decision, the participants engaged in risk and cost-benefit analyses, as Riaan demonstrated:

If you go to a formal place you get variety and you can pick from a handful of women. If you go to a private worker it's one individual, and they might not look the same as they look in the picture, so it's a bit more risky. They might be older, or uglier, or overweight, it can be hit-and-miss Whereas if you go somewhere at least you get to hand pick someone, you have more choice. 
Akin to Riaan, locating independent sex workers through the internet was perceived by many participants as riskier, as many shared experiences where the sex workers looked dissimilar from advertising in real life. Participants found this situation uncomfortable and deciding on whether to proceed with their booking is complicated by issues of false advertising on behalf of the sex worker or their management, a reluctance to induce offence, and their perceived obligation to proceed with the booking. Participants also found this decision more troubling when they were not sexually attracted to the sex worker. Mark explained:

It's pretty ballsy to say "no, go away". I used to just go through with it, but I have had someone arrive at a hotel, and they clearly looked nothing like they were described, and I did say "sorry, you've got the wrong hotel" or something like that. It is difficult, but at the end of the day you're buying a service.

Participants described these situations as nerve-wracking which for some, deterred them from seeking independent sex workers. Yet conversely, some participants enjoyed the process of looking through online advertisements. As Katie noted, "part of the excitement for me is looking through "NZ Girls"4 and choosing someone I would like to see". Some participants also preferred purchasing sex from independent sex workers, as they felt it was a more personalised interaction. As Riaan noted, "I prefer to go to private houses, so it's a one-on-one interaction". Such participants also preferred communicating with sex workers directly, as opposed to dealing with management. For Mark, talking prior to a booking was important: "if I haven't seen someone before I'll try to call them, because I think you can judge a lot about someone's approach via speaking to them".

However, other participants preferred the contexts of brothels or escort agencies, as they increased their access to a variety of sex workers and services. For example, JC preferred brothels for pre-planned services as he could communicate his desired service to the operators, who would assist in selecting a suitable sex worker. JC noted this involved providing the "outline to the agency I'm working with which lists sort of what I'm after and then I'll allow them to do the detail because that way they can be sure that everyone is comfortable with what's happening in the room". Brothels were further described by some participants as simply being 'easier' to access and the logical place to begin when you

\footnotetext{
${ }^{4} \mathrm{NZ}$ Girls is a website where sex workers in New Zealand can legally advertise their services to potential clients, and where clients may browse these advertisements and contact sex workers.
} 
were unfamiliar with how the sex industry operates. As Arthur noted, "the first time you have no idea what to expect, it just seemed natural to go there first".

However, brothels were also considered less desirable by some participants, as they were perceived as more confronting. For example, Adam found brothels hypermasculine, observing that "there's a lot of men around there, which I find very intimidating, I'm not a big guy. As an environment, I do find it quite scary". Similarly, Riaan felt that in brothels, "there's a hundred people around you", causing a host of unnecessary interactions. Additionally, Mark expressed a strong distaste towards brothels, which he perceived as “dehumanising" sex workers:

I don't like the system where you go and there's a bunch of women lined up and you have to pick one ... It seems unhealthy, like there's a competition. I just don't feel like it's very respectful ... This is potentially all imaginary stuff, but they kind of feel oppressive and the girls don't look happy, they don't laugh, smile or have a joke. So, I mostly go with independents.

To avoid the brothel context yet still have access to the variety they offer, Eddie purchased out-calls through escort agencies as he felt this context avoided the pitfalls associated with other markets:

All the girls looked like the girls in their photos, so I didn't open the door and it was someone completely not who I thought it was going to be ... Also, the safety aspect. In the hotel I know that if push comes to shove, and we're in a nice hotel, what can they do? If I was in their brothel, who knows. I thought that if I had it in my own little paid space, very little that could go wrong.

The preferences the participants held regarding where and how they accessed commercial sex were varied and revolved around reducing any risks to their own sexual and physical safety. The deliberations participants engaged in when making these decisions once again indicates conscious consumption and the reflexivity this highlights also extended to the service preferences these clients shared during our interviews.

\section{Participants' Preferred Sexual Services}

The interviews indicated the participants were purchasing a variety of sexual services, most of which were conventional and involved 'full-service' bookings with sex workers. Full-service sex work in New Zealand generally includes hand relief, oral sex, and vaginal intercourse in a limited number of positions, during which the use of a condom is mandated. These services vary in price according to the chosen market, establishment, duration of the booking, and/or personal rate set by the sex worker. All the interviewed 
clients purchased standard full-service, yet, as Katie demonstrates, some participants purchased additional services on top of this: "I just purchase a standard booking ... Some women charge more for toys, so that's the only extras I would purchase".

A deviation from standard full-service that four participants favoured was the Girlfriend Experience (GFE). As previously noted, GFE is a service which integrates acts such as kissing, cuddling, and mutual oral sex, with the standard full-service booking for an extra price (Milrod \& Monto, 2012). These participants considered GFE superior to regular fullservice, which they regarded as predictable and mechanical. As Alex observed, "the standard sex was what you got in the old days and I wanted to move on from that and take it to another level ... full-service is a bit boring". Outside of this, the participants sought GFE for reasons beyond sexual pleasure. For example, Eddie wanted purchasing sex to "feel like I was actually with a girl", and suggested GFE more accurately simulated this:

When you meet someone, and you go on a few dates and you make out on the couch, but it doesn't lead anywhere, so you go to the next date and upgrade to feel each other up. To me, the girlfriend experience is like that, but you cram it all in within two hours, butyou're still getting the intimate kissing and the slow petting and stuff and building up to everything else.

Three other participants noted that GFE created the illusion they were not paying for sex. For participants such as Eddie, it was "very important" that their bookings mimicked the type of sex they would be engaging in within the context of a relationship. In fact, Alex noted that "I probably wouldn't go and see a sex worker if they didn't do girlfriend experience ... I sort of draw the line by asking myself if I would do that with my wife". Milrod and Monto (2012) found similar results, as $80.2 \%$ of their sample indicated GFE appealed to them, as the sex worker "acts like a girlfriend and not a prostitute at all" (p. 803). In a similar vein, most participants shared the consensus that kissing and engaging in conversation with sex workers was essential. When defining their ideal booking, five participants referenced kissing, including Steve:

A couple of girls have said they don't kiss and that was really disappointing ... It's a big part of intimacy and a big part of feeling that illusion that it's real ... If you can't do it then there's always a reminder in the back of your mind that you're just paying for it.

The importance of kissing was twofold - it sustained the illusion that the sex was more than a transaction and imbued the exchange with perceived intimacy. The desire for intimacy strongly influenced the service preferences of 10 participants, as did the importance they placed on conversation with sex workers, which was considered 
essential to a fulfilling and rewarding booking. As Alex explained, "you can have sex and that's over in 10 minutes, but if you've booked for 45 minutes or an hour it's not a pleasant experience to spend that time talking to someone who gives you one-sided answers". These 10 participants placed emphasis on the entertainment this conversation offered, as well as the unique opportunity to share intimate feelings without fear of judgments. Katie explained:

When you're paying as a client you can let it out a little more and allow yourself to feel stuff. I think that's a part of the reason why I gravitate towards female workers as well, because they're much more used to acting as pseudo-therapists and listening to people about their lives and talking with clients ... It is cathartic.

Considering the benefits of conversing with sex workers, Steve noted, "if I had the money, I would pay extra just to have time to make a little more conversation. I wish I had longer to talk with them". Conversation with sex workers served multiple purposes, including creating a more relaxed environment, offering entertainment, facilitating a discussion of sexual boundaries, and providing clients with pseudo talking therapy. The importance the participants placed on talking with sex workers mirrors the findings of prior research, which has found that a core interest of clients is the "listening services" sex workers provide (Lever \& Dolnick, 2000, p. 86) and the emotional release involved with talking to someone confidentially (Plumridge et al., 1997).

As a further deviation from full-service, three participants purchased bondage, discipline, dominance, and submission (BDSM) services with sex workers. Yet as Riaan noted, this represented a small percentage of the services they sought: "obviously your preferences vary over time. But it's mostly pretty standard. I would sort of add things or fetishes to it ... Let's say 20\% of the time I'd go for something like that". The BDSM services these participants purchased varied. Riaan preferred to occupy the dominant role and impart anal play, facial ejaculation, "violence, but not in a bad way", and strangulation onto sex workers. Conversely, Mark and Victor preferred to be submissive and receive acts such as being tied up, "cock and ball torture", caning and flogging, and strap-on play from sex workers. When explaining his affinity for BDSM, Mark explained, "I really enjoy the complete surrender of control as the sub ... after I have a BDSM session for a couple of hours, I just come out of it completely chilled and completely relaxed". 
It is difficult to isolate any client's sexual preferences to a single service, as the commercialised nature of the sex industry enables access across a broad range of sexual acts. Likewise, the participants each presented evolving service preference, which changed according to their experiences and personal circumstances. The variety evident across the individual participant's purchasing frequencies and preferences depended largely on their mood and the reason they were seeking commercial sex on that occasion. As JC explained:

The most common for me is girlfriend experience ... There other things I like, such as porn star experience, which brings into use of toys, dirty talk and that sort of thing ... Other services I like are threesomes. ... A lot of it is what your frame of mind is like and a lot of the more extreme ones, if you want to call it that, they tend to be not about destressing or relief, they're just about pure physically having fun.

Moreover, it was found that as a group, the participants purchased a range of sexual services, yet shared preferences for kissing, conversation, and GFE. The nature of these service preferences was relatively normative and, hence, contradicts abolitionists, who argue that due to their legal freedom, clients under decriminalisation demand depraved and risky sexual services (Coy \& Molisa, 2016). Likewise, there was little evidence which indicated the participants sought to enact non-consensual violence onto sex workers or upheld perverse sexual interests, suggesting not all clients are deviant in their pursuit of commercial sex. Instead, their service preferences provide support for the 'every man perspective', because, as explained by JC, "having human contact is a very essential part of being a human being".

The findings discussed so far directly challenge the stigma attached to clients and the stereotypical image this fosters. At its most extreme, stigma constructs all clients as deviant, out-of-control sex addicts who seek commercial sex as a form of violence and to harm sex workers (Birch, 2015). At the less extreme end of the stigma spectrum, clients are constructed as awkward, inadequate men, incapable of forming meaningful relationships (Monto \& McRee, 2005). Through these stereotypes and the secrecy surrounding clients, stigma contributes to a broader misunderstanding of sex workers' clients and leads the public to rely on outdated and inaccurate stereotypes when seeking to understand why and how clients engage with the sex industry (Jordan, 1997). Considering how the data presented so far indicates a normative trend among the 
participants, the following analysis will now turn to addressing the stigmatisation of clients.

\section{Stigma and the Spoiled Identities of Clients}

Stigma, a concept developed by Goffman (1963), has undergone a variety of definition changes. In his classic work, Goffman (1963) described stigma as a spoiled identity resulting from an attribute that is deeply discrediting. However, this definition has since been considered too individualistic and vague (Link \& Phelan, 2001). In recognition of this, Jones et al. (1984) produced a definition of stigma as a mark that connects a person to an undesirable characteristic. In a further development, Link and Phelan (2001) draw together insights from multiple disciplines to define stigma as a "convergence of labelling, stereotyping, separation, status loss, and discrimination which co-occur in a power situation" (p. 367). Link and Phelan (2001) claim that, at its core, stigma begins with the recognition of difference across human behaviour, and the labelling of these differences as deviant. While many behavioural variances remain irrelevant and unaccounted for, sexual differences are significant in that they represent a "process of selection that will matter socially" (Link \& Phelan, 2001, p. 367; Sanders, 2008b).

Stigma is inherent to understanding why clients are subject to status loss, social isolation, and criminalisation. This act of highlighting difference facilitates the separation of 'us' from 'them', which further categorises 'normal' and 'abnormal', and 'respectable' from 'unrespectable' (Link \& Phelan, 2001). If identified, clients are singled out as faulty persons and compared against those who have non-commercial sexual partners (Sanders, 2008b). As previously noted, the clients of sex workers have often been narrowly isolated to the category of 'peculiar men' - men who are psychologically, physiologically, and socially inadequate (Monto \& McRee, 2005). This stereotyping was recognised by key informant Dr Jenny Hayward:

I think clients are very stereotyped, often as sleazy, middle-aged men, particularly older men with younger women ... I think there is still a huge stigma around clients and workers. I don't think it's something that people feel comfortable with ... I think that the image of a client is the classic image of a geeky, older, white bloke with a beautiful young Asian woman. People think that clients are in a sense, inadequate, you have to buy sex because you cannot relate to another person.

Likewise, Mary Brennan described the public perception of clients in New Zealand as: 
Just like how the sex industry is perceived, that we are all dodgy, all scum, that you couldn't trust us ... Clients are seen as people who are cheating on their wives, spending their child's inheritance or their mortgage payments. Anything you could think to make a man seem like a terrible human being for providing employment to a sex worker. The worst level of it is seeing them as rapists and seeing them as having no respect for women. The general perception of clients would not be good, because people don't know, they don't care enough to find out, and they don't open their hearts and their mind enough to listen.

Sanders (2008b) indicates that stereotypes surrounding clients involve a spectrum of undesirable characteristics. The clients she interviewed identified the following labels as society's way of classifying men who purchase sex: sexually dysfunctional, social misfit, ugly, reclusive, incapable of attracting women, an irresponsible father, an adulterous husband, a sexual fantasiser, sadists, and out of control (Sanders, 2008b, p. 116). Moreover, the clients of sex workers have historically been positioned as deviant, or even dangerous (Birch, 2015). As noted by Birch (2015), the use of the term 'deviant' reflects the "social construction of the sex work industry and sexual services as bad, immoral and criminal" (p. 131). Hence, the clients of sex workers are considered deviant for purchasing sex, as they contradict the context under which sex is deemed acceptable by society.

Following this, clients have been positioned as disproportionately attracted to violent or perverse sexual activity, and, further, that they use the sex industry to fulfil these abnormal needs (Birch, 2015). As explained by Sanders, O'Neil, and Pitcher, (2009) "anything other than this image would challenge the notion that 'good sex' is that which exists only in the confines of a heterosexual reproductive relationship ... and that 'bad sex' is something which is outside of this" (p. 83). Such assumptions are consistent with abolitionist arguments, which claim clients engage in violent sexual acts. For example, Farley et al. (2015) argues that "men who buy sex share certain key characteristics with men at risk of committing sexual aggression" (p. 1). Any interest in irregular sexual activity is then used to justify the conceptualisation of clients as peculiar and psychologically abnormal (Birch \& Louise, 2015).

\section{The Impacts of Stigma and Stereotyping on Clients}

The harms of stigma are innumerable, including at the institutional level where stigma becomes state sanctioned. For example, the Swedish women's movement labelling of clients as sexual predators enabled the purchase of sex to be criminalised in Sweden and 
more recently in Canada (Gould, 2001; Persak, 2012; Svanstrom, 2004). As noted earlier, the construction of clients as deviant led to the introduction of John Schools in the United States (Gurd \& O'Brien, 2013), and targeting clients in the United Kingdom (Sanders, 2009). The typical discourses which surround clients paints an image of a sex addict - a man who is so sexually insatiable he must frequent sex workers to meet his needs (Birch, 2015). The association between sex addiction and purchasing sex is so pervasive that clients are often forced to undergo sex addiction treatment in some criminalised contexts (Mower, 2006; Shively et al., 2012). When analysing the curriculum of Californian John Schools, Gurd and O'Brien (2013) identified this theme - psychologists promoted sex addiction as the cause of purchasing sex and the curriculum has sections which drew heavily on input from organisations like Sex Addicts Anonymous. Similar trends were identified by Shively et al. (2008), who found that the programmes urged clients to consider sex addiction as a "possible explanation for why they engage in prostitution".

The imposed deviancy that clients face may also lead to harm at the individual level, resulting from the internalisation of stigma and self-imposed isolation. Steve reflected this when noting: "I don't want to think of myself as a guy who purchases sex". As argued by Link (1997), rejection by others and the expectation of rejection can lead stigmatised individuals to cope through withdrawal and self-imposed isolation. Sanders (2008b) notes that "the consequence of social disapproval is that men live 'double lives' where commercial sex activities are consigned to a separate part of their lives, minds, and emotions" (p. 113). This was felt heavily by JC, who noted that "it's actually a very lonely existence as a client". Research conducted by Campbell (1998) indicates that clients such as JC conceal their behaviour due to a fear of being labelled strange or sexually perverted, a fear of rejection from partners, and a sense of shame. Peng (2007) also found their participants concealed their behaviour, one of which noted, "I feel guilty for doing it ... I am afraid that I will be found out in the future" (p. 321). More recently, Birch (2015) found that of the 260 surveyed clients, 118 had never disclosed their status as clients, concluding that, "overall, men reported that they believed that the public thought negatively about men who procure sex" (p. 82).

A trend of concealment was also evident among the participants of this research, as all 12 expressed a strong resolve that their lives as clients remain entirely secret or restricted to close social circles. Because of stigma, the clients of sex workers must engage in strict 
gate-keeping tactics to control who is aware they purchase sex, much like how sex workers constantly negotiate and manage disclosure (Sallmann, 2010). Goffman (1963) summarises this dilemma when explaining, "to tell or not to tell; to let on or not to let on; to lie or not to lie; and in each case to whom, how and where" (p. 42). If their engagements with the sex industry become public knowledge, clients face the fourth component of stigmatisation - status loss. Status loss, as defined by Link and Phelan (2001) is an "almost immediate consequence of successful negative labelling" and is a "general downward placement of a person in a status hierarchy" (p. 371). Mirroring this, Kevin explained:

I wouldn't talk about it at work because I'd be concerned about the perceptions it would cause and what those perceptions would do. That frustrates me ... I'm concerned about how their perceptions would colour their interactions with me ... because the whole perception of sex work is it being evil, or wrong, or filthy, or bad for the community, when it's entirely the opposite.

Arthur was also "really nervous" about his public image and explained he "used to think, 'oh what are people going to think of me?' So I would make sure that before I went into a place no one was on the street". Likewise, when explaining why he kept his life as a client secret, Alex noted that "it would ruin my image. I come across as quite a conservative person in general, in the community and in the workplace. I think people would be genuinely horrified if they knew what I do". Many of the participants feared how disclosing their activities as clients would affect their social, familial, romantic, or work relationships. While five participants shared their history as clients with close friends or partners, none felt comfortable or safe sharing this publicly. Such findings are particularly salient when compared to abolitionist claims that "under legalisation and decriminalisation, sex buyers are de-stigmatised and enabled in their pursuits to purchase women at their will" (Bindel, 2017, p. 153).

\section{How do the Participants Compare to Common Stigmatisation?}

Despite the prevalence of client stereotypes, the assumption that clients are uniform and consume sex in an out-of-control, problematic way does not apply to the participants, as their purchasing frequencies varied considerably, with some clients preferring to purchase sex at a lower rate. Moreover, the participants purchased sex in a self-aware and controlled manner, remaining cognisant of risks to their own health and safety. The stereotyping of men who purchase sex as sexually deviant also fails to apply to the participants. The sexual experiences they purchased were largely conventional and it was 
found that, overall, the participants were not accessing the sex industry to engage in perverse or dangerous sex. Instead, it was found that the clients were purchasing a variety of sexual services that could be considered normative and found within the confines of non-commercial relationships. While three clients did seek BDSM, it would be incorrect to misconstrue this as 'deviant' or non-consensually violent. As argued by Wismeijer and Van Assen (2013), "BDSM may be thought of as a recreational leisure, rather than the expression of psychopathological processes" (p. 1943). Furthermore, Holvoet et al. (2017) uncovered a high interest in BDSM among the Belgian population, as $46.8 \%$ of the 1207 participants in their study had performed BDSM-related activities. Such research indicates that an interest in BDSM is a relatively normative sexual pursuit, enjoyed by client and non-client populations alike. Accordingly, no desire to harm sex workers was witnessed within the participants' experiences. Rather, most participants preferred to purchase intimate acts and converse with sex workers, indicating they value their perspectives and often seek comfort from sex workers.

\section{Conclusion}

The aim of this chapter was to introduce the clients I spoke with and their engagements with the New Zealand sex industry. Through analysing their experiences purchasing sex, the participants cannot be haphazardly lumped together as clients, and to do so would be playing into the stigma surrounding clients. The stigmatisation of clients largely depends upon reductionist arguments about who they are, and while the misperceptions this encourages depict the clients of sex workers as homogeneously inadequate and deviant, evidence from this research suggests otherwise. The analysis of their experiences indicates that the participants are a varied group who purchase sex consciously, at alternating frequencies, and seek normative, intimate services from sex workers. Based on these findings, it would be more appropriate that, instead of framing clients as 'deviant' for purchasing sex, we shift our thinking to consider them as simply 'different' from those who do not combine sex with commerce. The following chapter will build on this analysis and offer a more in-depth understanding of what motivates these participants to purchase sex and how they were impacted by sex workers. 


\title{
Chapter Five: Client Motivations for Purchasing Sex and the Resulting Impacts
}

\author{
I don't know what it would have been like if I'd never seen a working \\ lady ... I don't know what would have happened if I'd never seen a sex \\ worker, I don't know how I'd be - Victor
}

The purpose of this chapter is to provide comprehensive insight into what motivates the participants of this research to purchase sex, and to address the impacts they experienced from spending time with sex workers. Sanders' (2008b) 'push vs pull' framework will be applied when discussing the various factors which 'pushed' the participants towards sex work, and the elements of commercial sex which 'pulled' them towards the sex industry. Following this, expressions of masculinity among the participants will be discussed, including how masculinity featured in their motivations. Lastly, the impacts the participants experienced from purchasing sex will be addressed. Considering that prior literature into such impacts is extremely limited, these findings contribute to an emerging field of study. The chapter concludes with a discussion of what element of sex work is most influential on the participants and the extent to which sex work promotes their wellbeing.

\section{Push vs Pull Factors for Purchasing Sex}

To varying degrees, all clients are driven to the sex industry by sexual desire. Yet, client motivations should not be simplistically interpreted as 'they just wanted sex', as previous research indicates clients seek sex workers for more than sexual pleasure; see Campbell, 1998; Birch, 2015; Holzeman and Pines, 1992; Jordan, 1997; Sanders, 2008a, 2008b; and Xantidis and McCabe, 2000. The participants' motivations for purchasing sex will be discussed in line with Sanders' (2008b) framework of 'push vs pull' factors. This divides client motivations into two categories: push factors, which are the elements within clients' lives that are lacking and push them towards commercial sex; and the pull factors, elements of commercial sex that appeal to clients and pull them towards the sex industry. Sanders (2008b) identified emotional needs, unsatisfactory sexual relationships, and unease with dating as the key push factors, while the illicit or taboo nature of purchasing sex, thrill-seeking behaviour, the ability to purchase sex from a variety of women, and the ability to fulfil sexual fantasies were identified as key pull factors. 
The motivations participants offered closely mirrored those identified by Sanders (2008b), yet also fell into two further categories separated by intent - access to sex, where clients were primarily sexually motivated, and access to human contact, where sex was a secondary motivation and functioned as a facilitator to connection. However, as Steve demonstrates, it can be difficult to disentangle a client's drive for sex, from human interaction:

It's not just physical, it's an emotional thing. The need for intimacy is also important ... Have you ever had that feeling where you just need a hug? You know, sometimes that feeling for a hug gets mixed up in the feeling to fuck and you kind of need both at the same time.

Research supports the notion that client motivations are interconnected - Hoigard and Finstad (1992) suggest that while some clients are attracted to unemotional sex, they simultaneously seek intimacy and understanding from sex workers. Likewise, Sanders (2008b), argues men's motivations for purchasing sex fluctuate and do not follow a fixed pattern. The current research reflects this as participants presented shifting motivations throughout their lives or offered multiple motivations concurrently. For this reason, these categories should be considered fluid, allowing for the clients' desires to exist in a dynamic state and shift depending on their experiences and circumstances outside of the sex industry.

\section{Access to Sex - Pleasure as the Primary Motivator}

The 'access to sex' clients were primarily motivated to purchase sex for sexual pleasure. While this appears straightforward, a range of sexual motivations were identified. Prior research recognises this variance - across 143 male clients, McKeganey and Barnard (1996) identified sexual motivations reflected among the participants of this research: the ability to purchase specific sexual acts from women with specific characteristics, access to a variety of sexual partners, temporary engagements, and thrilling experiences. Six of the interviewed clients were originally pushed towards purchasing sex when experiencing an absence of sex, be that while in a sexually unsatisfactory relationship, or single. As Kevin explained:

I have never been very successful with women for whatever reason ... but I have a high sex drive. I like sex, I like to have sex, but I wasn't getting any and I haven't throughout most of my life, so that has always been quite frustrating.

Five other participants also suggested that a deficiency in experience or confidence contributed to their difficulty engaging women, which left them without access to sex 
through the more conventional means of 'hook-up culture'5 or relationships. However, four of the participants explained they purposely avoid committed relationships and as such, turned to purchasing sex to meet the quantity of sex they desired. For example, Mark's aversion to relationships made interactions with sex workers attractive:

I've got two kids who live with my ex-wife. I split my life between Wellington for work and Marlborough on the weekends. I don't really see how a partner would be compatible in my life right now. I've had consistently bad experiences in past relationships ... Just women who have cheated on me, women who have been mentally and physically aggressive ... I avoid relationships, but I like sex and I like sex more often than I get sex as a single guy.

Existing research has repeatedly found that avoiding relationships is a key factor motivating clients to purchase sex (Monto, 2000; Plumridge, Chetwynd, Reed, \& Gifford, 1997). For Mark, purchasing sex meant he could "get as much sex as I'm willing to pay for without having to be in a relationship". Unfortunately, Eddie and Steve also experienced domestic violence, both of whom noted this influenced their aversion to relationships. The violence their female partners perpetrated included verbal assaults, as Steve noted, "she would just scream at me and smash plates, on the regular every day". Like Steve, Mark also experienced physical violence during his marriage and sported facial scars as evidence: "she was mentally nasty and at times violent, not to the kids ... but in front of the kids". These participants also experienced gaslighting (a practise where the victim is made to doubt their own memories, perception and sanity), and emotional abuse, including Eddie: "you start questioning your own judgement and sanity, it makes you think maybe I'm the one who is causing all of this".

Sanders (2008b) notes that men find the nature of the sex industry alluring and that the "glitzy or gritty images and promises that emanate from adverts, websites, stereotypes, pictures and the allurement of fantasy" (p. 45) draw them in. As previously noted, Hawkes (1996) claims that "sex as entertainment" has been culturally promoted, yet this is "without commitment, transitionary, anonymous and promiscuous" (p. 14). This type of sex appealed to Mark, who explained that, "I just find it exciting ... one of the reasons it's quite erotic and sexy is because it's quite clandestine ... because you're just meeting someone to have sex and leave". For the four participants who wished to avoid relationships,

\footnotetext{
${ }^{5}$ The term 'hook-up culture' is frequently referred to in academic literature yet does not have a precise meaning. Bogle (2008) identifies that hooking up encapsulates a wide array of sexual and intimate experiences. Hooking up is often the dominant way for men and women to initiate sexual engagements and form potential relationships.
} 
commercial sex was perceived as uncomplicated, a quality which appealed to them. As explained by Arthur:

You get these feelings and I don't know how to deal with it ... relationships, they were always painful for me ... It's easier to have sex with somebody you don't know rather than have sex with somebody you know. It's more complicated if you both don't agree on how you feel about each other ... it makes it simple.

Five participants shared the observation that dating, relationships, and hook-up culture are too convoluted. Hence, JC believed sex workers provides "all the advantages of a relationship without the disadvantages". The participants perceived purchasing sex as simplistic, as it allowed them to bypass the expectations traditionally attached to dating and relationships, including monogamy, and that sex must be imbued with emotional meaning. Riaan also highlighted the difficulty of dating in his thirties when "women at my age want to get married, have been married, want kids or already have kids. It's a hassle. You're 32, you meet someone your age, and they want a kid yesterday". Accordingly, these participants were attracted to what Adam described as the "honest" experience of purchasing sex:

I go there, I pay money, we do the dirty, I leave. Very honest transaction, no bullshit and no pressures on anybody to do anything. I love that. I think that's beautiful. Some people think it's horrible, they go "that's disgusting". I don't think it's disgusting; I think it's fantastic.

In addition to the convenience of purchasing sex, the ability to engage in a variety of different sex acts with a variety of different women appealed to many participants. As Riaan explained:

I think it's also the variety ... Even the build-up differs. Some women want to sit, chat and have a bit of a conversation, while others just want to get into it as soon as possible ... it's sort of a liquorice allsorts.

Many participants shared Riaan's excitement at this prospect, as they were unable to achieve significant variety in their sexual partners outside of commercial sex. The opportunity to specifically select women with certain attributes they found attractive, such as breast size or physical build, also motivated participants to purchase sex. Riaan argued this point, explaining that "we talk about a scale of 1 to 10, 10 being gorgeous, 1 being ugly. If most men on average are a 6 or 5, the chances of banging a 9, 8 or 10 are slim". The "liquorice allsorts" quality also allows clients to access niche sexual acts, which was the primary reason Adam visits sex workers:

I have a niche part of my sexuality where I'm attracted to transgender people ... So for quite a few years I've had this fantasy in my mind and I said, well, are 
you going to fucking do something about it? When's that opportunity going to

come? I never really meet transgender people socially.

Accessing niche sexual acts was also a primary reason Katie purchased sex from female sex workers, as she observed a difference in how queer women and heterosexual people engage in casual sex: "we don't tend to be as forward as straight men do and it can be really difficult, especially if you're looking for casual partners ... we're not partially headstrong in our pursuit". The motivations discussed so far echo the theorising of Egan, Frank, and Johnson (2006), who note that the success of the sex industry hinges on the construction of fantasy and predicating the sexual desires of clients. However, as explained by Eddie, "it wasn't just the sex or just the fantasy of girls, it was the intimacy. I think last year I really was missing company and intimacy". The following section will now address participants who were primarily seeking human connection when purchasing sex.

\section{Access to Human Connection - Sex as the Secondary Motivator}

As noted by Milrod and Weitzer (2012), for clients who are seeking human connection, the service is experienced alongside mutual companionship, support, and caring. While all participants presented the motivation for sexual gratification, for half the interviewed clients, their desire for connection superseded their drive for sexual pleasure. Alongside prior research (Campbell, 1998; Jordan, 1997), Birch (2015) observes that purchasing sex is used by some clients to improve their emotional well-being through attending to feelings of loneliness. Mirroring this, loneliness was a prominent factor motivating four clients to purchase sex, as JC demonstrated:

It was mostly about loneliness more than anything else ... It's about the ability just to talk to someone and explore your feelings with them. Just to have that point of human contact, which when you're living alone is very, very difficult to find.

Scholars theorise that modern-day society is becoming increasingly socially fragmented (Eitzen, 2000) and the isolation this produces affects non-clients and client populations alike. For some, the experience of loneliness is a step towards mental distress and, when left unattended, a step towards mental deterioration (Mereish \& Poteat, 2015). Kimmel and Plante (2004) have established that sex is one of the core means through which people interact with one another - hence, four participants turned to the sex industry when experiencing loneliness. The loneliness these participants experienced was caused 
by a difficulty in socialising and forming lasting relationships, another factor pushing them towards sex workers. Arthur explained:

I've never enjoyed socialising. It gives me mental stress. I don't enjoy going out drinking and dancing. I don't know how to meet people ... Socialising in general is painful. I don't really have a social life. If you could call it [buying sex] a social life, that's what I do.

Purchasing sex provided JC, Victor, and Arthur with their main source of human connection and, considering their limited engagements outside of the sex industry, their lives lacked intimacy. As JC observed: "I don't really have an intimate life, apart from the intimacy I generate myself with sex work". Prior literature has acknowledged that some clients are motivated to purchase sex by the psychological and interpersonal need for intimacy (Birch, 2015; Earle \& Sharp, 2007; Kennedy et al., 2004; Sanders, 2008b; Milrod and Weitzer, 2012; Xantidis \& McCabe, 2000). Reflecting this, six of the participants noted that a desire for intimacy was responsible, at least in part, for motivating them to purchase sex. Katie explained that following a break-up:

I wanted intimacy as well as sex. I missed intimacy and it felt a lot safer for me doing it through sex work as opposed to going out ... Since then, it tended to line up with times of emotional turmoil as well, or times when I was lonely.

Despite the experiences of these participants, the nature of intimacy within the sex industry is contested. Some scholars believe that only 'counterfeit intimacy', described as the "illusion that sexual intimacy is possible if the customer has the seductive finesse" (Sijuwade, 1995, p. 30), can exist within the client-worker exchange. Lever and Dolnick (2000) propose this illusion requires sex workers to engage in "surface acting" (p. 86), which denotes the faking of emotion and intimacy (Hochschild, 2003). Kevin's perspective supports the existence of surface acting:

I don't like to be pandered to. I'm not paying for the fantasy, I'm paying for the recreational pleasure. I guess that's the difference. I want to go and have sex with an attractive woman ... But I don't want to pretend that she's my girlfriend, I don't want to pretend that we're on a porn set, I don't want to pretend anything.

The behaviours Kevin outlined are strategies reported extensively by sex workers (Brewis \& Linstead, 2000; Chapkis, 1997; Frank, 1998; Swygart-Hobaugh \& Amanda, 1998). Sanders (2005) notes that sex workers manipulate their femininity and sexuality to deliver the perfect female image tailored to individual customers. Included in this performance is the faking of mutual pleasure with clients. Evidence on the "myth of mutuality' has shown that sex workers usually do not experience genuine sexual pleasure 
with clients (Plumridge et al., 1997; Weinberg et al., 1999), though occasionally can (Sanders, 2008b). Interestingly, not all the participants shared Kevin's insight, including Steve:

When the girl does a good job of pretending that she's enjoying it, or better yet, when she is enjoying it, it's great. One of my favourite times I didn't cum in the whole hour, but she came three times. I felt like it was the best thing ever, and she was really enjoying it, and she kept giving me compliments and telling me about my dick size. It was great, it made me feel so good.

However, the six clients who experienced intimacy as a push factor regarded the intimacy they generated with sex workers as genuine. As Katie explained: "it's a different kind of interaction with a person when you're naked with them in a room, it is intimacy". Rejecting the notion of 'counterfeit intimacy', Bernstein (2007) proposes that clients purchase a form of "bounded authenticity" (p. 203) - an emotional and physical connection that is genuine but limited by the reality that the exchange is a service purchased. Developing intimacy was so salient for participants such as JC, that connecting with a sex worker superseded the importance placed on physical attraction: "It used to be that I had this idea of physical perfection ... but I've drifted away from that ... When someone's personality shines through, that's really what draws me back".

While the presence of 'counterfeit' or 'authentic' intimacy between a client and sex worker is murky (Milrod \& Weitzer, 2010), these participants experienced intimacy with sex workers as genuine. When explaining the motivations for intimacy, Sanders (2008b) argues that commercial sexual interactions often attempt to mimic social relationships, which include desirable commodities such as companionship, socialisation, intimacy, and romance. This conceptualisation is highly applicable to the participants seeking human connection, as the ability to communicate with sex workers was a significant pull factor. As Victor noted:

Apart from the people at work, I could go a week or so without talking to anybody. I like the connection, the discussion and the conversation, the interaction between the two of us, mental if not physical ... I probably tell them more about myself or my experiences than I've told anybody else. I don't have a lot of close mates, or many, well you could take the ' $m$ ' off if you wanted to ... I've never ever had a door shut on me when a sex worker opens the door, and that's obviously a big thing for me.

Communicating with sex workers appealed to clients for two reasons - the previously discussed 'pseudo therapy' (Plumridge et al., 1997), and the comfort they derived from sharing their lives with a sex worker when no one else was available to them. In doing so, 
three participants achieved another factor motivation: meeting new people. As explained by JC, "purchasing sex is the road to meeting people. Some people I've met doing this have been some of the most wonderful human beings I've ever met". Likewise, Arthur noted, "there's always that chance of you meeting somebody and thinking wow, that's such a cool experience, I'm happy that I've met that person". For the clients who were unable to maintain relationships, both sexual and non-sexual, visiting sex workers was an essential means for maintaining human connection and offered the chance to interact with different kinds of people than those accessible through their everyday routine.

Following a trend identified by Birch (2015), Sanders (2008a, 2008b) and Milrod and Weitzer (2012), the participants shared motivations for purchasing sex that mirror the reasons people seek casual sex and have sex in non-commercial relationships. When seeking to understand 'why humans have sex', Meston and Buss (2007) identified stress reduction, physical pleasure, attraction to the other person, and new sexual experience seeking as physical incentives. Moreover, Sanders (2008a) asserts that developing emotional connections and intimacy are key goals for entering non-commercial relationships. Evidently, Sanders' (2008a) conclusion that "understandings of sex work and prostitution are based on false dichotomies between commercial and noncommercial relationships" (p. 400) applies to this research and suggests the participants are engaging with the sex industry for similar reasons that men and women engage in sexual activity in the wider community. Such evidence provides compounding support for the notion that clients' motivations are normative, and further supports the 'every man perspective' (Monto \& McRee, 2005). However, what must also be considered is the gendered nature of their interactions with sex workers, hence, this chapter will address how masculinity manifested in the participants' motivations.

\section{Motivational Masculinity}

Hart (2003), explains that "male selves are messier than many studies of 'masculinity' would like to acknowledge, and so too are client selves" (p. 47). Equally, some participants offered nuanced experiences of masculinity and relationships with sex. While research within a New Zealand context connecting masculinity and commercial sex is sparse, an imbedded culture has been documented by Monod (2017), who identifies the 'Kiwi bloke' as the New Zealander's most authentic expression of masculinity. As previously noted, sexual achievement is inherent to the ideology of 'what it means to be 
a man' (Joseph \& Black, 2012). Accordingly, Frank (2003) argues that developing or affirming masculinity can drive men to purchase sex. This observation is applicable to the current research, and this connection was often articulated through the 'male sex-drive discourse', which argues that biology necessitates men regularly achieve sexual gratification (Gilfoyle, Wilson, \& Own, 1992). For example, Alex noted that sex workers provided him with "something I feel that I need really", and Riaan explained:

For men, sex is like peeing is for women. You have to do it. Females pee a lot right? You have to get it out and you can't keep it in. That's the exact same thing with men. It's a build-up of the fluid and you want to get it out ... and you've got testosterone that just makes you want it.

While the high male sex drive has been noted as biologically accurate (Fisher, 2000), Hollway (1998) proposes the additional 'urgent' and 'uncontrollable' traits are culturally perpetuated. Likewise, masculinity mandates that men be "sexually dominant, skilled and experienced" (Huysame \& Boonzaier, 2015, p. 542) when expressing their sexuality. When compounded, these ideologies have been shown to facilitate men's engagement with commercial sex (Huysame \& Boonzaier, 2015). Reflecting this, discourses connecting sexual achievement to self-evaluated levels of masculinity featured in the motivations of three participants. For example, purchasing sex created inner turmoil for Steve, as it carried a dual impact of both affirming and contradicting his masculinity:

It means I'm getting laid, so I feel a lot more of a man ... When I feel needy I feel pathetic and being pathetic is the opposite of masculinity. But there's also the problem of she's only doing it because you're paying her and that's a bad thing. But ... would I rather be hugely needy, not getting laid and just be completely sexless, or would I rather admit to myself that "ok, I'm not getting laid, I'm paying for it"? At least I'm getting laid.

Likewise, Kevin felt strongly motivated to purchase sex following a prolonged absence and how this threatened his masculine pride:

I watched all my friends have a copious amount of sex ... I wanted to be included in that experience, but I felt very excluded from it throughout my life and it felt like paying for it was the ultimate admittance of exclusion. I literally said to myself, "nobody else is paying for it, why the fuck should I have to?

However, for Kevin, the impact of failing to secure his masculine ego was severe as he noted not having sex could "break me as a person" and "make me feel bad about myself". Riaan further noted that having sex is "obviously an ego thing, especially if you're having sex with a fairly good-looking woman". Research conducted by Frank (2003) supports this sentiment, as the interviewed sex workers understood their roles as “boosting a man's 
ego by convincing him that he is desirable, masculine and successful" (p. 72). The difficulty with which Kevin and Steve initially purchased sex supports Kinnell's (2013) argument that men's masculinity can be insulted if they are insufficient in attractiveness and persuasive skill to obtain sex without paying. Consistent with this, Steve felt "what would be even better for my masculinity is if I had the social skills to go out, flirt and seduce a woman". For Steve, seducing a woman represented a "huge part" of being masculine and was achieved if "someone doesn't show much particular interest in you, then you are able to influence her until she does".

Steve's understanding of masculine sexuality as the ability to persuade women into sexual contact fundamentally locates the male sexual drive as more important than, and able to over-ride, a woman's preference. This speaks to men's historical sexual entitlement towards women, which developed through socialisation in a patriarchal context that constructs women as readily available to men (Hill \& Fischer, 2001). Prior research has connected this to men procuring commercial sex (Huysame \& Boonzaier, 2015) and, further, within men's non-commercial sexual interactions (Jewkes et al., 2012). For example, Riaan argued that when dating, "at some stage you will want sex ... I think that if you go on a date and the lady accepts you paying for her, you do expect something in return, right? Let's be honest". Problematic perspectives were further identified in how Riaan's perception of women facilitated his affinity for commercial sex. During the interview, Riaan stressed that, "you're in a relationship to get a constant feed of sex. We all just want to date to have sex right? You've been dating, you do realise that the guy only wants sex right?". Considering he primarily sought sex from women, purchasing sex appealed to Riaan as:

It is taking a shortcut and saying you're not going to put up with all the drama and just have sex with them and leave ... It's just that men are fed up with women's bullshit, so this is the perfect solution. You don't have to date them now, you don't have to marry them or have kids with them ... Having sex workers mitigates that, it cuts it out.

Here, Riaan has characterised men's engagements with women as exclusively motivated by sex. More concerning, however, was his understanding that a woman's primary worth is her sex appeal and, further, that women are only equal to, or exceed men, through their sexual capacity: "it's the one thing women have over men, it's harnessing your vagina. You have this special power over someone just because you have a vagina. It's fact". This perspective is reminiscent of the patriarchal sexual hierarchy, a relationship between the 
sexes that is characterised by domination and subordination - where men are viewed as superior to women (Beechey, 1979). This understanding motivated Riaan to purchase sex as a method of avoiding relationships and, when addressing the "growing entitlement" he identified among women, Riaan argued that:

Men and women aren't compatible. Men are totally rational, and women are totally irrational ... In relationships, women use sex to get what they want out of it. Let's say you have sex and it takes you 45 minutes each time and in a healthy relationship you do that twice or three times a week. That's an hour and a half of sex. If you live with someone all your chores and drama and bullshit is going to way outweigh an hour and a half of sex ... This is how men in general feel.

The way Riaan describes a woman's worth to him suggests that his engagement with the sex industry comes more from a place of detesting women than having sex for pleasure. His perspective that women are manipulative through their sexuality and carry "baggage" contributed to his aversion to women outside of the sex industry yet facilitated his enjoyment of commercial sex being "a transaction, it's nothing more or nothing less". Accordingly, misogyny was evident in Riaan's motivation to avoid any extended contact with women beyond purchasing sex, as this way, he was able to attain what he considered to be the cornerstone of masculinity - sex - while disconnecting from women.

Another motivation Riaan offered for purchasing sex was access to specific attributes in sex workers, especially the prospect of 'travelling the globe' through sex: "you can have an Asian woman one night, next time you could have a blonde from somewhere in Europe, and the next night you can have a Brazilian". However, the client's ability to apply specificity to their purchase has been problematised by some feminist academics, who identify this as men instrumentalising women to their bodies (Dworkin, 1993). This is otherwise known as objectification, which Westkott (1986) defines as "the socially sanctioned right of all males to sexualise all females" (p. 95). Scholars such as Connell (1987) and Kuhn (1985) argue that objectification is the expression of patriarchy and is experienced by women as dehumanising. Objectification was evident in how four participants targeted specific bodily attributes of sex workers. In doing so, the participants reduced sex workers to consumable objects, findings also presented by Huysame and Boonzaier (2015). However, eight participants did not engage in the objectification of sex workers. For example, JC noted he saw "ladies of all ages, all sizes, all shapes. The thing that takes me back to someone generally is their personality and how we 
get on". Moreover, Kevin expressed an aversion to dehumanising sex workers: "I don't like when their face isn't showing ... I want to see the person, I want to see their eyes basically ... I just don't like the dehumanisation that comes from cutting one's head off'.

Clients do not operate in a vacuum - they operate within a society, and this societal context imposes heavy pressures on how to be successfully masculine (Courtenay, 2000). Reflecting this, some participants performed their masculinity through purchasing sex. However, despite concerns this may raise regarding the gender dynamics of the sex industry, the participants presented dual states - while some promoted problematic attitudes towards women, others rejected this. Moreover, the masculine and misogynistic motivations discussed did not appear to negatively impact on how participants conducted themselves. For example, Riaan acknowledged the mistreatment of sex workers and explained:

I don't really treat working women differently. I don't discriminate or treat them badly or use foul language to describe what they look like and what they do as workers. Some men do, some men really like doing that, they like being very dominant and treating them with disrespect ... Obviously all of these women have boundaries and there are certain things they are comfortable doing for a price.

This speaks to the potential impact of decriminalisation on these participants and its capacity to direct behaviour and overpower fundamental ideals. Even though changing gender perspectives were not evident across all the participants, decriminalisation could be providing the setting for an ideological shift among clients - as explained by Kevin, while the "patriarchal view point" surrounding sex work is difficult to shift, he believed that "those social attitudes change generationally". Following this discussion of client motivations, the analysis will now shift to addressing the impacts the participants experienced from purchasing sex and fulfilling these motivations.

\section{The Impact of Purchasing Sex on Clients}

Regardless of their motivations, be that sexual pleasure, affirming masculinity, or seeking human interaction, purchasing sex revolved around meeting the personal needs of the participants. While insights into clients' motivations are interesting and important, it is also important to consider how the participants experienced the impacts of purchasing sex and fulfilling these motivations. Unfortunately, prior literature addressing this is relatively scarce. Yet, Birch (2015) has touched on this topic and concludes that "men 
flourish and feel fulfilled through the procurement of sexual services as an array of emotional, psychological and social needs are met" (p. 146). Accordingly, the impacts discussed were primarily offered by the participants who sought access to human contact, as purchasing sex for them was more pivotal - it imbued their lives with both sexual and non-sexual interpersonal intimacy, regardless of its genuine or counterfeit nature.

\section{Confidence and Comfort with the Self and Sexuality}

Many participants experienced an increase in confidence from purchasing sex, yet this was felt most heavily by three clients. While this may seem trivial, the significance of this impact cannot be understated - prior to seeing sex workers, their lack of confidence was a significant hurdle preventing them from interacting with others and developing social and sexual relationships. For Steve, this rang true, as when asking women on dates, he felt "very nervous ... like it's a huge deal and I've been preparing for days to ask ... and, they almost always said no". Yet, sex workers provided a means of remedying this:

Last year I had a stutter and was awkward. Everybody kind of knew me as this socially awkward guy who has low self-esteem ... I've lost the stutter and now I think I'm kind of semi-normal. Most people wouldn't think there was anything particularly weird about me now ... People have made comments to me several times, like "Steve, you're so different than you were last year" ... My confidence has gone up a lot.

This new-found confidence meant Steve could engage with women outside of the sex industry without the "creepy and desperate" feeling he projected. Consequentially, Steve felt less emotionally invested in his pursuit of women, and, if rejected, his self-worth was not as negatively impacted. Similarly, Mark explained that sex workers helped him "rebuild some confidence in relation to females", which he had lost following a difficult divorce. While Mark believed he "used to be an extremely confident person", he has now "gotten most of it back". In addition to increased confidence, four clients also experienced a new-found comfort with themselves, including JC: "I'm far more comfortable with myself as a human being ... I can live with myself a lot easier and I have more value in myself now. I have maybe even a bit more self-confidence in general". JC noted that sex workers retaught him the value of his own self-worth, which he lost sight of following his divorce and the consequential loss of familial ties and identity. JC accredited this transformation to the sex workers he saw, who he described as "remarkable women ... Sex workers are a lesson on how to live your life. I've adapted and learnt an awful lot. As a result, it's made me 
a better person". Two participants also experienced this increased comfort by expressing

and confirming their sexuality through purchasing sex. As previously noted, while commercial sex is largely geared towards heterosexual needs, a wide spectrum of sexualities participates in the sex industry (Laing, Pilcher, \& Smith, 2015), including Adam:

The first time I watched transsexual porn I would have been about 16 ... I was sexually confused and suppressed because I had harboured these desires for as long as I had. Never having experienced them I was always going to wonder what if. Now that I have done it, I do feel very comfortable in my own skin from a sexuality stand point ... The most positive impact is certainly the being comfortable in my own skin and sexuality.

For Adam, sex work provided an avenue to ease the inner turmoil he felt regarding his sexuality. The ability to specify the gender of sex workers also aided Katie in confirming her sexuality, which she explained helped "in terms of affirming my queer identity, that's probably the main point. It has definitely helped me know that I'm super gay too". After questioning herself, purchasing sex from female sex workers provided Katie with validation, thus providing a sense of reaffirmed identity. The comfort and confidence that purchasing sex restored within these clients positively impacted on their relationships with the self, their sexuality, and others. This influential shift is also strongly linked to the improvement some participants witnessed in their mental health.

\section{Improved Mental Health and Well-Being}

Joseph and Black (2012) note that sex workers often draw parallels between the work of a psychotherapist and their own sexual labour, describing clients who mainly want to talk during bookings or who seek the pseudo-therapist experience. Clients have further reported being drawn to commercial sex by these 'listening services' and the ability to communicate with sex workers (Lever \& Dolnick, 2000) - a trend also observed by this research as three participants drew explicit connections between purchasing sex and their mental health. As Arthur explained:

I see it as more like a health thing. You go to your physical therapist or you have a psychiatrist, what's the difference? It's almost therapeutic I guess. Sometimes you want to see somebody, but you don't have anybody to see at that moment, so you could just go see a sex worker.

For these clients, purchasing sex offered a form of mental health management and improved the state of their ongoing mental well-being. The conceptualisation of erotic labour as therapeutic is supported by sex workers themselves, who regard their work as 
inherently containing a therapy element (Lindemann, 2011). For example, a sex worker interviewed by Sanders (2006) noted that "a lot of clients talk about their problems. I had a gentleman last week who suffers with depression and when he came down here he said he was suicidal" (p. 2437). Similarly, loneliness and depression were key factors driving JC to engage with sex workers:

People who have not experienced sex workers don't understand that they are human beings as well, and if you work hard at making them happy they'll make you happy ... I won't downplay the depression part of it. I was in a very bad space and this [seeing sex workers], as well as the medication I was taking, helped me through it.

JC explained that sex workers made him "feel worthwhile again", which contributed to the alleviation of his depression. Moreover, JC indicated that purchasing sex taught him to address his "work-life balance", which facilitated an improvement in self-care through refocusing him "away from work being the be all and end all to make me take a look at myself ... I have to make sure I'm ok". Likewise, Katie struggles with "several mental illnesses" and applied commercial sex as symptom management:

During like during very depressive periods, or periods of high anxiety, or periods where PTSD flashbacks are happening a lot, I do tend to seek out sex as a coping mechanism. It wasn't always healthy ... Whereas now I have the ability to do it in a way that is healthy and consensual ... Hyper-sexuality a lot of the time isn't safe, so sex work is great as a coping mechanism to start with ... The most positive impact would be that ability to help with my mental health issues.

Much like JC, Katie applied a combination of therapy, medication, and sex work to manage her mental health, which she noted gradually produced "an upward swing". Katie proposes that the impacts of sex work throughout her life are significant - as she explains, "things that help in the short-term always build up to help in the long-term, especially with coping mechanisms ... I'm super happy with the way my life is going". For most participants, purchasing sex also improved their mental well-being indirectly through the mitigation of stress. Mark explained, "its relaxing, it's fun, it's a real stress release ... I just come out of it completely chilled and completely relaxed", while Adam noted "there's definitely an element of stress-relief, people like sex, so do I, it's fun". Five participants further proposed that this stress relief impacted on their general dispositions. For example, JC observed that sex workers encouraged a different approach to life, shifting him from "a glass half empty person" to a "glass half full person", while Steve explained that he is more "casual and relaxed" since he began to see sex workers. 
The likeness with which these participants compared purchasing sex to traditional avenues of treatment and the effectiveness of their self-prescribed 'therapy' suggest sex workers' erotic labour can be experienced as therapeutic by clients. The conceptualisation of erotic labour as a therapeutic activity has previously been considered by 'pro-sex' feminists, who suggest the formal credentialing of sex workers as sexual therapists (Lindemann, 2011). Scholar Laurie Shrage (1994) argues that through "redefining the prostitute" as an "erotic therapist" (p. 86), the qualities sought from sex workers would be altered, including raising the social status of sex workers beyond the stigma they experience. While not addressed by Shrage, such a redefining of sex work would undoubtedly impact the social perception of clients' and their engagements with the sex industry. While purchasing sex impacted on the participant's relationships with themselves, five clients also observed a shift in their relationships with others.

\section{Perceptions of Relationships and Women}

Research suggests it is common for clients to be in monogamous relationships while purchasing sex (Birch, 2015; Monto \& McRee, 2005). Alex was the only participant who disclosed he is married yet still purchases, explaining that "it was just sort of years and years of the same sex and it was getting less and less interesting. No real desire from either of us to have sex with one another on a regular basis". Following this, Alex observed a negative impact on his marriage and felt that "maybe because I'm purchasing it now I don't really want to do it with her". Some feminist academics, such as Hunt (2013), argue that purchasing sex is detrimental to relationships and families as "treating sex as an impersonal transaction decreases the ability of an individual to use sexuality as a language of love" (p. 238). Two participants exhibited this decrease and noted that purchasing sex was deterring them from entering relationships. Riaan explained:

I think honestly, it will impact me dating going forward ... There always an alternative now and if your partner uses sex to change your ways or to manipulate you, women do that right? It happens all over the show, it happens every day in all relationships. To me, there's an alternative, I don't need to deal with that.

Similarly, Mark also felt sex work was impacting on questioning his compatibility with monogamous relationships:

If I didn't see sex workers I'd be more inclined to have actual committed relationships ... it gives me an easy way to have sex ... and a desire for variety that wouldn't be reasonable to sustain within a relationship. 
Despite this negative impact, Mark and Riaan concurrently witnessed a positive change in their interactions with women outside of the sex industry. For example, Mark observed a notable shift in the way he interacted with women in social and professional settings:

If I'm horny there's always this thing in the back of my mind thinking "could I sleep with this woman?". You just notice women more and all that sort of stuff, all those animalistic urges. If I'm satiated, that's just not there, and so I think it enables me to behave or think in a better way.

Moreover, Riaan explained that the consistent stream of sexual satisfaction allowed him to have female friends, as he could now "talk to them about things but not want to have sex with them", and from this new perspective, he no longer viewed "all women as sex objects". In contrast to their experiences, Eddie believed that purchasing sex aided him in healing from past abusive relationships and encouraged him to seek a relationship: "it made me realise that I wanted a real relationship again. I really enjoyed the two hours we had and it brought back good memories of being with someone, so I knew that I wanted that again". Katie also noted that purchasing sex had "been good" and "very helpful" for two of her previous relationships:

Having paid threesomes is great for two people being sexually intimate and opens doors and keeps things fresh. But also, in my just finished relationship, it was really good as a non-monogamous couple to reaffirm that that was how we wanted to do things. It would have been a really easy way to turn up any hidden issues.

As our understanding of the traditionally heterosexual and monogamous relationship evolves to be more inclusive, so too should our understanding of the connection between commercial sex and intimate partner relationships. The stereotyping of commercial sex creates the image of an illicit side activity painstakingly hidden from partners (Jordan, 1997). However, while this does happen in some relationships, it appears that this is not always the case - Katie's experiences indicate that sex work can be shared between partners to strengthen sexual bonds and it can be undertaken separately with affirmed consent. Despite Alex's experiences, it appears that the impact of commercial sex on the participant's non-commercial relationships and interactions with women were largely positive, most notable of which being the facilitation of future relationships and the confirmation and continuation of current relationships.

\section{Conclusion}

Following the previous analysis chapter, which introduced the participants and their engagements with the sex industry, this chapter provided insight into why the 
participants purchased sex and how they experienced the impacts of seeing sex workers. Alongside applying Sanders' (2008b) 'push vs pull' framework to address their motivations, the participants were separated into two original categories - access to sex, and access to human interaction. A range of motivations were situated within these categories and when analysed, they reflected normative reasons for seeking sex shared by non-client populations. The masculine motivations of the participants were also addressed, and it was found that many participants were performing their masculinity and gendered attitudes through commercial sex. Following this discussion, the impacts the participants experienced from seeing sex workers were analysed. The key impacts identified included increased confidence and comfort with the self, improved mental health, and altered perceptions of relationships and women. Now an in-depth profile of the participants and their engagements with the New Zealand sex industry has been provided, the following chapter will map their interactions with sex workers under decriminalisation. 


\section{Chapter Six: Clients under Decriminalisation}

The New Zealand model is wonderful ... Purchasing sex is not something to be ashamed of, it is something I enjoy and that gives me an awful lot of joy. I just wish more people in New Zealand were aware that it's not something that is dirty or should be hidden away - JC

Considering the heated debate that surrounds decriminalisation in New Zealand and speculation regarding clients within this unique context, it is important to understand how clients are affected by decriminalisation. Hence, this chapter will examine how participants interacted with sex workers in the decriminalised context by exploring how they perceived and navigated boundaries and communication in commercial sexual encounters, and their ethical considerations when purchasing sex. This chapter will also explore the participants' perceptions of decriminalisation, evident within the comparisons some drew between purchasing sex within New Zealand's decriminalised sex industry and those found internationally. Through exploring how the participants interacted with sex workers, this chapter is intended to highlight how decriminalisation is impacting on their conduct within the New Zealand sex industry.

\section{Client Interactions with Sex Workers under Decriminalisation}

As previously discussed, the controversy surrounding decriminalisation primarily rests on fears that removing the illegality of selling and buying sex will skew power in favour of clients and third-party mangers, leaving sex workers vulnerable and lacking control (Laurie, 2010). However, research conducted in New Zealand post-decriminalisation by Abel, Fitzgerald, and Brunton (2007) suggests that sex workers now have increased control over their working conditions. Based on this, the PLRC (2008) concluded that decriminalisation has empowered sex workers, while also arguing that research "suggests coercion is not widespread" (p. 161) in the New Zealand sex industry. Corroborating these arguments, the interviews revealed a strong awareness of the power dynamics involved with commercial sex and suggested that the participants positioned sex workers as in control of their encounters. This awareness was best exemplified by Eddie, who noted: "I knew straight away that it's not real, I know they are not into me, I know that. And I know that my dollar doesn't mean I've got any power or control over them or anything". 
Adam also located control over the direction of the booking with sex workers, explaining sex workers "have the power for the most part. In terms of the social dynamic of the booking, they can kind of dictate how it goes". Adam accredited this to the control he believed sex workers held over clients, as many men experience vulnerability when purchasing sex, including Adam who felt "fucking scared, I was so nervous" during his firsttime purchasing sex. Therefore, for these clients, the sex worker was very much in charge in the context of decriminalisation. However, it is also important to explore how, in reality, their perceptions and expectations of power and control manifested in their interactions with sex workers.

\section{Client Recognition of Sex Worker Boundaries and Comfort}

All the participants recognised that there are legal boundaries surrounding the purchase of sex in New Zealand. However, half the participants also overtly acknowledged the personal boundaries sex workers establish for themselves and their importance in ensuring a sex worker's comfort during bookings. For example, when discussing his conceptualisation of the different boundaries clients observe, JC explained that:

There are two separate boundaries, one is the legal boundary and one is her comfort boundary. You know one to start with because that's what is legally set down, but you also know the second one by ensuring that the service being

provided is something she is comfortable with.

Underlying JC's understanding of boundaries was a recognition that sex workers are people and, thus, the letter of the law was not the only consideration in the encounter. This was evident when JC noted "the girls' boundaries are probably more important than the legal boundaries, because they are unique to the individual". Soothill and Sanders (2005) claim that a consensus exists among some clients that sex workers are experts in their work and, hence, prices and rules must be respected. Arthur reflected this sentiment when acknowledging the importance of respecting individual boundaries: "sometimes they will refuse to kiss you or allow you to give them oral. That's just the rules they have for themselves, that's just the service that they provide. They have their boundaries so that's the way it is". Likewise, while Kevin identified commercial sex as a personal indulgence, he acknowledged this was to be enjoyed according to the sex worker's boundaries:

I guess sex work to me is quite similar to counselling, it's an hour about you. You paid for the time, so you get to indulge in it, within the boundaries the sex worker has set, within those boundaries you can indulge in it. 
The responses of these participants echo research which shows decriminalisation provides sex workers with the legal power to dictate the services they wish to offer, enforce client standards, and seek retribution when their terms have been violated (Abel et al., 2010; Armstrong, 2014, 2016). Moreover, Sullivan (2004) argues that providing sex workers with legal rights increases the recognition of a sex worker's capacity for consent, which ensures non-consensual activity is more effectively recognised and responded to (Sullivan, 2004). Reflecting this, the participants' recognition of boundaries suggests that they are aware their payment does not revoke a sex worker's capacity for consent and, further, that consent must be actively sought. Hence, these participants understood that in purchasing the services of a sex worker, they are not purchasing unbridled access to her body, but, rather, conditional access that is restricted legally and by sex workers.

However, this was not the case for all participants as Mark, Alex, and Victor claimed to request and engage in unprotected oral sex, both providing and receiving, with sex workers. Accounts from sex workers in New Zealand indicate that clients frequently request oral and penetrative sex without a condom (Abel, Fitzgerald, \& Brunton, 2007; Laverack \& Whipple, 2010). In doing so, clients are attempting to push sex workers' boundaries for the sake of their own pleasure, thus contradicting the narratives previously discussed. While he was "embarrassed to say", Alex explained:

I have asked for unprotected oral sex, and they've said no. Not in a coercive way, but I've just asked if it's something they offer. I don't do it now, but there was an escort I was seeing for quite some time that was quite happy to do it if I paid more.

Likewise, Victor admitted to receiving "unprotected oral sex by a lady within the last 12 months". Alex and Victor requested unprotected oral sex because of the increased pleasure this offered - considering his explanation that "it was so good", Alex noted "I did ask other escorts if they would do it. One or two others said yes, but most declined”. Research indicates that Alex's observation is correct, as Abel, Fitzgerald and Brunton (2007) found that just over $10 \%$ of the 772 surveyed sex workers reported not using condoms or dental dams with clients. However, while condom use for penetrative sex and oral sex on male clients is common, sex workers using of dental-dams is less frequent (Abel, Fitzgerald, \& Brunton, 2007). Three participants referenced this, including Victor, who perceived dental-dams as falling under "a grey area, if you have to have protection or not". 
While clients clearly understood that engaging in unprotected oral sex with sex workers was illegal under decriminalisation, their pleasure was considered more important. As explained by Mark, "you're supposed to use them for oral on women, but no one ever does. I've never been asked to, and it would kind of spoil the fun". While some clients may successfully pressure sex workers to engage in unprotected sex, it has been argued that the number of sex workers engaging in risky sexual practices is actually lower than those in non-worker populations (Jordan, 2005). Moreover, despite the three participants who claimed to request and engage in unprotected oral sex, this occurred infrequently and, generally, these clients were rejected by sex workers. This is indicative of the legal power that decriminalisation provides sex workers in dictating the services they are comfortable offering and refusing clients when they attempt to push their boundaries (Abel, 2010, 2014; Fitzharris \& Taylor, 2010; Jordan, 2005). As noted by Abel, Fitzgerald, \& Brunton (2007), since decriminalisation sex workers felt that the negotiation of condom use with clients is "a one-sentence statement now. It is not a 10-minute argument" (p. 21). This has been connected to increased safety for both sex workers and their clients, which was also a defining feature of how the participants perceived decriminalisation.

\section{The Safety of Purchasing Under Decriminalisation}

Despite the three participants who engaged in unprotected oral sex, the remaining nine participants did not indicate pushing the sex workers' personal boundaries or those established under the PRA 2003. In fact, these boundaries were perceived as promoting a safer interaction with sex workers. For example, JC believed that "the PRA sets the boundaries of where you can and cannot go. To me they are actually very sensible boundaries which keep you safe ... it's a great environment". However, the experiences of Dr Jenny Hayward imply that not all clients under decriminalisation comply in this manner, as she observed instances of non-consensual condom removal:

We see the situation where the condom has come off but where it did not happen deliberately, and the workers feel that the client genuinely did not remove it ... Other cases have been where it was removed deliberately, and they have seen it in the end. I'm not sure how commonly it happens, but it's not uncommon for people to come and see me when it has been removed.

This is also colloquially known as 'stealthing' or 'rape-adjacent' behaviour (Brodsky, 2016) and sex workers across legal frameworks have noted non-consensual condom removal by clients (McKeganey et al., 1992). Additionally, court cases in New Zealand since decriminalisation have seen sex workers successfully prosecute clients for 
removing condoms during bookings without their consent (Shadwell, 2015). On the successful prosecution, the involved sex worker commented that it was "certainly indicative of a different relationship where a sex worker feels that they have rights and can access justice and so forth if they feel a crime has been committed against them" (Shadwell, 2015). Yet, none of the participants discussed stealthing during the interviews, so it is not possible to discuss their perceptions of this behaviour.

Nonetheless, the participants were highly cognisant of their own sexual health, as seven indicated a strong aversion to 'natural' services and felt that using condoms when purchasing sex was imperative. For example, Mark noted he had "never asked for any natural services or stupid shit like that", while Steve explained he "would never go to a woman who wanted to go without a condom. That's really important to me". Likewise, Alex expressed that he would "never purchase it unprotected" and had "never asked for it either". When explaining why they felt a strong obligation to use condoms, the participants drew on arguments relating to sexual health, rather than the laws directing decriminalisation. For example, while Riaan noted that purchasing sex is "safe in New Zealand", this was only relevant "as long as you wear a condom, as long as you're safe and have certain boundaries ... Obviously in ... New Zealand STDs are fairly big, so wearing condoms and protective gear is a must".

Conversely, participants felt that purchasing sex outside of decriminalisation was significantly riskier. For example, JC noted that he does not "see sex workers in Australia, because I don't think the safety standards are good enough. Canada, I had no issues with. But they changed the law in 2013, so now I'm very careful, very careful". Research indicates that the criminalisation of sex work operates as a barrier to safe sexual practice, as police routinely confiscate condoms for evidence (Jordan, 2005; Wurth et al., 2013), sex workers encounter violence when negotiating condom use (Jordan, 1991), and stigma deters sex workers from seeking health care (Lazarus et al., 2012). In comparison, JC felt that the New Zealand sex industry was much safer for both sex workers and their clients due to the safety boundaries decriminalisation established: "if I trust where I'm going, I know that there will be measures in place to make sure that it's safe. The law is pretty good in this respect, as it protects both the sex worker and client". Accordingly, the disparities in risk across legal contexts were so significant that Arthur was no longer interested in 
purchasing sex outside of New Zealand: “you wouldn't even consider going over to America ... There's no point because you have the criminal part. Why take the risk?".

Research supports these client narratives and has found that, since decriminalisation in New South Wales and New Zealand, sexually transmissible infection rates are at a historic low and high levels of safe sex are evident across these jurisdictions (Donovan et al., 2010; Fitzharris \& Taylor, 2010). While research on the health and safety standards of the New Zealand sex industry prior to decriminalisation is sparse, the existing literature indicates that a strong culture of safe sex existed among sex worker communities prior to lawreform (Abel et al., 2010; Chetwynd, 1992; Chetwynd and Plumridge, 1993; Laverack \& Whipple, 2010; Jordan, 2005) The NZPC were a key force driving this culture and did so through facilitating peer education among sex workers, which increased awareness around their occupational health and safety (Laverack \& Whipple, 2010). Therefore, the experiences of the participants suggest that, rather than creating a new culture of safe sex, decriminalisation has provided sex workers with the tools to enforce safer sex. This can be observed as a direct manifestation of decriminalisation and its purpose to create an environment that is "conducive to public health" (PRA 2003, s 3). This was further evident in how the participants engaged in open communication with sex workers, which also promoted safety within the exchange.

\section{Communication with Sex Workers and Sex Work Accessibility}

Effective communication between sex workers and their clients is essential for ensuring safe and consensual commercial sex. A sex worker's initial screening process involves communicating their boundaries to clients and setting the terms of the encounter (Armstrong, 2014; Sanders, 2005). This process allows sex workers to set boundaries which protect themselves physically, but also mentally through separating their professional and personal lives (Day, 2007). Sanders (2001) has explained that these initial conversations provide an opportunity to evaluate the extent to which clients may bargain and attempt to push these boundaries. Communication, which JC defined as "unrestrained and unrestricted", was a key factor defining the participants' interactions with sex workers. For example, Adam felt that communication was important to establish the experience levels of clients:

I think it's important to negotiate and figure out what the experiences of the customer are and then agree on at least loosely, what they want to get out of it 
... "have you done this before? Yes ok, "what do you enjoy and what are you here for?" This, this and this.

In doing so, Adam felt that sex workers can respond in turn and clarify their boundaries when noting "ok, these are all services I offer" or "ok, I can offer this and not that". Through this process, Adam perceived that sex workers "have the power for the most part. In terms of the social dynamic of the booking, they can kind of dictate how it goes". Katie also felt that communication was important to establish comfort and consent at all stages of a booking. When describing conversations prior to sex, Katie noted:

It's nice to just sit and have a chat, it doesn't have to be anything serious, just talk to them for a little so you can get a feel for that person ... Sit down, chill, make sure that they're comfortable and you're comfortable, make sure that everyone is good with what's going on and no one feels like they want to walk out.

Katie further explained the importance of communicating after bookings: "it's good to have established that you're both good with one another and there's no unfinished business or anything left unsaid". Similarly, JC linked clear communication to consensual commercial sex and argued that to effectively gauge a sex worker's boundaries and the services they are comfortable providing, clear communication is essential: "you don't just go in there and start poking around unless she has told you that you can do that. You've got to be very clear at the start before the booking commences and make clear the expectations on both sides".

These experiences indicate that the participants felt able to communicate openly when interacting with sex workers under decriminalisation. However, achieving this before decriminalisation would have been difficult, as prior to the 2003 law reform sex workers risked entrapment on soliciting charges if they attempted to explicitly negotiate with clients (Abel \& Fitzgerald, 2010). Sanders (2004) argues that the client screening process is complicated by the criminalisation of sex work, as sex workers must manage the risk of arrest for both themselves and their client (Sanders, 2004). Sanders (2001) further argues criminalisation places pressure on both sex workers and clients to negotiate quickly to avoid law enforcement. The experiences of participants who purchased sex in New Zealand prior to decriminalisation support such arguments, as they witnessed a significant lapse in communication with sex workers. When reflecting on purchasing sex 
in the 1980s and 1990s through massage parlours, ${ }^{6}$ Alex shared accounts of cumbersome interactions with sex workers:

You would walk in and pay for a massage ... The girl would start massaging you and then after a while they would have to come up with something like "is there anything else I can do for you?", or "can I help you with anything else?". They couldn't offer it directly, they would have to get you to ask for the sex.

When purchasing sex in this context, Alex explained "you were going in blind" and had to endure "awkward conversations about having sex even though both people knew why you were there". Jordan (2005) also argues that the duplicity criminalisation mandated within massage parlours hindered sex workers from openly communicating with clients. These disjointed exchanges are opposed to the accessibility of sex work under decriminalisation, which Alex felt was significantly more straightforward: "now, you just pay up front at the beginning ... you make an appointment and just turn up". Alex's experience across legal contexts suggests that the seamless nature of the decriminalised transaction rests on the transparency with which sex workers can communicate their services. Victor's experiences across legal contexts further emphasise this:

The ladies are more open to being upfront about what they do and what they offer, as opposed to you having to wait until you've committed to the massage before you find out what they do or don't do ... which might not have been the understanding that the front desk gave you ... It's quite upfront now.

The difference participants observed across contexts are well summarised by JC, who argued that decriminalisation meant "dealing with the known rather than the unknown". Similarly, Arthur described purchasing sex in New Zealand as a straightforward transaction that was "totally different" from purchasing sex internationally: "here, everything is already settled ... Here, it's "ok, this is the amount you pay and this is what you get ... Here is way better". These experiences reflect accounts provided by sex workers which indicate they can more easily negotiate services with clients since decriminalisation (Abel, 2010, 2014). As decriminalisation fosters transparency, the participants perceived sex work in New Zealand to be more accessible. As Alex explained, "pre-decriminalisation, you really had to look around and see where the massage parlours were". Likewise, Victor felt that sex work in New Zealand was "more out in the open and upfront" since decriminalisation, as "there's no secrecy about it anymore".

\footnotetext{
${ }^{6}$ In massage parlours, clients pay the parlour a fee for a massage, then negotiate with an individual worker for anything 'extra' they might like provided. The masseuses are totally dependent on the provision of 'extras' for their income, receiving no wages from the parlour operator (Jordan, 2005).
} 
Similarly, Riaan felt that sex work in New Zealand is "more visible and user-friendly than the criminalised context of South Africa, where he relied on "behind the scenes'activity" in strip clubs and informal social networks of "men that get together over weekends or Friday nights". Riaan's experience highlights the underground and informal quality that criminality imposes on sex work (Mac, 2016). Riaan perceived this in stark contrast to the way clients engage with commercial sex in New Zealand: "there are so many choices here, especially in Wellington ... Whereas in South Africa you could go to a place and it would be hidden away ... It's not in the central CBD area, it's in a suburb". Criminalising sex work inevitably impacts on its accessibility - as demonstrated by Riaan, Alex, and Victor, criminalisation forces sex work to operate under secrecy and at the fringes of society, which has been widely noted to place sex workers at increased risk (Krüsi et al., 2014; Sallmann, 2010). Riaan, JC, and Arthur further connected this underground quality to increased risk. As Riaan observed, "there is always that factor of you might get caught out or the place might get raided". Likewise, Arthur was concerned about "all the baggage that comes with it being criminal" and, accordingly, felt that to purchase sex internationally, you had to "take the risk", whereas in New Zealand "there is already structure for the transaction, so it is more predictable".

Mark, Victor, and Riaan perceived that the accessibility of decriminalisation had impacted on the stigma surrounding sex work. For example, as decriminalisation reduces the concealment of sex work, Victor felt that "it's more open and people are discussing it more" and noted he would be more likely to "talk to my friends about it now ... it's more socially open now". Likewise, Mark felt that, since decriminalisation, purchasing sex has shifted from "something you do late at night once you've had a couple of beers or because you're horny and alone" to "something you can do during the day when you're stone-cold sober". Riaan also perceived this shift and felt that while sex work has traditionally been "socially unacceptable", under decriminalisation "it's changing now" and becoming more socially acceptable. Previous research has indicated that, while decriminalisation in New Zealand has not entirely erased the stigma surrounding sex work, providing legal rights to sex workers may offer some leverage against stigma (Abel, Fitzgerald, \& Brunton, 2007). While further research is needed to understand this impact, the experiences of Mark, Victor, and Riaan offer an initial insight into how client stigmatisation may shift under this legal framework. 
The participants considered open communication with sex workers important in establishing boundaries, comfort during bookings, and for negotiating services. The comparisons participants drew between purchasing sex across legal frameworks highlighted how influential sex work legislation was in shaping their interactions with sex workers - while criminalisation led to cumbersome, inaccurate, and rushed negotiations of services, decriminalisation was paired with clear and transparent communication with sex workers, leading to safer and more consensual sex work. These findings contradict two central arguments promoted by critics of decriminalisation - first, that sex workers lose control over client encounters under decriminalisation; and second, that clients cannot, or do not want to look beyond their own experiences and extend consideration to the circumstances for sex workers (Bindel, 2017). These arguments were further challenged by the ethical considerations the participants described when interacting with sex workers.

\section{Clients' Ethical Considerations when Purchasing Sex}

Following clear communication with sex workers and the recognition of their boundaries, participants also described several ethical considerations when seeking commercial sex. These ethical considerations presented in a variety of ways across participants and were concerned with different stages of interacting with sex workers, be that during the booking process or the exchange of service. Through these ethical considerations, participants indicated an awareness of the sex workers' experience during their booking and a desire to improve this. As demonstrated by Kevin:

What I hope from their point of view is that they have a good day at work, that's all I hope for. If they have a fantastic day at work and if they have really good sex with me, or a genuine orgasm, that's great! But I don't pretend that's going to happen. If they have a good day at work, then I'm happy, that's all I need.

When discussing their bookings with sex workers, many participants mentioned strategies they would apply to ensure that sex workers were comfortable. Prior research has found similar behaviour evident in chat rooms and message boards organised by clients, where men engage in discussions about how to and not to behave when purchasing sex (Soothill \& Sanders, 2005). For example, Alex recognised that there were some sex acts that may be experienced as demeaning, such as "cumming on someone's face". To ensure he was treating sex workers with respect, he drew comparisons between his engagements with sex workers and his wife: 
I do look at them as people who deserve respect and I've never done anal with my wife, so I wouldn't do it with a sex worker either ... At least I can say that I'm not treating her any different to how I treat my wife.

Similarly, JC recognised that sex workers often have numerous clients and, hence, felt that it was important to "try to make their hour with you as least stressful as possible and at times, to make it as enjoyable as possible". To achieve this, JC explained that clients must "be polite, respectful, don't walk in drunk or anything like that, always be clean. Be there as a person, rather than someone who is just there to take what you can from them". Likewise, Eddie understood that sex workers "must have good sessions but also bad sessions", and so he made the hotel room welcoming and comfortable for the sex workers he booked outcalls with: "I'd have music going or the TV going ... I'd always offer them a wine, or a beer, or a coffee, or orange juice, never straight into it ... I wanted to make it a nice setting for them."

The effort these participants channelled into creating a comfortable environment for sex workers contradicts the abolitionist claim that clients seek to dehumanise sex workers and refuse to perceive sex workers as more than their occupation (O'Connell Davidson, 1998). Rather, the participants emphasised sex worker humanity, as demonstrated by Alex: "it's just the way you treat people really. I do look at them as people who deserve respect". Similarly, JC explained that "people who have not experienced sex workers don't understand that they're human beings as well" and believed it was important to "not treat the girls as objects when you're discussing them". Moreover, abolitionists have argued that under decriminalisation, clients are more likely to extort sex workers (Bindel, 2014, 2017; Coy \& Molisa, 2016; Molisa, 2015). Yet, three clients specifically avoided circumstances they perceived to be potentially exploitative. For example, Katie always talked to independent sex workers over the phone, as she felt this meant "someone is not controlling their clients", and perceived that migrant sex workers were more likely to be exploited, so preferred to "see women who are from New Zealand purely because if they are from overseas it's more difficult to tell if they are here consensually". JC also identified migrant sex workers as being at higher risk of exploitation, noting that "maybe they are being manipulated, being coerced, who knows. I don't want to put myself in that environment". Similarly, Kevin noted he "wouldn't feel terribly comfortable about streetbased" sex workers and expressed concerns over their exploitation: 
I've tried to reorganise my thinking around street-based work away from the sort of conditioning that says it's all about horrific situations ... But I want it to be ethical, I don't want to be exploiting anyone. I don't want to be going to see anyone who is doing it for any other reason other than they are comfortable having sex with random people for money ... As long as it doesn't hurt them in any way emotionally or mentally, that's the main thing for me.

Instead of purchasing through the street-based sector, Kevin preferred the context of a brothel or an independent worker, as he felt "like the sex workers themselves are in a better situation, or are safer, or surrounded by a more professional environment". Kevin, JC, and Katie's desire to avoid exploitative sex work directly opposed the stereotypical image of an unattached consumer and arguments which claim that purchasing sex raises no moral issues for clients (Sanders, 2008b). Yet, it is important to note that despite JC and Katie's concerns, research indicates that migrant sex workers are diverse and are capable of consenting to sex work (Armstrong, 2017; Roguski, 2013). Segrave, Milivojevic, and Pickering (2009), argue that the abolitionist perspective positions all migrant and streetbased sex workers as coerced and unwillingly trafficked. While JC and Katie reflect this misconception, their concerns are well-intentioned and indicate they consider the ethicality of their conduct. The consideration some New Zealand clients direct towards sex workers, particularly migrant workers, was also recognised by Catherine Healy:

We do have people ringing up about sex workers or ... about migrant sex workers. I think it's a positive if they are moving through these communities and have a perception that is related to a concern. So, if they see somebody, and they are concerned about their welfare it is a very strong positive that they would take the extra act to contact us.

The ethical considerations discussed throughout this chapter demonstrate that the participants are aware of sex worker rights and wish to purchase sex ethically. As explained by Catherine Healy, while decriminalisation did not alter the legality of purchasing sex in New Zealand, "clients must have a sense from sex workers, that the sex workers have rights now, and perhaps that contributes to better behaviour". Likewise, as Manning (1978) notes, "the more power and authority a profession has, the better able it is to gain and maintain control over the symbolic meanings with which it is associated" (p. 97). A core argument mobilised against decriminalisation is that legally sanctioning the purchase and sale of sex will embolden clients who wish to abuse, degrade, and dehumanise sex workers (Farley, 2004). However, the participants' interactions with sex workers are defined by the recognition and respect of sex worker boundaries, improved 
safety, clear communication, and ethical purchasing; fundamentally, these are the goals of decriminalising sex work.

\section{Conclusion}

This chapter presents the first empirical evidence on client interactions with sex workers under decriminalisation. When reflecting on the participants' interactions with sex workers, four key themes emerged. These included the acknowledgement of sex worker boundaries, a perception that purchasing sex under discrimination was safe, clear and effective communication with sex workers, and ethical considerations directing how and where participants chose to purchase sex. When compared to the experiences of six clients who had experienced purchasing sex under alternative legal contexts, it was evident that these characteristics were unique to their experiences within New Zealand's decriminalised sex industry. Such defining characteristics imply that participants prioritised the ethicality of their purchase and located power and control over the exchange with sex workers. This chapter concludes the analysis and the final chapter which follows concludes and contextualises the significance of these findings. 


\section{Chapter Seven: Thesis Conclusion}

This final chapter brings together the key issues discussed throughout this thesis and addresses their implications in relation to the clients of sex workers in New Zealand and the decriminalisation of sex work. Research on client experiences of purchasing sex under decriminalisation has not previously been conducted. In fact, little research exists on sex workers' clients in New Zealand specifically, and international research on clients, as driven by their own perspectives and experiences, is limited. This thesis has begun to amend this literature gap and emerges at a time when momentum for the decriminalisation of sex work is building internationally.

\section{Contextualising Clients - The Good, The Bad, or The Bogus?}

It is important to acknowledge that the participants presented in a predominantly positive light and while the findings highlighted that clients can be respectful and harmreductionist in their conduct, accounts from sex workers sometimes offer experiences of discomfort, coercion, and violence perpetrated by clients (Kinnell, 2013). Considering this disparity, applying a framework offered by Kinnell (2013) assists in contextualising this research, without distracting from the reality that clients are diverse. Kinnell (2013) proposes that clients exist on a continuum of 'good', 'bad', and 'bogus' (p. 56). When explaining that sex workers have "clear expectations of how clients should behave, and how 'the business' - the complete transaction between sex worker and client - should proceed", Kinnell (2013, p. 56) observes that 'good' or 'genuine' clients adhere to these expectations. Unfortunately, not all clients do so and, as Kinnell (2013) explains, 'bad' clients are those who dispute their responsibilities and attempt coercion. Actions which signal a 'bad' client include refusal to pay upfront; refusal of sex workers' boundaries; attempts at bargaining over the services offered and the price, location, and duration of the booking; removing condoms; being offensive; and being violent (Kinnell, 2013; Sanders, 2005).

Nevertheless, Kinnell (2013) argues that most violence experienced by sex workers is perpetrated by non-clients or those who do not pay. Kinnell (2008) terms these individuals' 'bogus' clients. McKeganey and Barnard (1996) further argue only a minority of interactions between sex workers and clients involve violence, and that instances of violence are the exception, not the rule. Hence, most 'client' violence is committed by men who mimic paying clients and, as explained by Sanders (2005), "mimics are those who 
appear as good types but are really bad types aware of the signs that good types display ... The mimic is a customer who appears to be trustworthy but in fact has dangerous intentions" (p. 54). Considering that paying for sex is the qualifying characteristic of a client, Kinnell (2013) argues that these 'bogus' clients should not be identified as belonging to the broader client population.

The clients involved with this research occupy the 'good' of Kinnell's (2013) framework following their accounts of how they interacted with sex workers. While Riaan exhibited misogynistic attitudes, and two participants acknowledged requesting unprotected oral sex, overall the participants described fulfilling their obligations to sex workers and thus, represented themselves as 'good' clients. As such, how they conducted themselves appeared to be largely due to their understanding that purchasing sex represents a business transaction and that a sex worker's consent is not inherent to their payment. Decriminalisation in New Zealand also mirrors this ethos and, while the interviewed clients did not explicitly link decriminalisation and their conduct, the ethos driving decriminalisation was evident in their interactions with sex workers.

\section{The Participants and Client Stereotypes}

As noted in earlier sections, the clients of sex workers are a hidden population. Existing research has primarily focused on sex workers and until recently, failed to sufficiently acknowledge the consumers of commercial sex (Marttila, 2008; Monto, 2000; Weitzer, 2000). This trend occurs for several reasons, including the constraints of engaging with concealed populations, the compounding stigma sex workers face, and the reality that sex workers experience the most harm of repressive laws and are most likely to be criminalised (Soothill \& Sanders, 2005). However, while the efforts of researchers such as Sanders (2008b) and Birch (2015) have begun to remedy this on an international scale, clients under decriminalisation remain unexplored, until now. When analysing the participant demographic variables, it was found they could be described as relatively ordinary. Most of the participants were male, white or New Zealand European, were employed and financially secure, most were well-educated and held tertiary qualifications, and had previously, or currently maintained intimate relationships. This indicated the participants were contributing members of society and, further, that their engagements with sex workers did not detract from this. The perspectives of key informants challenged the stereotypes traditionally attached to men who purchase sex, 
which they felt ranged from the demonization of clients, to judgments of their social and sexually inadequacy.

However, analysis of the purchasing frequencies and preferences of the participants suggested they are conscious consumers of commercial sex. This was demonstrated by participants managing the frequency of their purchasing and attempts to reduce instances of compulsion or negative impacts. The participants' purchasing frequencies varied significantly and ranged from multiple times a week, to monthly, yearly, or a single experience. The interviewed clients also held varied preferences for the services they purchased, yet most preferred intimate services including kissing and conversation with sex workers. The participants offered differing justifications of their preferences regarding the markets they accessed, yet most purchased interchangeably from brothels, escort agencies, and independent sex workers. However, the markets they preferred also suggested some endorsement of sex work stigma since they shared a common perception that street-based sex work would be riskier for their physical and sexual health, hence their avoidance of street-based sex workers.

The participant's experiences indicate that they face stigmatisation, as several felt a pressure to conceal their activity within the sex industry. To protect their reputations, most participants kept their engagements with sex workers a secret. However, despite clearly being aware of societal judgement, the participants contradicted the traditional stereotyping of clients in some ways. Such stereotypes construct clients as undesirable, unfaithful, incapable of attracting women, and sexually dysfunctional or incompetent (Jordan, 1997; Sanders, 2008b). Stigma further positions clients as sexually deviant, out of control, and a danger to the public (Birch, 2015; Sanders, 2008b). However, no parallels can be drawn between the participants and these stereotypes, thus challenging their accuracy and highlighting the nuance of client populations. It is imperative we seek to interrogate the stigma attached to clients, as, while such stereotyping is broadly socially accepted, the public image of clients will remain distorted and homogenised (Jordan, 1997). While stereotypes surrounding client populations may ring true for some individuals, the clients interviewed and their experiences, suggest that such stereotypes are overly simplistic and do not represent the entire client population. 


\section{Motivations and Impacts - The Client's Perspective}

This thesis also explored participants' motivations for purchasing sex, drawing on Sander's (2005) push and pull framework, with the addition of two original categories access to sex, where sexual pleasure was the primary motivator; and access to human contact, where sex came second and, instead, facilitated human connection. Reflecting prior research (McKeganey \& Barnard,1996; Monto, 2000; Plumridge, Chetwynd, Reed, \& Gifford, 1997), the five participants motivated by sexual pleasure cited a lack of sex and the avoidance of committed relationships as factors pushing them to purchase sex. Additionally, they noted the uncomplicated nature of commercial sex, access to niche services, and the variety of sexual acts and women available as elements of commercial sex which appealed to them. Conversely, the six participants primarily motivated by access to human connection mirrored the findings of Birch (2015) and Sanders (2008b) when citing loneliness, difficulty socialising, and a desire for intimacy as factors pushing them towards visiting sex workers, though whether this intimacy could be considered genuine or counterfeit is debated. Lastly, these clients referenced communication with sex workers and meeting new people as factors pulling them towards the sex industry. The development of these opposing categories majorly reinforces prior research on the non-sexual motivations of clients and urges the understanding that men purchase sex for complex reasons beyond the purely sexual, namely for companionship, elevation of loneliness, and mental health support.

The motivations participants offered mirrored the findings of Birch (2015), Sanders (2008a, 2008b) and Milrod and Weitzer (2012), as they reflect the reasons people offer for seeking casual sex and non-commercial relationships. This demonstrates that participants purchase sex for normative reasons and, hence, such findings contribute to narrowing the gap Sanders (2008a) observes separates client populations from nonclient populations. The participants' motivations were further linked to masculinity and it was found that some male participants purchased sex to affirm masculinity, which reflected the research of Frank (2003), Huysame and Boonzaier (2015), and Joseph and Black (2012). Yet, two participants noted purchasing sex also threatened their masculinity, as they saw seducing women as representing successful masculinity. Gender dynamics were also performed through purchasing sex, as four participants inadvertently objectified sex workers when targeting specific body types or ethnicities. 
Riaan further demonstrated misogyny through his purchasing, which was driven by the desire to avoid any prolonged contact with women following his perception of women as inferior to men. The analysis saw these problematic perspectives as expressions of the patriarchal foundations of our society (Beechey, 1979; Fredrickson \& Roberts, 1997), and social forces dictating successful masculinity to the participants (Courtenay, 2000). Through examining their motivations, it was clear the participants experience masculine social pressure much like the non-client populations yet adopt purchasing sex to manage this and express masculinity.

As discussed in Chapter Five, it was found that purchasing sex and interacting with sex workers significantly impacted the participants. Broadly, the impacts they experienced included an improvement in confidence and comfort with the self and sexuality, improved mental health, and altered perceptions of relationships and women. Echoing the findings of Birch (2015), purchasing sex was found to enhance the well-being of the participants. Recent theorising by Seligman (2011) in the school of positive psychology identified positive emotion, engagement, relationships, meaning and accomplishment (PERMA) as cornerstones of well-being. It was found that through purchasing sex, the participants could supplement these components when they were otherwise unattainable. For those participants who primarily sought sexual gratification, commercial sex offered a straightforward solution to their physiological needs, which touches on the positive emotion, engagement and accomplishment elements of Seligman's (2011) framework. Moreover, inherent to Seligman's (2011) PERMA framework is human interaction, and, for the participants who sought human connection, interacting with sex workers remedied their social isolation and enabled them to achieve all five cornerstones of well-being identified by Seligman (2011). Following this, it appears that the participants constructed the positive impacts they experienced as relating more to the time spent in the company of sex workers than the actual act of having sex. Thus, these findings reinforce debates which position sex workers and their services as therapeutic to clients and supporting their well-being.

\section{Client Interactions with Sex Workers under Decriminalisation}

The results discussed so far culminate in a conclusion which mirrors Kinnell's (2006) findings that clients are "a substantial subsection of the male population, broadly representative of most demographic variables with fairly mundane reasons for engaging 
in commercial sex" (p. 213). To build on this, this thesis also provides some useful insights into how clients conduct themselves specifically in the context of decriminalisation. During the interviews, the participant's offered accounts of their interactions with sex workers and how they understood their position within the exchange. Most notably, the participants' behaviour located power and control over the interaction with sex workers. This was most evident in their recognition of individual sex worker boundaries and their desire to adhere to these. The personal boundaries sex workers established were considered more important than the legal boundaries mandated by the PRA 2003, which suggested the participants understood their financial investment in the exchange separate from a sex worker's consent. However, two participants contradicted this trend, when revealing they had requested unprotected oral sex and, hence, sought to manipulate these boundaries. Despite this, no other participants indicated coercion and, instead, engaged in clear and open communication with sex workers. The participants considered effective communication important, as it enabled boundaries, experience levels, and comfort to be established with sex workers. The participants understood communication as facilitated by the transparency of decriminalisation, which they further connected to the improved accessibility of commercial sex. When compared to Alex and Victor's experiences in New Zealand prior to decriminalisation, it was found that clear communication only existed after law reform and, prior to it, ambiguity defined the exchange.

The six participants who had experience purchasing sex across legal contexts further perceived that decriminalisation fosters a safer environment in which to purchase sex. Much like Sanders and Campbell's (2007) conclusion, overall the participants' interactions with sex workers indicated a collective responsible environment that prioritised sexual health. Lastly, ethical considerations defined five participants' interactions with sex workers. These considerations varied yet began with the drive to improve the sex workers' experience when purchasing their services. To facilitate sex worker comfort, some participants tried to improve their own behaviour and appearance to be as inoffensive as possible, while others improved the physical environment. Moreover, three participants expressed a desire to avoid the exploitation of sex workers and, instead, pursued ethical commercial sex. To achieve this, they avoided purchasing from street-based and migrant sex workers, in favour of workers operating independently or through agencies. 
Concerns have been raised that under policies which approach sex work as an immoral and shameful behaviour, violence and prejudice against sex workers is reinforced (Campbell \& Storr, 2001). This connection has previously been discussed, yet it is again relevant as the opposing reaction can be applied to the participants and their conduct under decriminalisation. When analysing the participants' interactions with sex workers, the ethos of decriminalisation was evident in their conduct, as the interviewed clients approached purchasing sex from a labour standpoint and recognised the exchange as a temporary transaction restricted by the personal boundaries of sex workers. Moreover, the participants extended consideration to sex workers and their working conditions, culminating in a desire to engage in safe, ethical sex work. As concluded by the PLRC (2008) "the PRA has been effective in achieving its purpose, and the Committee is confident that the vast majority of people involved in the sex industry are better off under the PRA than they were previously" (p. 14). The participants of this research reflect such findings and indicate they understand how to behave appropriately when purchasing sex as per the guidelines mandated by the PRA 2003. When compared to accounts from clients and sex workers under alternative legal models, these findings strongly suggest that the legal context surrounding sex work does make a difference and affects conduct within the industry. Under decriminalisation, this difference was personified in the participants' awareness of sex worker rights and working conditions, thus indicating an informed approach to purchasing sex.

\section{Looking Forward - Recommendations for Future Research}

Future research in this field should take into consideration the limitations of this research and seek to capture a broader, more representative image of the New Zealand client landscape. It would be beneficial to include a more diverse sample through recruiting a more varied gender profile. Likewise, it would be beneficial to expand the geographical reach of future research to recruit clients from the other centres of sex work in New Zealand, namely Auckland and Christchurch (Abel, Fitzgerald, \& Brunton, 2007). Furthermore, conducting interviews with sex workers in New Zealand regarding their clients would offer an alternative, and potentially more realistic, perspective on client conduct under decriminalisation. Comparisons between sex worker and client experiences in New Zealand would allow for a more comprehensive insight into the contested issues discussed in this thesis. Following diversification by location and 
participants, future research should diversify by sector and include perspectives and experiences from the street-based sex industry. In doing so, future research would build on the data collected for this thesis and contribute to an advanced understanding of the decriminalised context.

This thesis emerges at a time when the regulation of sex work is subject to ongoing international debate, and New Zealand's pioneering move to decriminalise sex work has been central to this. Concurrently, despite evidence of its harms, we have witnessed some increase in support for client criminalisation, evidenced through it being adopted in Sweden, Norway, Canada, France, and Northern Ireland (Howard, 2018; Soothill \& Sanders, 2005). Despite clear evidence of the positive impacts of decriminalisation in New Zealand, there has been strong opposition in some corners through arguments focusing primarily on the violent and exploitative nature of some clients (Bindel, 2014, 2017; Coy \& Molisa, 2016; Geddes, 2018; Molisa, 2015; Raymond, 2004). Hence, this research sought to provide an evidence-based account of client conduct within a decriminalised sex industry. The findings demonstrate that the participants contradict stereotypes of clients as deviant in their pursuit of commercial sex and hence, support the 'every man perspective'. Moreover, they provide compounding support for the existence of non-sexual client motivations and contributes to the emerging evidence-base recognising the potential therapeutic benefits of sex worker-clients relationships. This therefore highlights how emotion and meaning can be integral aspects of a client's decision to purchase sex. Lastly, the findings provide clear evidence that legal context does make a difference to conduct within the sex industry. Under decriminalisation, this difference saw the participants demonstrate an awareness of sex workers' rights, thus producing informed, harm-reductionist interactions with sex workers. As such, this thesis actively challenges the anecdotal claims critics of decriminalisation have made about the clients of sex workers. Through providing this evidence, it is hoped this thesis will accompany the building momentum advocating for changes to sex work regulation internationally and facilitate an overall shift away from criminalisation towards the decriminalisation of sex work. 


\section{References}

Abel, G. (2010). Decriminalisation: A harm minimisation and human rights approach to regulating sex work (Unpublished PhD thesis). University of Otago, Dunedin, New Zealand. Retrieved from https://ourarchive.otago.ac.nz/handle/10523/3362

Abel, G. (2014). A decade of decriminalization: Sex work 'down under' but not underground. Criminology \& Criminal Justice, 14(5), 580-592. doi:10.1177/1748895 814523024

Abel, G., \& Fitzgerald, L. (2010). Risk and risk management in sex work postProstitution Reform Act: A public health perspective. In G. Abel, L. Fitzgerald, C. Healy, \& A. Taylor (Eds.), Taking the crime out of sex work: New Zealand sex workers' fight for decriminalisation (pp. 217-237). Bristol, England: Policy Press.

Abel G., Fitzgerald L., \& Brunton C. (2007). The impact of the Prostitution Reform Act on the health and safety practices of sex workers. Christchurch, New Zealand: Christchurch School of Medicine, University of Otago.

Abel, G., Fitzgerald, L., \& Brunton, C. (2009). The impact of decriminalisation on the number of sex workers in New Zealand. Journal of Social Policy, 38(03), 515 doi:10.1017/s0047279409003080

Abel, G., Fitzgerald, L., Healy, C., \& Taylor, A. (2010). Taking the crime out of sex work: New Zealand sex workers' fight for decriminalization. Bristol, England: Policy Press.

Aggleton, P. (1999). Men who sell sex: International perspectives on male prostitution and AIDS. London, United Kingdom: Taylor \& Francis

Agustín, L. M. (2007). Sex at the margins: Migration, labor, and the rescue industry. London, United Kingdom: Zed.

Agustín, L. M. (2008). Sex and the limits of enlightenment: The irrationality of legal regimes to control prostitution. Sexuality Research and Social Policy, 5(4), 73-86. doi:10.1525/srsp.2008.5.4.73

Amnesty International. (2016). The human cost of 'crushing' the market: Criminalization of sex work in Norway. Retrieved from https://www.amnestyusa.org/reports/the-human-cost-of-crushing-the-marketcriminalization-of-sex-work-in-norway/

Anderson, B., \& Davidson, J. O. C. (2003). Is trafficking in human beings demand driven?: A multi-country pilot study. Report No. 15). Grand-Saconnex, Switzerland: International Organization for Migration.

Armstrong, L. (2010). Out of the shadows (and into a bit of light): Decriminalisation, human rights and street-based sex work in New Zealand. In Hardy, K., Kingston, S., \& Sanders, T (Eds.). New Sociologies of Sex Work. London: Routledge.

Armstrong, L. (2014). Screening clients in a decriminalised street-based sex industry: Insights into the experiences of New Zealand sex workers. Australian \& New Zealand Journal of Criminology, 47(2), 207-222.

doi:10.1177/0004865813510921 
Armstrong, L. (2016). From law enforcement to protection? Interactions between sex workers and police in a decriminalized street-based sex industry. British Journal of Criminology, 57(3), 570-588.

Armstrong, L. (2017). Commentary: Decriminalisation and the rights of migrant sex workers in Aotearoa/New Zealand: Making a case for change. Women's Studies Journal, 31(2), 69-76.

Armstrong, L. (2018). Stigma, decriminalisation, and violence against street-based sex workers: Changing the narrative. Sexualities, 0(0) 1-21. doi:

$10.1177 / 1363460718780216$

Atchison, C., Fraser, L., \& Lowman, J. (1998). Men who buy sex: Preliminary findings of an exploratory study. In Elias, J., Bullough, V., Elias, V., and Elders, J (Eds.), Prostitution: On whores, hustlers and johns (pp. 172-203). New York, NY 10017: Prometheus Books.

Beechey, V. (1979). On patriarchy. Feminist Review, 3, 66-82.

Beran, K. (2012). Revisiting the prostitution debate: Uniting liberal and radical feminism in pursuit of policy reform. Law \& Inequality, 30, 19-56.

Berger, R. (2013). Now I see it, now I don't: Researchers' position and reflexivity in qualitative research. Qualitative Research, 15(2), 219-234. doi:10.1177/1468794112468475

Bernstein, E. (2001). The meaning of the purchase: Desire, demand and the commerce of Sex, Ethnography 2(3), 389-420.

Bernstein, E. (2007). Temporarily yours: Intimacy, authenticity, and the commerce of sex. Chicago, IL: University of Chicago Press.

Bindel, J. (2014). Decriminalising the sex trade will not protect its workers from abuse. Retrieved from: https://www.theguardian.com/commentisfree/2016/jul/13/decriminali sing-sex-trade-protect-workers-abuse

Bindel, J. (2017). Pimping of prostitution. London: Palgrave Macmillan.

Birch, P. (2015). Why men buy sex: Examining clients of sex workers (Vol. 17). London: Routledge.

Bouffard, L. A. (2010). Exploring the utility of entitlement in understanding sexual aggression. Journal of Criminal Justice, 38(5), 870-879.

Braun, V., \& Clarke, V. (2006). Using thematic analysis in psychology. Qualitative Research in Psychology, 3(2), 77-101. doi:10.1191/1478088706qp063oa

Braun, V., \& Clarke, V. (2012). Thematic analysis. In Cooper, H., Camic, P. M., Long, D., Panter, A., Rindskof, D., \& Sher, K (Eds.) APA Handbook of Research Methods in Psychology (pp. 57-71). doi:10.1037/13620-004

Braun, V., \& Clarke, V. (2017). Thematic analysis. The Journal of Positive Psychology, 12(3), 279-298. doi:10.1080/17439760.2016.1262613

Brents, B. G., \& Hausbeck, K. (2005). Violence and legalized brothel prostitution in Nevada. Journal of Interpersonal Violence, 20(3), 270-295. doi:10.1177/0886260504270333

Brewis, J., \& Linstead, S. (2000) "The worst thing is the screwing" (1): Consumption and 
the management of identity in sex work. Gender, Work and Organization, 7(2), 84-97.

Brodsky, A. (2016). Rape-adjacent: Imagining legal responses to non-consensual condom removal. Columbia Journal of Gender \& Law., 32, 183.

Bromberg, S. (1997, March). Feminist issues in prostitution. In International Conference on Prostitution at California State University, Northridge. Retrieved May (Vol. 17).

Brooks-Gordon, B., \& Gelsthorpe, L. (2003). Prostitutes' clients, Ken Livingstone and a new Trojan horse. The Howard Journal of Criminal Justice, 42(5), 437-451.

Brothels Task Force (2001). Report of the Brothels Task Force. Sydney, Australia: New South Wales Government.

Butcher, K. (2003). Confusion between prostitution and sex trafficking. The Lancet, 361(9373), 1983. doi:10.1016/s0140-6736(03)13596

Campbell, R. (1998). Invisible men: Making visible male clients of female prostitutes in Merseyside. In Elias, J., Bullough, V., Elias, V., \& Brewer, G. (Eds.) Prostitution: On Whores, Hustlers and Johns (pp. 134-154). Prometheus Books.

Campbell, R., Coleman, S., \& Torkington, P. (1996). Street prostitution in inner city Liverpool: Abercromby Prostitution Project. Liverpool Hope University College, Applied Research Centre.

Carael, M., Slaymaker, E., Lyerla, R., \& Sarkar, S. (2006). Clients of sex workers in different regions of the world: Hard to count. Sexually Transmitted Infections, 82(3), 23-32. doi: 10.1136/sti.2006.021196

Chapkis, W. (1997). Live sex acts: Women performing erotic labour. New York, NY 10017: Routledge.

Charmaz, K. (1996). The search for meanings - Grounded theory. In J. A, Smith, R. Harre, \& L. Van Langenhove (Eds.), Rethinking methods in psychology. London, United Kingdom: Sage Publications Ltd.

Charmaz, K. (2006). Constructing grounded theory: A practical guide through qualitative analysis. London, United Kingdom: Sage Publications Ltd.

Charmaz, K. (2014). Constructing grounded theory. London, United Kingdom: Sage Publications Ltd.

Charmaz, K. (2017). Constructivist grounded theory. The Journal of Positive Psychology, 12(3), 299-300.

Charmaz, K., \& Bryant, A. (2010). Constructing grounded theory analyses. In D. Silverman (Eds.) Qualitative research (347-363). London: Sage Publications.

Chetwynd, J. (1992). HIV/AIDS and sex workers. New Zealand Medical Journal, 105, 227. Chetwynd, J., and Plumridge, L. (1993). Clients of female sex workers: A pilot study. Department of Community Health and General Practice, Christchurch School of Medicine, New Zealand.

Chu, S., \& Glass, R. (2013). Sex work law reform in Canada: Considering problems with the Nordic Model. Atlanta Law Review, 51, 101-124.

Cohan, D., Lutnick, A., Davidson, P., Cloniger, C., Herlyn, A., Breyer, J., Klausner, J. (2006). Sex worker health: San Francisco style. Sexually Transmitted Infections, 82(5), 418-422. doi:10.1136/sti.2006.020628 
Collins, A., \& Judge, G. (2008). Client participation in paid sex markets under alternative regulatory regimes. International Review of Law and Economics, 28(4), 294-301.

Comte, J. (2013). Decriminalization of sex work: Feminist discourses in light of research. Sexuality \& Culture, 18(1), 196-217. doi:10.1007/s12119-013-9174-5

Connell, R. W. (1987). Gender and power. Stanford, CA: Stanford University Press.

Connell, R. W. (1995) Masculinities. Cambridge, United Kingdom: Polity Press.

Corbin, J. (2017). Grounded theory. The Journal of Positive Psychology, 12(3), 301-302.

Courtenay, W. H. (2000). Constructions of masculinity and their influence on men's wellbeing: A theory of gender and health. Social Science and Medicine, 50(10), 1385-1401.

Coy, M. (2008). The consumer, the consumed and the commodity: Women and sex buyers talk about objectification in prostitution. In Giusta, D. (Eds.) Demanding Sex: Critical Reflections on The Regulation of Prostitution (pp. 181-198). London: Routledge

Coy, M., Horvath, M., Kelly, L., \& Horvath, A. (2007). It's just like going to the supermarket: Men buying sex in East London. Retrieved from http://citeseerx.ist.psu.edu/viewdoc/ download?doi=10.1.1.691.6289\&rep=rep1\&type=pdf

Coy, M., \& Molisa, P. (2016). What lies beneath prostitution policy in New Zealand? Retrieved from https://www.opendemocracy.net/en/5050/what-lies-beneathprostitution-and-policy-in-new-zealand/

Creswell, J. W. (2014). Research design: Qualitative, quantitative, and mixed methods approaches. Thousand Oaks, California: Sage Publications.

Crofts, T., \& Summerfield, T. (2006). The licensing of sex work in Australia and New Zealand. eLaw Journal, 13(269-288).

Crotty, M. (1998). The foundations of social research: Meaning and perspective in the research process. St Leonards, Australia: Allen \& Unwin.

Cunningham, S., and Kendall, T. D. (2011). Prostitution, technology, and the law: New data and directions. In Cohen, L. R., \& Wright, J. D. (Eds.) Research Handbook on the Economics of Family Law (pp. 221-270). London: Edward Elgar Publishing.

Cutcliffe, J. R. (2003). Reconsidering reflexivity: Introducing the case for intellectual entrepreneurship. Qualitative Health Research, 13(1), 136-148. doi:10.1177/1049732302239416

Davidson, J. O. C (1998). Prostitution, power and freedom. Michigan, US: University of Michigan Press.

Davidson, J. O. C., \& Layder, D. (1994). Methods, sex, and madness. London: Routledge.

Deatrick, J., \& Faux, S. (1991). Conducting qualitative studies with children and adolescents. In J. Morse (Ed.), Qualitative nursing research: A contemporary dialogue (pp. 203-223). Newbury Park, CA: Sage.

Delacoste, F., \& Alexander, P. (1988). Sex work: Writings by women in the sex industry. London, United Kingdom: Virago. 
De Santis, M. (2005). Opposing prostitution as a form of male violence: The Swedish Model. Women's Justice Centre, Santa Rosa, California. Retrieved from http://www. peacework magazine.org/pwork/0506/050616.

Decker, M. R., Crago, A., Chu, S. K., Sherman, S. G., Seshu, M. S., Buthelezi, K., \& Beyrer, C. (2015). Human rights violations against sex workers: Burden and effect on HIV. The Lancet, 385(9963), 186-199. doi:10.1016/s0140-6736(14)60800-x

Author of Paper, A., \& Author of Paper, B. (Year, Month date). Title of paper. Paper presented at Title of Conference: Subtitle of Conference, Location. Place of publication: Publisher.

Dodillet, S., \& Östergren, P. (2011, March 4). The Swedish Sex Purchase Act: Claimed success and documented effects. Paper presented at the International Workshop: Decriminalizing Prostitution and Beyond: Practical Experiences and Challenges. The Hague, Netherlands.

Donovan, B., Harcourt, C., Egger, S., \& Fairley, C. K. (2010). Improving the health of sex Workers in NSW: Maintaining success. New South Wales Public Health Bulletin, 21(4), 74-77.

Duff, M. (2014, February 28). Sex worker gets $\$ 25,000$ over harassment. Retrieved from http://www.stuff.co.nz/business/industries/9777879/Sex-worker-gets-25-000over-harassment

Dworkin, A. (1993). Prostitution and male supremacy. Michigan Journal of Gender \& Law, 1(1-12).

Dworkin, A. (1997). Life and death: Unapologetic writings on the continuing war against women. New York, NY 10017: Free Press.

Dwyer, S. C., \& Buckle, J. L. (2009). The space between: On being an insider-outsider in qualitative research. International Journal of Qualitative Methods, 8(1), 54-63.

Earle, S., \& Sharp, K. (2008). Intimacy, pleasure and the men who pay for sex. In Letherby, G., Williams, K., Birch, P., \& Cain, M. E (Eds.). Sex as crime? Willan Publishing.

Egan, R. D., Frank, K., \& Johnson, M. (2006). Flesh for fantasy: Producing and consuming exotic dance. New York, NY 10017: Thunder's Mouth Press.

Egan, R. D. (2003) I'll be your fantasy girl, If you'll be my money man: Mapping desire, fantasy and power in two exotic dance clubs. Journal for the Psychoanalysis of Culture and Society, 8(1), 277-96.

Eitzen, D. S. (2000). The fragmentation of social life: Some critical societal concerns for the new millennium. Vital Speeches of the Day, 66(18), 563.

Ekberg, G. (2004). The Swedish law that prohibits the purchase of sexual services: Best practices for prevention of prostitution and trafficking in human beings. Violence Against Women, 10(10), 1187-1218. doi:10.1177/1077801204268647

Farley, M. (2004). "Bad for the body, bad for the heart": Prostitution harms women even if legalized or decriminalized. Violence Against Women, 10(10), 1087-1125. doi:10.1177/1077801204268607 
Farley, M., Golding, J. M., Matthews, E. S., Malamuth, N. M., \& Jarrett, L. (2017). Comparing sex buyers with men who do not buy sex: New data on prostitution and trafficking. Journal of Interpersonal Violence, 32(23), 3601-3625.

Farley, M., Macleod, J., Anderson, L., \& Golding, J. M. (2011). Attitudes and social characteristics of men who buy sex in Scotland. Psychological Trauma: Theory, Research, Practice, and Policy, 3(4), 369.

Fisher, H. (2000). Lust, attraction, attachment: Biology and evolution of the three primary emotion systems for mating, reproduction, and parenting. Journal of Sex Education and Therapy, 25(1), 96-104.

Fitzharris, P., \& Taylor, A. (2010). Review of the Prostitution Reform Act. In L. Fitzgerald, C. Healy, A. Taylor (Eds.), Taking the crime out of sex work: New Zealand sex workers' fight for decriminalisation (pp. 105-118). Great Britain: The Policy Press.

Frank, K. (1998). The production of identity and the negotiation of intimacy in a 'gentleman's club'. Sexualities, 1(2), 175-201.

Frank, K. (2003). "Just trying to relax": Masculinity, masculinizing practices, and strip club regulars. Journal of Sex Research, 40(1), 61-75.

Fredrickson, B. L., \& Roberts, T. A. (1997). Objectification theory: Toward understanding women's lived experiences and mental health risks. Psychology of Women Quarterly, 21(2), 173-206.

Gaia, A. C. (2002). Understanding emotional intimacy: A review of conceptualization, assessment and the role of gender. International Social Science Review, 77(3), 151-170.

Gangoli, G., \& Westmarland, N. (2011). International approaches to prostitution: Law and policy in Europe and Asia. Great Britain: The Policy Press.

Geddes, C. (2018). No, decriminalisation of johns and pimps has not improved our safety or lives. Retrieved from https://nordicmodelnow.org/2018/08/26/nodecriminalisation-of-johns-and-pimps-has-not-improved-our-safety-or-lives/

Gerassi, L. (2015). A heated debate: Theoretical perspectives of sexual exploitation and sex work. Journal of Sociology and Social Welfare, 42(4), 79.

Gerstl-Pepin, C., \& Patrizio, K. (2009). Learning from Dumbledore's Pensieve: Metaphor as an aid in teaching reflexivity in qualitative research. Qualitative Research, 9(3), 299-308.

Giddens, A. (1992). The transformation of intimacy: Sexuality, love and eroticism in modern societies. Stanford, CA: Stanford University Press.

Gilfoyle, J., Wilson, J., \& Own, B. (1992). Sex, organs and audiotape: A discourse analytic approach to talking about heterosexual sex and relationships. Feminism \& Psychology, 2(2), 209-230.

Glaser, B. G., \& Strauss, A. L. (2012). Discovery of grounded theory: Strategies for qualitative research (7th ed.). The State University, NJ: Transaction Publishers.

Glover, E. (1943). The psychopathology of prostitution. London, United Kingdom: Institute for the Study and Treatment of Delinquency.

Goffman, E. (1963). Stigma: Notes on a spoiled identity. London: Penguin Books. 
Grenz, S. (2005). Intersections of sex and power in research on prostitution: A female researcher interviewing male heterosexual clients. Signs: Journal of Women in Culture and Society, 30(4), 2091-2113.

Guillemin, M., \& Gillam, L. (2004). Ethics, reflexivity, and "ethically important moments" in research. Qualitative Inquiry, 10(2), 261-280. doi:10.1177/1077800403262360

Gurd, A., \& O'Brien, E. (2013). Californian 'John Schools' and the social construction of prostitution. Sexuality Research and Social Policy, 10(2), 149-158.

Hagner, D. (2009). Prostitution and sex work. The Georgetown Journal of Gender and Law, 10(433), 433-456.

Hammond, N. (2018). Researching men who pay for sex: Using online methods for recruiting and interviewing. Methodological Innovations, 11(1-11). doi:10.1177/ 2059799118768408

Harcourt, C., \& Donovan, B. (2005). The many faces of sex work. Sexually Transmitted Infections, 81(3), 201-206.

Hart, A. (2003). Missing masculinity? Prostitutes' clients in Alicante, Spain. In Cornwall, A., \& Lindisfarne, N. (Eds.) Dislocating Masculinity (pp. 59-76). London: Routledge.

Hawks, H. (1996). Sex and pleasure in Western culture. Cambridge, United Kingdom: Polity Press Ltd.

Hayes-Smith, R., \& Shekarkhar, Z. (2010). Why is prostitution criminalized? An alternative viewpoint on the construction of sex work. Contemporary Justice Review, 13(1), 43-55. doi:10.1080/10282580903549201

Hearn, J., \& Pringle, K. (2006). European perspectives on men and masculinities: National and transnational approaches. New York, NY 10017: Palgrave Macmillan.

Hertz, R. (1995). Separate but simultaneous interviewing of husbands and wives: Making sense of their stories. Qualitative Inquiry, 1(4), 429-451.

Hesse-Biber, S. N., \& Leavy, P. (2011). The practice of qualitative research. Thousand Oaks, California: Sage Publications.

Hill, M. S., \& Fischer, A. R. (2001). Does entitlement mediate the link between masculinity and rape-related variables? Journal of Counselling Psychology, 48(1), 39.

Hochschild, A. R. (2003). The commericalization of intimate life: Notes from home and work. Berkeley, CA: University of California Press.

Høigård, C., \& Finstad, L. (1992). Backstreets: prostitution, money, and love. Cambridge, United Kingdom: Polity Press.

Hollway, W. (1998). Gender difference and the production of subjectivity. In J. Henriques, W. C. Hollway, U. C. Venn, \& V. Walkerdine (Eds.), Changing the subject: Psychology, social regulation and subjectivity (pp. 227-263). London, United Kingdom: Routledge.

Holvoet, L., Huys, W., Coppens, V., Seeuws, J., Goethals, K., \& Morrens, M. (2017). Fifty shades of Belgian grey: The prevalence of BDSM-related fantasies and activities in the general population. The Journal of Sexual Medicine, 14(9), 1152-1159. 
Holt, T. J., \& Blevins, K. R. (2007). Examining sex work from the client's perspective: Assessing johns using on-line data. Deviant Behaviour, 28(4), 333-354.

Holzman, H. R., \& Pines, S. (1982). Buying sex: The phenomenology of being a john. Deviant Behaviour, 4(1), 89-116.

Home Office. (2004). Paying the price: A consultation paper on prostitution. London, United Kingdom: HMSO.

Home Office. (2006). Coordinated prostitution strategy. London, United Kingdom: HMSO.

Howard, S. (2018). Better health for sex workers: which legal model causes least harm? The BJM, 361:k2609. 1-4. doi: https://doi.org/10.1136/bmj.k2609

Humphreys, L. (2012, December 4). Cop accused of sexual favour bribery. Retrieved from http://www.stuff.co.nz/\%20national/crime/8033582/Cop-accused-ofsexual-favour-bribery

Hunt, S. (2013). Deconstructing demand: The driving force of sex trafficking. The Brown Journal of World Affairs, 19(2), 225-241.

Hutchinson, S., Marsiglio, W., \& Cohan, M. (2002). Interviewing young men about sex and procreation: Methodological issues. Qualitative Health Research, 12(1), 4260.

Huysamen, M., \& Boonzaier, F. (2015). Men's constructions of masculinity and male sexuality through talk of buying sex. Culture, Health \& Sexuality, 17(5), 541-554.

Jamieson, L. (1998). Intimacy: Personal relationships in modern societies. Cambridge, United Kingdom: The Polity Press.

Jeffreys, S. (1997). The idea of prostitution. Melbourne, Australia: Spinifex Press.

Jewkes, R., Morrell, R., Sikweyiya, Y., Dunkle, K., and Penn-Kekana, L. (2012.

Transactional relationships and sex with a woman in prostitution: Prevalence and patterns in a representative sample of South African men. BMC Public Health, 12(1), 325.

Jones, A. (2015). Sex work in a digital era. Sociology Compass, 9(7), 558-570.

Jones, E. E., Farina, A., Hastorf, A. H., Markus, H., Miller, D. T., \& Scott, R. A. (1984). Social stigma: The psychology of marked relationships. New York, NY: W. H. Freeman \& Co.

Jolin, A. (1994). On the backs of working prostitutes: Feminist theory and prostitution policy. Crime \& Delinquency, 40(1), 69-83. doi:10.1177/0011128794040001005

Jordan, J. (1991). Working girls: Women in the New Zealand sex industry talk to Jan Jordan. Auckland, New Zealand. Penguin Books.

Jordan, J. (1997). User pays: Why men buy sex. Australian \& New Zealand Journal of Criminology, 30(1), 55-71.

Jordan, J. (2005). The sex industry in New Zealand: A literature review. Retrieved from https://www.justice.govt.nz/assets/Documents/Publication s/sex-industry-innz.pdf

Jordan, J. (2010). Of whalers, diggers and 'soiled doves': A history of the sex industry in New Zealand. In G. Abel, L. Fitzgerald, C. Healy, \& A. Taylor (Eds.), Taking the 
crime out of sex work: New Zealand sex workers' fight for decriminalization (pp. 25-44). Great Britian: The Policy Press.

Joseph, L. J., \& Black, P. (2012). Who's the man? Fragile masculinities, consumer masculinities, and the profiles of sex work clients. Men and Masculinities, 15(5), 486-506.

Kantola, J., \& Squires, J. (2004). Discourses surrounding prostitution policies in the UK. European Journal of Women's Studies, 11(1), 77-101.

Karnieli-Miller, O., Strier, R., \& Pessach, L. (2009). Power relations in qualitative research. Qualitative Health Research, 19(2), 279-289.

Kemp, S., \& Squires, J. (1998). Feminisms. New York, NY 10017: Oxford University Press.

Kennedy, M. A., Klein, C., Gorzalka, B. B. and Yuile, J. C. (2004). Attitude change following a diversion program for men who solicit sex. Journal of Offender Rehabilitation, 40, 41-60.

Kesler, K. (2002). Is a feminist stance in support of prostitution possible? An exploration of current trends. Sexualities, 5(2), 219-235.

Kilvington, J., Day, S., \& Ward, H. (2001). Prostitution policy in Europe: A time of change? Feminist Review, 67(1), 78-93. doi:10.1080/01417780150514510

Kimmel, M. S. (1994). Masculinity as homophobia: Fear, shame and silence in the construction of gender identity. In H. Brod and M. Kaufman (Eds.), Theorising Masculinities. (182-199). Thousand Oaks, California: Sage Publications.

Kimmel, M. S., and Plante, R. (2004). Sexualities: Identities, behaviour and society. New York, NY 10017: Oxford University Press.

Kinnell, H. (2006). Clients of female sex workers: Men or monsters? In R. Campbell, \& M. O’Neil (Eds.), Sex work now (pp. 212-234). Willan.

Kinnell, H. (2013). Violence and sex work in Britain. New York, NY 10017: Routledge.

Kissil, K., \& Davey, M. (2010). The prostitution debate in feminism: Current trends, Policy and clinical issues facing an invisible population. Journal of Feminist Family Therapy, 22(1), 1-21. doi:10.1080/08952830903453604

Koken, J. A. (2011). Independent female escorts' strategies for coping with sex work related stigma. Sexuality \& Culture, 16(3), 209-229. doi:10.1007/s12119-0119120-3

Krüsi, A., Pacey, K., Bird, L., Taylor, C., Chettiar, J., Allan, S., \& Shannon, K. (2014). Criminalisation of clients: Reproducing vulnerabilities for violence and poor health among street-based sex workers in Canada - A qualitative study. BMJ Open, 4(6). 1-10, doi: 10.1136/bmjopen-2014-005191

Kuhn, A. (1985). The power of the image: Essays on representation and sexuality. London, United Kingdom: Routledge \& Kegan Paul.

Kulick, D. (2003). Sex in the new Europe: The criminalization of clients and Swedish fear of penetration. Anthropological Theory, 3, 199-218.

Laing, M., Pilcher, K., \& Smith, N. (2015). Queer sex work. London: Routledge.

Laurie, A. (2010). Several sides to this story: Feminist views of prostitution reform. In G. Abel, L. Fitzgerald, C. Healy, \& A. Taylor (Eds.), Taking the crime out of sex work: 
New Zealand sex workers' fight for decriminalization (pp. 85-101). London: the Policy Press.

Laverack, G., \& Whipple, A. (2010). The sirens' song of empowerment: A case study of health promotion and the New Zealand Prostitutes Collective. Global Health Promotion, 17(1), 33-38.

Lazarus, L., Deering, K. N., Nabess, R., Gibson, K., Tyndall, M. W., \& Shannon, K. (2012). Occupational stigma as a primary barrier to health care for street-based sex workers in Canada. Culture, Health \& Sexuality, 14(2), 139-150. doi:10.1080/1369105 8.2011.628411

Leafgren, F. (1990) Men on a journey. In D. Moore and F. Leafgren (Eds.), Problem solving strategies and interventions for men in conflict. New York, NY 10017: Basic Books.

LeBrun, J. (1999). Prostitute as sex worker: Feminist theory contextualized (Unpublished Master's thesis). Quebec, Canada: Concordia University.

Lee, D. (1997). Interviewing men: Vulnerabilities and dilemmas. Women's Studies International Forum, 20(4), 553-564.

Lee, R. M. (1993). Doing research on sensitive topics. London, United Kingdom: Sage.

Letherby, G. (2003). Feminist research in theory and practice. Ball Moor, United Kingdom: Open University Press.

Lever, J., \& Dolnick, D. (2000). Clients and call girls: Seeking sex and intimacy. In R. Weitzer (Ed.), Sex for sale: Prostitution, pornography, and the sex industry (pp. 85100). London, United Kingdom: Routledge.

Levy, J. (2014). Criminalising the purchase of sex: Lessons from Sweden. London: Routledge.

Levy, J., \& Jakobsson, P. (2014). Sweden's abolitionist discourse and law: Effects on the dynamics of Swedish sex work and on the lives of Sweden's sex workers. Criminology \& Criminal Justice, 14(5), 593-607. doi:10.1177/1748895814528926

Liamputtong, P. (2007). Researching the vulnerable: A guide to sensitive research methods. London, United Kingdom: Sage Publications.

Lindemann, D. (2011). BDSM as therapy? Sexualities, 14(2), 151-172.

Link, B. G., \& Phelan, J. C. (2001). Conceptualizing stigma. Annual Review of Sociology, 27(1), 363-385. doi:10.1146/annurev.soc.27.1.363

Link, B. G., Struening, E. L., Rahav, M., Phelan, J. C., \& Nuttbrock, L. (1997). On stigma and its consequences: Evidence from a longitudinal study of men with dual diagnoses of mental illness and substance abuse. Journal of Health and Social Behaviour, 38, 177-190.

Logan, T. D. (2010). Personal characteristics, sexual behaviours, and male sex work: A quantitative approach. American Sociological Review, 75(5), 679-704.

Lohan, M. (2000). Extending feminist methodologies: Researching masculinities and technologies. In A. Byrne, \& R. Lentin (Eds.), Researching women: Feminist research methodologies in the social sciences in Ireland (167-187). Dublin, Ireland: Institute of Public Administration. 
Louie, R., Crofts, N., Pyett, P., \& Snow, J. (1998). Project client call: A phone-in survey of male clients of female sex workers. Paper presented at the Fifth HIV/AIDS and Society Conference, National Centre in HIV Social Research, Macquarie University, Sydney.

Mac, J. (2016). The laws that sex workers really want. Retrieved from https://www.ted.com/talks/juno_mac_the_laws_that_sex_workers_really_want \#t-225206

MacKinnon, C. (1987). Feminism unmodified. Cambridge, MA: Harvard University Press. MacKinnon, C. (1989). Toward a feminist theory of the state. Cambridge, MA: Harvard University Press.

Månsson, S. A. (2004). Men's practices in prostitution and their implications for social work. Social Work in Cuba and Sweden: Achievements and Prospects. Department of Social Work/Department of Sociology, 267-279.

Marttila, A. M. (2008). Desiring the 'other': Prostitution clients on a transnational redlight district in the border area of Finland, Estonia and Russia. Gender, Technology and Development, 12(1), 31-51.

Maynard, M. (1994). Methods, practice and epistemology: The debate about feminism and research. In M. Maynard \& J. Purvis (Eds.), Researching women's lives from a feminist perspective (pp. 1-26). Abingdon, United Kingdom: Routledge.

McCarthy, B., Benoit, C., Jansson, M., \& Kolar, K. (2012). Regulating sex work: heterogeneity in legal strategies. Annual Review of Law and Social Science, 8(1), 255-271. doi:10.1146/annurev-lawsocsci-102811-173915

McCormack, F. (2008). Moral economy and Maori fisheries. A Journal of Social Anthropology and Cultural Studies, 4(1), 45-69.

McCosker, H., Barnard, A., \& Gerber, R. (2001). Undertaking sensitive research: Issues and strategies for meeting the safety needs of all participants. Forum Qualitative: Qualitative Social Research, 2(1), 1-14.

McKeganey, N. P., \& Barnard, M. (1996). Sex work on the streets: Prostitutes and their clients. Buckingham, United Kingdom: Open University Press.

McKeganey, N., Barnard, M., Leyland, A., Coote, I., \& Follet, E. (1992). Female street working prostitution and HIV infection in Glasgow. BMJ, 305(6857), 801-804.

Mereish, E. H., \& Poteat, V. P. (2015). A relational model of sexual minority mental and physical health: The negative effects of shame on relationships, loneliness, and health. Journal of Counseling Psychology, 62(3), 425.

Meston, C. M., \& Buss, D. M. (2007). Why humans have sex. Archives of Sexual Behaviour, 36(4), 477-507.

Michael, R. T., Gagnon, J. H., Laumann, E. O., \& Kolata, G. (1994). Sex in America: A definitive survey. Boston, MA: Little, Brown.

Miller, J., \& Schwartz, M. D. (1995). Rape myths and violence against street prostitutes. Deviant Behavior, 16, 1-23.

Milrod, C., \& Monto, M. A. (2012). The hobbyist and the girlfriend experience: Behaviours and preferences of male customers of internet sexual service providers. Deviant Behavior, 33(10), 792-810. 
Milrod, C., \& Weitzer, R. (2012). The intimacy prism: Emotion management among the clients of escorts. Men and Masculinities, 15(5), 447-467.

Molisa, P. (2015). Breaking the silence on prostitution and rape culture. Retrieved from https://e-tangata.co.nz/comment-and-analysis/breaking-the-silence-on prostitution -and-rape-culture/

Monod, S. W. (2017). Making Sense of Moral Panics: A Framework for Research. Springer.

Monto, M. A. (2000). Why men seek out prostitutes. In Weitzer, R (Eds.) Sex for sale: Prostitution, pornography, and the sex industry (pp. 67-83). New York, NY 10017: Routledge.

Monto, M. A., \& Hotaling, N. (2001). Predictors of rape myth acceptance among the male clients of female street prostitutes. Violence Against Women, 7(3), 275-293.

Monto, M. A., \& McRee, N. (2005). A comparison of the male customers of female street prostitutes with national samples of men. International Journal of Offender Therapy and Comparative Criminology, 49(5), 505-529. doi:10.1177/0306624x04272975

Monto, M. A., \& Milrod, C. (2014). Ordinary or peculiar men? Comparing the customers of prostitutes with a nationally representative sample of men. International Journal of Offender Therapy and Comparative Criminology, 58(7), 802-820.

Munro, V. E., \& Giusta, D. M. (2008). The regulation of prostitution: Contemporary contexts and comparative perspectives. In Giusta, M. (Eds.) Demanding sex: Critical reflections on the regulation of prostitution. London: Routledge.

Noaks, L., \& Wincup, E. (2004). Criminological research: Understanding qualitative methods. London, United Kingdom: Sage.

Nordic Model Now. (2016, August 12). Meme about rape in New Zealand since the full decriminalisation of the sex trade. Retrieved from https://nordicmodelnow.org/ 2016/08/11/meme-about-new-zealand-since-the-full-decriminalisation-of-thesex-trade

NZPC. (2013). Decriminalisation of Sex Work in New Zealand. Retrieved from http://www.nzpc.org.nz/wpcontent/uploads/Decriminalisation_of_Sex_Work_in _New_Zealand-1.pdf

NZPC. (2015, August 4). Decriminalisation of sex work in New Zealand. Retrieved from https://www.youtube.com/watch?v=o7J4s4CvsWk.

O'Connell Davidson, J. (1998). Prostitution, power and freedom. Ann Arbor, MI: University of Michigan Press.

O’Neill, M. (2001). Prostitution and feminism. London, United Kingdom: Polity Press.

Overall, C. (1992). What's wrong with prostitution? Evaluating sex work. Signs: Journal of Women in Culture and Society, 17(4), 705-724.

Pateman, C. (1988). The sexual contract. Stanford: Stanford University Press.

Peng, Y. W. (2007). Buying sex: Domination and difference in the discourses of Taiwanese Piao-Ke. Men and Masculinities, 9(3), 315-336.

Perkins, R. (1991). Working girls: Prostitutes, their life and social control. Canberra, Australia:

Australian Institute of Criminology. 
Phillips, D. C. (1995). The good, the bad, and the ugly: The many faces of constructivism. Educational Researcher, 24(7), 5-12. Doi: 10.3102/0013189X024007005

Phoenix, J. (2002). Making Sense of Prostitution. New York, NY 10017: Palgrave Macmillan.

Phoenix, J. (2007). Regulating prostitution: Different problems, different solutions, same old story. Safer Communities, 6(1), 7-10. doi:10.1108/17578043200700002

Pilcher, K. (2012). Dancing for women: Subverting heteronormativity in a lesbian erotic dance space? Sexualities, 15(5-6), 521-537.

Pillow, W. (2003). Confession, catharsis, or cure? Rethinking the uses of reflexivity as methodological power in qualitative research. International Journal of Qualitative Studies in Education, 16(2), 175-196. doi:10.1080/0951839032000060635

Pini, B. (2005). Interviewing men: Gender and the collection and interpretation of qualitative data. Journal of Sociology, 41(2), 201-216.

Pitts, M. K., Smith, A. M., Grierson, J., O’brien, M., \& Misson, S. (2004). Who pays for sex and why? An analysis of social and motivational factors associated with male clients of sex workers. Archives of Sexual Behavior, 33(4), 353-358.

Plummer, K. (1995). Telling sexual stories: Power, change and social worlds. London, United Kingdom: Routledge.

Plumridge, E. W. (2001). Rhetoric, reality and risk outcomes in sex work. Health, Risk \& Society, 3(2), 199-215. doi:10.1080/13698570125239

Plumridge, L., \& Abel, G. (2000). Services and information utilised by female sex workers for sexual and physical safety. New Zealand Medical Journal, 113(1117). 370-372.

Plumridge, L., \& Abel, G. (2001). A 'segmented' sex industry in New Zealand: Sexual and personal safety of female sex workers. Australian and New Zealand Journal of Public Health, 25(1), 78-83. doi:10.1111/j.1467-842x.2001.tb00555.x

Plumridge, E. W., Chetwynd, S. J., \& Reed, A. (1997). Control and condoms in commercial sex: Client perspectives. Sociology of Health \& Illness, 19(2), 228-243.

Plumridge, E. W., Chetwynd, S. J., Reed, A., \& Gifford, S. J. (1996). Patrons of the sex industry: Perceptions of risk. AIDS Care, 8(4), 405-416.

Plumridge, E. W., Chetwynd, S. J., Reed, A., \& Gifford, S. J. (1997). Discourses of emotionality in commercial sex: The missing client voice. Feminism \& Psychology, $7(2), 165-181$.

Poulton, E. (2014). Having the balls: Reflections on doing gendered research with football hooligans. In Lumsden, K., \& Winter, A. (Eds.) Reflexivity in Criminological Research (pp. 77-89). London, United Kingdom: Palgrave Macmillan.

Prieur, A., \& Taksdal, A. (1993). Clients of prostitutes: Sick deviants or ordinary men? A discussion of the male role concept and cultural changes in masculinity. Nordic Journal of Women's Studies, 1(2), 105-114.

Prostitution Law Review Committee. (2008). Report of the Prostitution Law Review Committee on the operation of the Prostitution Reform Act 2003. Retrieved from 
http://prostitutescollective.net/wpcontent/uploads/2016/10/report-of-the-nzprostitution-law-committee-2008.pdf

Raymond, J. (2003). Ten reasons for not legalizing prostitution and a legal response to the demand for prostitution. Journal of Trauma Practice, 2, 315-332.

Raymond, J. G. (2004). Prostitution on demand: Legalizing the buyers as sexual consumers. Violence Against Women, 10(10), 1156-1186.

Reedy, T. (2000). Te Reo Māori: The past 20 years and looking forward. Oceanic Linguistics, 39(1), 57-169.

Renzetti, C. M., \& Lee, R. M. (1993). Researching sensitive topics. Newbury Park, CA: Sage Publications.

Roguski, M. (2013). Occupational health and safety of migrant sex workers in New Zealand. Retrieved from https://www.nzpc.org.nz/pdfs/Roguski,-(2013),-OSHof migrant-sex-workers-in-NZ.pdf

Sallmann, J. (2010). Living with stigma: Women's experiences of prostitution and substance use. Affilia, 25(2), 146-159. doi:10.1177/0886109910364362

Sanders, T. (2001). Female street sex workers, sexual violence, and protection strategies. Journal of Sexual Aggression, 7(1), 5-18.

Sanders, T. (2004). The risks of street prostitution: Punters, police and protesters. Urban Studies, 41(9), 1703-1717.

Sanders, T. (2005). It's just acting: Sex workers' strategies for capitalising on sexuality. Gender, Work and Organization, 12(4), 319-342

Sanders, T. (2006). Female sex workers as health educators with men who buy sex: Utilising narratives of rationalisations. Social Science \& Medicine, 62(10), 24342444.

Sanders, T. (2007). The politics of sexual citizenship: Commercial sex and disability. Disability and Society, 22(5), 439-455.

Sanders, T. (2008a). Male sexual scripts: Intimacy, sexuality and pleasure in the purchase of commercial sex. Sociology, 42(3), 400-417.

Sanders, T. (2008b). Paying for pleasure: Men who buy sex. London: Willan Publishing.

Sanders, T. (2009). Kerb crawler rehabilitation programmes: Curing the deviant male and reinforcing the respectable moral order. Critical Social Policy, 29(1), 77-99.

Sanders, T., \& Campbell, R. (2007). Designing out vulnerability, building in respect: Violence, safety and sex work policy. The British Journal of Sociology, 58(1), 1-19.

Sanders, T., \& Campbell, R. (2008). Why hate men who pay for sex? Exploring the shift to 'tackling demand' in the UK. In Giusta, D. (Eds.) Demanding sex: Critical reflections on the regulation of prostitution. London: Routledge.

Sanders, T., Connelly, L., \& King, L. J. (2016). On our own terms: The working conditions of internet-based sex workers in the UK. Sociological Research Online, 21(4), 1 -14 .

Sanders, T., O’Neill, M., \& Pitcher, J. (2009). Prostitution: Sex work, policy and politics. London, United Kingdom: Sage Publications.

Satz, D. (1995). Markets in women's sexual labor. Ethics, 106(1), 63-85. 
Sausa, L. A., Keatley, J., \& Operario, D. (2007). Perceived risks and benefits of sex work among transgender women of colour in San Francisco. Archives of Sexual Behaviour, 36(6), 768-777.

Sawyer, S., Metz, M. E., Hinds, J. D., \& Brucker, R. A. (2001). Attitudes towards prostitution among males: A “consumers' report". Current Psychology, 20(4), 363-376. Schmidt, J. (2017). The regulation of sex work in Aotearoa/New Zealand: An overview. Women's Studies Journal, 31(2), 35-49.

Schwalbe, M., \& Wolkomir, M. (2001). The masculine self as problem and resource in interview studies of men. Men and Masculinities, 4(1), 90-103.

Segrave, M., Milivojevic, S., \& Pickering, S. (2009). Sex trafficking: International context and response. New York, NY 10017: Willan Publishing.

Seidler, V. J. (1994). Unreasonable men: Masculinity and social theory. New York, NY 10017: Routledge.

Serughetti, G. (2013). Prostitution and clients' responsibility. Men and

Masculinities, 16(1), 35-48.

Shadwell, T. (2015). Man charged with failing to use condom with prostitute. Retrieved from https://www.stuff.co.nz/national/crime/67464897/null.

Shively, M., Jalbert, S., Kling, R., Rhodes, W., Finn, P., Flygare, C., \& Wheeler, K. (2008). Final report on the evaluation of the First Offender Prostitution Program: Report summary. Washington, DC: National Institute of Justice, US Department of Justice.

Shrage, L. (1994). Moral dilemmas of feminism. New York, NY 10017: Routledge

Shrage, L. (1989). Should feminists oppose prostitution. Ethics, 99(2), 347-361.

Sijuwade, P. 0. (1995). Counterfeit intimacy: A dramaturgical analysis of an erotic performance. Social Behaviour and Personality: An International Journal, 23(4), 369- 376.

Skeggs B. (1994). Situating the production of feminist ethnography. In Maynard, M., Purvis, J. (Eds.) Researching women's lives from a feminist perspective (pp. 72-81). London, United Kingdom: Taylor \& Francis.

Sloan, L., \& Wahab, S. (2000). Feminist voices on sex work: Implications for social work. Affilia, 15(4), 457-479. doi:10.1177/088610990001500402

Smith, N. J., \& Laing, M. (2012). Introduction: Working outside the (hetero) norm? Lesbian, gay, bisexual, transgender and queer (LGBTQ) sex work. Sexualities, 15(5), 517-520.

Soothill, K., \& Sanders, T. (2005). The geographical mobility, preferences and pleasures of prolific punters: A demonstration study of the activities of prostitutes' clients. Sociological Research Online, 10(1), 1-14.

Sprague, J. (2005). Feminist methodologies for critical researchers: Bridging differences. Lanham, Maryland: Rowman and Littlefield.

Stein, M. L. (1974). Lovers, friends, slaves. Nine male sexual types: Their psycho-sexual transactions with call girls. New York, NY 10017: Berkeley Pub. Co. and PT Putnam \& Sons. 
Strauss, A., \& Corbin, J. M. (1997). Grounded theory in practice. Thousand Oaks, California: Sage Publications Ltd.

Sullivan, B. (1999). Prostitution law reform in Australia: A preliminary evaluation. Social Alternatives, 18(3), 9.

Sullivan, B. (2004). Prostitution and consent: Beyond the liberal dichotomy of 'free or forced'. In Cowling, M. (Eds.) Making Sense of Sexual Consent, (127-139). London: Routledge.

Sullivan, B. (2010). When (some) prostitution is legal: The impact of law reform on sex work in Australia. Journal of Law and Society, 37(1), 85-104. doi:10.1111/j.14676478.2010.00496.x

Swygart-Hobaugh, M. L. S., \& Amanda, J. (1998). Staged sexuality: A dramaturgical analysis of erotic dancing (Unpublished PhD dissertation). West Lafayette, Indiana: Purdue University.

Vaismoradi, M., Turunen, H., \& Bondas, T. (2013). Content analysis and thematic analysis: Implications for conducting a qualitative descriptive study. Nursing and Health Sciences, 15(3), 398-405. doi:10.1111/nhs.12048

Vanwesenbeeck, I., De Graaf, R., Van Zessen, G., Straver, C. J., \& Visser, J. H. (1993). Protection styles of prostitutes' clients: Intentions, behaviour, and considerations in relation to AIDS. Journal of Sex Education and Therapy, 19(2), 79-92.

Wagenaar, H., \& Altink, S. (2012). Prostitution as morality politics or why is it exceedingly difficult to design and sustain effective prostitution policy? Sexuality Research and Social Policy, 9(3), 279-292. doi:10.1007/s13178-012-0095-0

Walby, S. (1989). Theorising patriarchy. Sociology, 23(2), 213-234.

Walby, K. (2012). Touching encounters: Sex, work, and male-for-male internet escorting. Chicago, IL: University of Chicago Press

Weinberg, M.S., Shaver, F.M., and Williams, C. J. (1999). Gendered sex work in the San Francisco Tenderloin. Archives of Sexual Behaviour, 28(3), 503-21.

Weiner, A. (1996). Understanding the social needs of streetwalking prostitutes. Social Work, 41(1), 97-105. doi:10.1093/sw/41.1.97

Weitzer, R. (2009a). Sex for sale: Prostitution, pornography, and the sex industry. New York: Routledge.

Weitzer, R. (2009b). The sociology of sex work. Annual Review of Sociology, 35, 213-234. doi:10.1146/annurev-soc-070308-120025

Weitzer, R. (2010). The mythology of prostitution: Advocacy research and public policy. Sexuality Research and Social Policy, 7(1), 15-29. doi:10.1007/s13178-010-00025

Weitzer, R. (2012). Legalizing prostitution. New York, NY 10017: University Press.

West, J. (2000). Prostitution: Collectives and the politics of regulation. Gender, Work \& Organization, 7(2), 106-118.

Westkott, M. (1986). The feminist legacy of Karen Homey. New Haven, CT: Yale University Press.

WHO. (2012, December 12). New WHO guidelines to better prevent HIV in sex workers. Retrieved from http://www.who.int/hiv/mediacentre/feature_story/sti_guide 
line/en/

Whowell, M. (2010). Male sex work: Exploring regulation in England and Wales. Journal of Law and Society, 37(1), 125-144.

Winchester, H. P. (1996). Ethical issues in interviewing as a research method in human geography. The Australian Geographer, 27(1), 117-131.

Wismeijer, A. A., \& Van Assen, M. A. (2013). Psychological characteristics of BDSM practitioners. The Journal of Sexual Medicine, 10(8), 1943-1952.

Wurth, M. H., Schleifer, R., McLemore, M., Todrys, K. W., \& Amon, J. (2013). Condoms as evidence of prostitution in the United States and the criminalization of sex work. Journal of the International AIDS Society, 16(1). doi:10.7448/ias.16.1.18626

Xantidis, L. \& McCabe, M. P. (2000). Personality characteristics of male clients of female sex workers in Australia. Archives of Sexual Behaviour, 22(2), 165. 


\section{Appendices}

Appendix A: Recruitment Flyer

\section{HAVEYOU EVER PURCHASED SEX?}

Participants needed for a study on the client experience of purchasing sex in New Zealand. If you:

- Are over 18

- Have purchased a sexual service from a sex worker in New Zealand post-decriminalisation in 2003

\section{I would love to talk to you!}

I am a Masters student in Criminology at VUW and am interested in the experiences of people who purchase sex in New Zealand. If you have any questions about my study, please get in touch with me. Participants will be interviewed face-to-face and receive $\$ 20$ in supermarket vouchers for participation.

This reserach has recived ethical approval from the VuW Human Ethics Committee \#0000026055

Researcher: Shannon Mower Supervisor: Dr Lynzi Armstrong shannon.mower@vuw.ac.nzｌynzi.armstrong@vuw.ac.nz 


\section{Appendix B: Client Information Sheet}

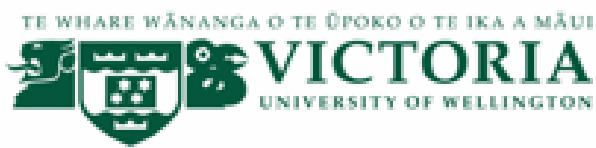

\section{The Client Experience of Purchasing Sex}

\section{INFORMATION SHEET FOR PARTICIPANTS - CLIENTS}

Thank you for your interest in this research project.

\section{Who am I?}

My name is Shannon Mower and I am a Masters student in Criminology at Victoria University of Wellington. This research project is part of my Masters work for my thesis.

\section{What is the aim of the project?}

The aim of this project is to explore people's experiences of paying for sex in New Zealand.

\section{How can you help?}

If you agree to participate in the research, you will take part in a face-to-face interview. These interviews will take place in a location that we have agreed on (e.g. café, library meeting room). During the interview, I will ask you questions about your experiences paying for sex in New Zealand. These questions will cover topics such as the different contexts you have seen sex workers in (such as visiting brothels), what motivates you to see sex workers, how you go about arranging a booking, any benefits you experience from purchasing sex, and so on. Essentially, I am interested in the "who, what, when, where and how" of your engagement with sex workers. With your consent, the interview will be recorded to ensure that no important comments are missed and for transcription (typed out word for word). It is expected that the interview will take approximately 1 hour and you will be gifted a supermarket voucher valued at $\$ 20$ as thanks and recognition of your participation. You can stop the interview at any time, without giving a reason. You may also withdraw from the study up to four weeks after the interview takes place.

\section{What will happen to the information you give?}

Only the researcher will be allowed to listen to the interview recordings. The information you give is strictly confidential. This means that I will be aware of your identity but the research data will be aggregated and your identity will not be disclosed in any reports, presentations, or public documentation. You are welcome to choose another name to be used in the research. However, you should be aware that in small projects your identity might be obvious to others in your community. The information given in the interviews will be used in my Masters thesis, may be published in academic journals, and may also| 
be presented at academic conferences. Only my supervisors and I will read the notes or transcript of the interview. The interview transcripts, summaries and any recordings will be kept securely (e.g. password protected computer files) and will be destroyed one years after the end of the research period. If you disclose that you or another person is at imminent risk of harm the confidentiality agreement may have to be broken. This will be discussed first, unless the researcher's personal safety is at risk.

\section{If you accept this invitation, what are your rights as a research participant?}

You do not have to accept this invitation if you don't want to. If you do decide to participate, you have the right to:

- choose not to answer any question;

- ask for the recorder to be turned off at any time during the interview;

- withdraw from the study up to four weeks after the interview takes place;

- ask any questions about the study at any time;

- receive a copy of your interview recording:

- request a copy of the interview transcript;

- agree on another name for me to use rather than your real name;

- be able to read any reports of this research by emailing the researcher to request a copy.

\section{If you have any questions or problems, who can you contact?}

If you have any questions, either now or in the future, please feel free to contact either:

\section{Student:}

Name: Shannon Mower

University email address:

shannon.mower@vuw.ac.nz

\section{Supervisor:}

Name: Dr Lynzi Armstrong

Role: Primary supervisor

School: Social and Cultural Studies

Lynzi.armstrong@vuw.ac.nz

\section{Human Ethics Committee information}

This study was approved by the Victoria University Human Ethics Committee, approval number 0000026055 . If you have any concerns about the ethical conduct of this research, you may contact the convenor of the Human Ethics Committee Associate Dr Judith Loveridge, (hec@vuw.ac.nz, 04463 6028)| 


\section{Appendix C: Client Interview Guide}

\section{Interview Schedule - Clients}

1. Could we please begin by you telling me a bit about yourself? For example, are you currently employed, where you are from, how long have you been in the Wellington region, ethnicity etc.

Prompts - Remind participants that the interview is confidential

2. Tell me about the first time you paid for sex. How did that come about?

Prompts - How long ago was this? Where were you? How did you first go about purchasing sex? Do you still currently see sex workers? Do you have regular session with workers, or one-offs? If you no longer see sex workers, what are the reasons behind your decision to stop?

3. Can you tell me a bit about the contexts you have paid for sex in?

Prompts - Do you have regular session with workers, or one-offs? Street based sex work or brothels, with a group or by yourself, single or in a relationship, day or| night sessions, group session with sex workers, variety of workers or a single worker etc.

Do you also have experience purchasing sex before decriminalisation (before 2003)? If yes, can you share any differences you noticed when purchasing sex before vs after?

4. Other than the obvious (sex), are there any other reasons you purchase sex?

Prompts - What motivates you to see a sex worker?

5. What are the personal benefits you experience from purchasing sex?

Prompts - sexually satisfied, more sexual experience, more confident, stress relief, confirming sexuality etc

6. How do you approach making a booking with a sex worker - can you walk me through what happens?

Prompt - what expectations do you have when making a booking?

7. What's your idea of an ideal booking? What would that look like for you?

Prompts - personal preferences such as workers disposition, services offered, pricing, hygiene, appearance, etc. 
8. Are there any particular sex workers who you would not see? What are some reasons you would not see a particular sex worker?

Prompts - street based sex workers, transgender workers, age of worker,

9. Can you think of a time where a booking hasn't gone to plan? What happened?

10.Does anyone else in your life know you have paid for sex? Who have you told and why?

Prompts - How have others reacted when you told them? If you haven't told anymore, why not?

11.I am now going to ask about how purchasing sex might have impacted on other areas of their life. How has it impacted on:

Prompts - yourself and your identity, family, intimate relationships with partners, social life, business life. Is there any other areas of your life that purchasing sex has impacted?

$\rightarrow$ What have been the most negative, or positive, impacts of purchasing sex on these areas of your life?

12.Apart from the money, what do they think sex workers get from selling sex?

13. How much do you know about the law on sex work in New Zealand?

$\rightarrow$ Have you ever heard of the Prostitution Reform Act 2003?

14. Has a sex worker ever refused to do what you wanted, or told you something is against the law?

Prompts - If yes, how did this make you feel?

15.Is there anything else you would like to add, or that you think is important for me to know? 


\section{Appendix D: Key Informant Information Sheet}

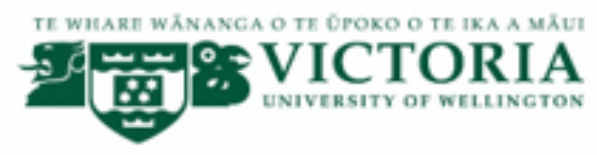

The Client Experience of Purchasing Sex

\section{INFORMATION SHEET FOR PARTICIPANTS - KEY INFORMANTS}

Thank you for your interest in this research project.

\section{Who am I?}

My name is Shannon Mower and I am a Masters student in Criminology at Victoria University of Wellington. This research project is part of my Masters works for my thesis.

\section{What is the aim of the project?}

The aim of this project is to explore people's experiences of paying for sex in New Zealand.

\section{How can you help?}

If you agree to participate in the research, you will take part in a face-to-face interview. These interviews will take place in a location that we have agreed on (e.g. café, university or library meeting room). During the interview, I will ask you questions about your current role and it's connection to clients and decriminalisation. The questions asked will cover topics such as your experience dealing with clients, how your wider organisation is involved with responding to sex work in New Zealand, how you think people who pay for sex are perceived in New Zealand and how you personally think decriminalisation has impacted on clients. With your consent, the interview will be recorded to ensure that no important comments are missed and for transcription (typed out word for word). It is expected that the interview will take approximately 1 hour and you will be gifted a supermarket voucher valued at $\$ 20$ as thanks and recognition of your participation. You can stop the interview at any time, without giving a reason. You may also withdraw from the study up to four weeks after the interview takes place.

\section{What will happen to the information you give?}

Only the researcher will be allowed to listen to the interview recordings. The information you give is strictly confidential. This means that I will be aware of your identity but the research data will be aggregated and your identity will not be disclosed in any reports, presentations, or public documentation. You are welcome to choose another name to be used in the research. However, you should be aware that in small projects your identity might be obvious to others in your community. The information given in the interviews will be used in my Masters thesis, may be published in academic journals, and may also be presented at academic conferences. Only my supervisors and I will read the notes or 
transcript of the interview. The interview transcripts, summaries and any recordings will be kept securely (e.g. password protected computer files), and will be destroyed one years after the end of the research period. If you disclose that you or another person is at imminent risk of harm the confidentiality agreement may have to be broken. This will be discussed first, unless the researcher's personal safety is at risk.

If you accept this invitation, what are your rights as a research participant?

You do not have to accept this invitation if you don't want to. If you do decide to participate, you have the right to:

- choose not to answer any question;

- ask for the recorder to be turned off at any time during the interview;

- withdraw from the study up to four weeks after the interview takes place;

- ask any questions about the study at any time;

- receive a copy of your interview recording;

- request a copy of the interview transcript;

- agree on another name for me to use rather than your real name;

- be able to read any reports of this research by emailing the researcher to request a copy.

If you have any questions or problems, who can you contact?

If you have any questions, either now or in the future, please feel free to contact either:

\section{Student:}

Name: Shannon Mower

University email address:

shannon.mower@vuw.ac.nz

\section{Supervisor:}

Name: Dr Lynzi Armstrong

Role: Primary supervisor

School: Social and Cultural Studies

Lynzi.armstrong@vuw.ac.nz

\section{Human Ethics Committee information}

This study was approved by the Victoria University Human Ethics Committee, approval number 0000026055 . If you have any concerns about the ethical conduct of this research, you may contact the convenor of the Human Ethics Committee Associate Dr Judith Loveridge, (hec@vuw.ac.nz, 04463 6028) 


\section{Appendix E: Key informant Interview Guide}

\section{Interview Schedule - Key Informants}

1. To begin, can you please tell me about your current role and how it relates to sex work in New Zealand.

Prompts - e.g. job title and description, your day-to-day duties in your role, specific projects that you have been involved in.

2. How is your wider organisation involved in responding to sex work in New Zealand?

3. What sort of contact do you have with clients, and how often?

4. How do you think people who pay for sex are perceived in our society?

5. Not all clients are the same - so can you describe for me the different kinds of clients you're aware of?

6. Have sex workers ever talked to you about difficulties they might have had with client behaviour?

7. How do you think decriminalisation has impacted on clients within New Zealand?

Prompts - influenced clients conduct, client accountability, impacted client purchasing habits, reduced amount of clients/increased the amount of clients etc.

8. Now that sex work has been decriminalised, do you think it's made a difference to how clients are perceived?

9. Have you encountered any significant differences in client conduct since decriminalisation in 2003 ?

$\rightarrow$ If yes, do you think these changes have had any positive or negative impacts on sex workers in New Zealand?

10. Do you think the current PRA provisions are adequate for protecting sex workers from exploitation and coercion?

$\rightarrow$ If no, what changes would you make to this legislation?

11.Is there anything else you would like to add, or that you think is important for me to know? 


\section{Appendix F: Consent Form}

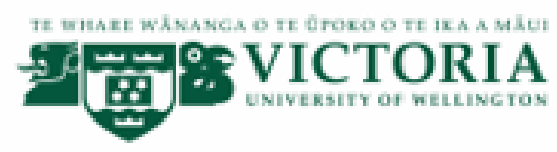

\section{The Client Experience of Purchasing Sex CONSENT TO INTERVIEW}

This consent form will be held for one year.

Researcher: Shannon Mower, Institute of Criminology - School of Social and Cultural Studies, Victoria University of Wellington

- I have read the information sheet and the project has been explained to me. My questions have been answered to my satisfaction. I understand that I can ask further questions at any time.

- I agree to take part in an audio recorded interview.

I understand that:

- I may withdraw or amend my contribution to this study up to four weeks after the interview without giving any reason, and any information that I have provided will be returned to me or destroyed.

- The information I have provided will be destroyed one year after the research is finished.

- If you disclose that you or another person is at imminent risk of harm the confidentiality agreement may have to be broken. This will be discussed first, unless the researcher's personal safety is at risk.

- My name will not be used in reports, nor will any information that would identify me.

- I would like a written transcript of my interview. $\quad$ Yes $\square$ No

- I would like to receive a copy of the final report. I have added my email Yes $\square$ No address below.

Signature of participant:

Name of participant:

Date:

Contact details: 